\title{
Behaviour of PVC Encased Reinforced Concrete Walls under Eccentric Axial Loading
}

\author{
by \\ Amr Abdel Havez \\ A thesis \\ presented to the University of Waterloo \\ in fulfilment of the \\ thesis requirement for the degree of \\ Master of Applied Science \\ in \\ Civil Engineering
}

Waterloo, Ontario, Canada, 2014

(C) Amr Abdel Havez 2014 


\section{Author's Declaration}

I hereby declare that I am the sole author of this thesis. This is a true copy of the thesis, including any required final revisions, as accepted by my examiners.

I understand that my thesis may be made electronically available to the public. 


\begin{abstract}
Stay-in-place (SIP) formwork has been used as an alternative to the conventional formwork system. The systems are mainly assembled on site, hence simplifying the construction process and reducing the construction time as the removal procedure has been eliminated. SIP formwork systems can be divided into two main categories; structural and non-structural formwork, based on their contribution to resist applied loads. The structural formwork provides the same advantages as the non-structural formwork, in addition to its contribution to resist the applied loads. As a result, the cross section and the reinforcement of the structural member can be reduced. Recently, polyvinyl chloride (PVC) has been used as a stay-in-place formwork because of its lower cost compared to other materials, durability, and ease to assemble.
\end{abstract}

The PVC SIP formwork consists of interconnected elements; panels and connectors that serve as permanent formwork for the concrete walls. In this study, the behaviour of the PVC encased reinforced concrete walls under eccentric compression loading was investigated. The variables in this study were the type of the specimen (PVC encased or control), the longitudinal reinforcement (4-10M or $4-15 \mathrm{M}$ rebars) and the eccentricity of the applied compression load $(33.87 \mathrm{~mm}, 67.73 \mathrm{~mm}$ and $101.6 \mathrm{~mm})$. Generally, the control walls (without PVC encasement) failed by yielding of the steel followed by crushing of the concrete, or by crushing of the concrete without yielding of the steel. For the PVC encased walls, buckling of the PVC occurred after the concrete crushed. The PVC encased specimens showed a higher peak load than their peer control walls. The effect of the PVC on increasing the ultimate capacity at a given eccentricity was more significant for the walls reinforced with 4-10M than the walls reinforced with 4-15M. For the lowest reinforcement ratio (4-10M), the PVC encased specimens showed an increase 
in peak load by $37.2 \%$ and $17.1 \%$ at an eccentricity of $67.73 \mathrm{~mm}$ and $101.6 \mathrm{~mm}$, respectively. When the reinforcement was increased to 4-15 M, the increase in the peak load dropped at all eccentricities to $10 \%$. For the vertical and the mid-span deflection, the PVC encased specimens and the control specimens showed the same values. Also, the test results showed an increase in the energy absorption capacity for the PVC encased specimens compared to the controls specimens, where the effect for the walls reinforced with $4-10 \mathrm{M}$ was higher than the walls reinforced with $4-15 \mathrm{M}$ at a given eccentricity.

An analytical model was developed to predict the ultimate load capacity of the specimens taking into consideration the effect of the PVC on the load carrying capacity of the walls. The provision was derived based on the moment magnification factor method in which the effect of secondary stresses associated with the column deformations was taken into consideration. The calculated capacities of the PVC encased specimens showed a conservative error of $5.9 \%$ on average. 


\section{Acknowledgments}

I would like to thank my late supervisor Professor Khaled Soudki, Professor and Canada

Research Chair in Innovative Structural Rehabilitation in the Department of Civil and Environmental Engineering at the University of Waterloo. I am eternally grateful, not only for his guidance and support as my supervisor but also for all the opportunities he gave me. His enthusiasm and knowledge were an inspiration.

I offer my sincerest gratitude to my supervisors Dr. Adil AL-Mayah and Dr. Noran Abdel Wahab who have supported me throughout my thesis with their, patience, support, motivation, enthusiasm, and immense knowledge which were invaluable to my research efforts. Their guidance and attention to every detail helped me in all the time of research and writing of this thesis.

I would also like to thank Professors Timothy Topper and Roger green and Dr. Jeff West for their guidance and support. Their expertise and understanding added considerably to my graduate experience. I am very grateful to them for the time and effort they dedicated to me.

Technical staff at the University of Waterloo, in particular, Richard Morrison, Doug Hirst, and Robert Sluban for sharing their knowledge and assisting with my testing efforts. My fellow graduate students at the Department of Civil and Environmental Engineering, University of Waterloo for continuous support, and being such a great friends. 


\section{Dedication}

To My Family: Mother, Father and Sister 


\section{Table of Contents}

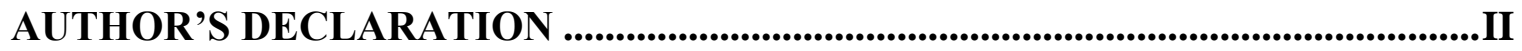

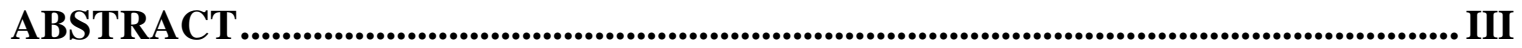

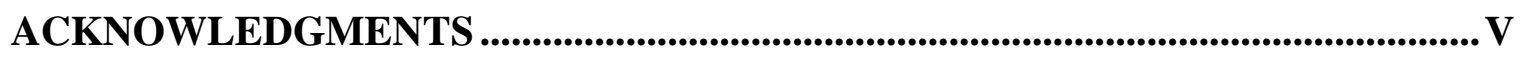

DEDICATION........................................................................................................................ VI

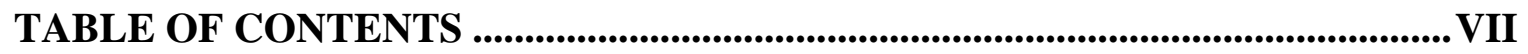

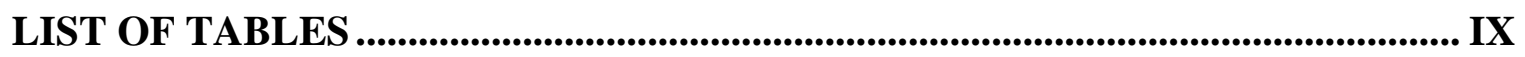

LIST OF FIGURES ...........................................................................................................................X

CHAPTER 1: INTRODUCTION AND LITERATURE REVIEW .............................1

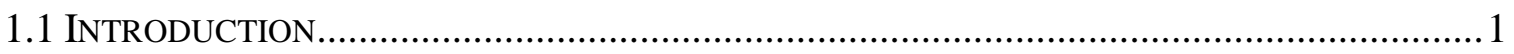

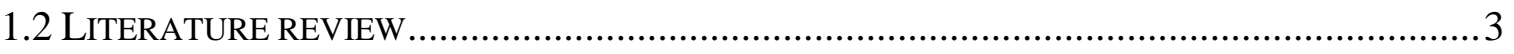

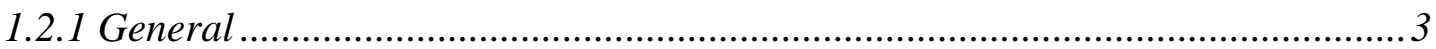

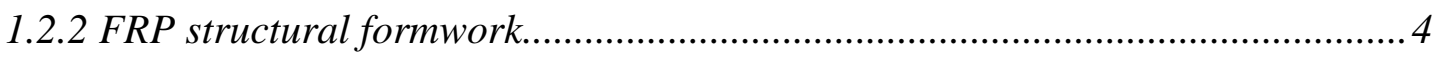

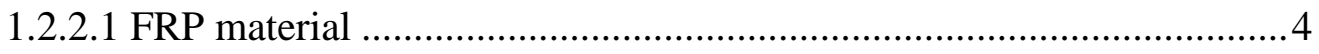

1.2.2.2 Behaviour of the FRP encased columns ............................................5

1.2.3 PVC encasement structural formwork ...................................................... 9

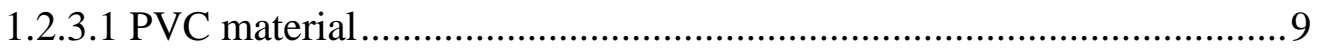

1.2.3.2 Behaviour of the PVC encased members........................................... 10

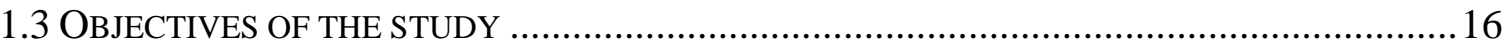

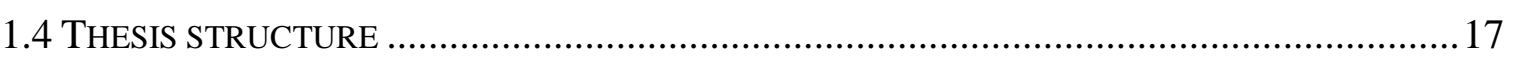

CHAPTER 2: EXPERIMENTAL PROGRAM ...................................................18

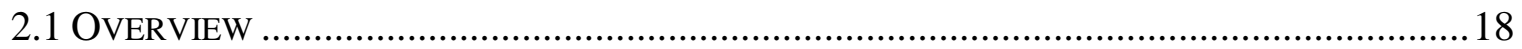

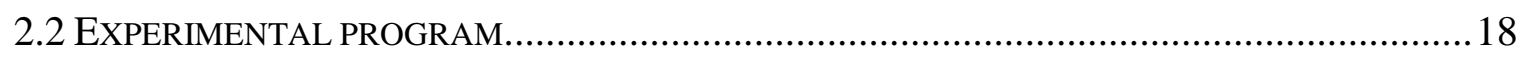

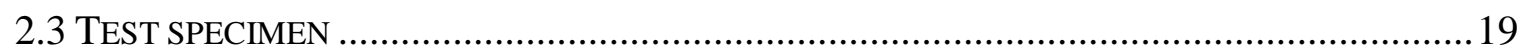

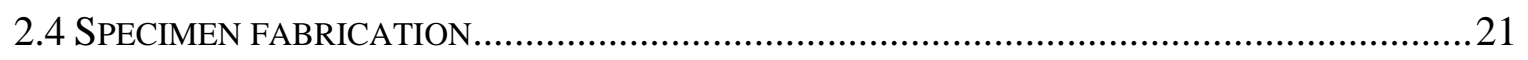

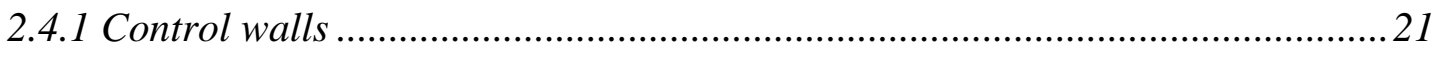

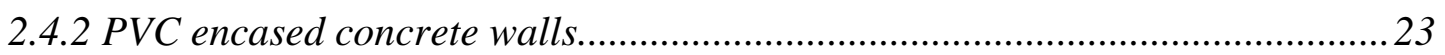

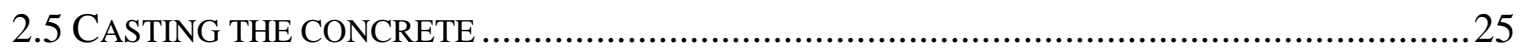

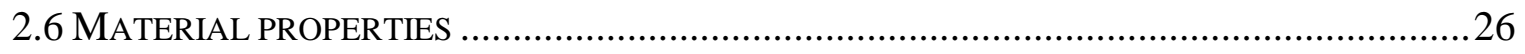

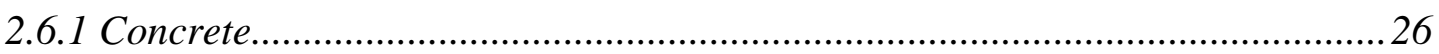

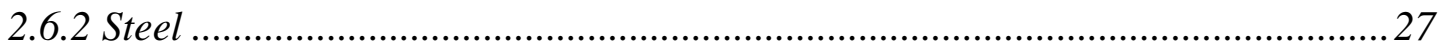

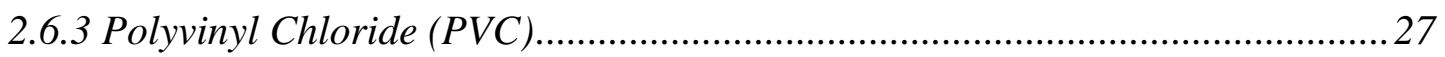

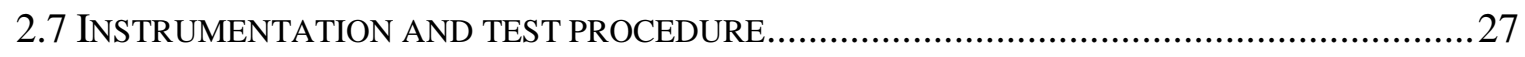

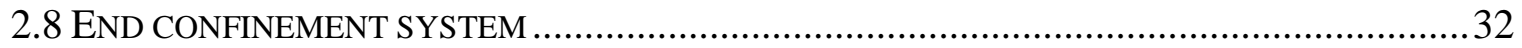

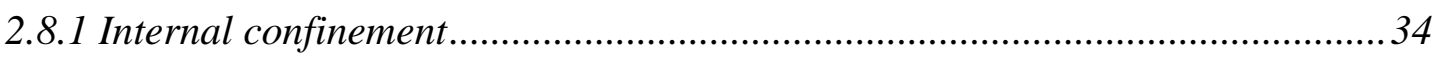

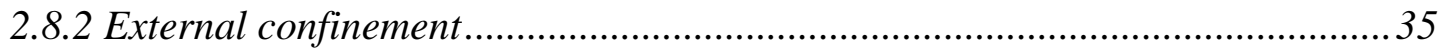

2.8.3 Calculations for the internal reinforcement using the Approximate Method.... 37

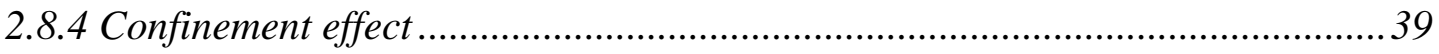


CHAPTER 3: EXPERIMENTAL TEST RESULTS............................................43

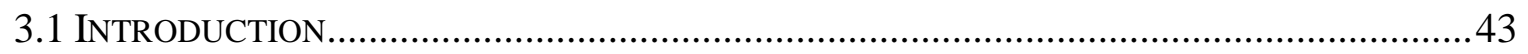

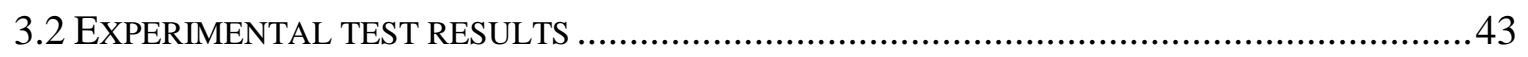

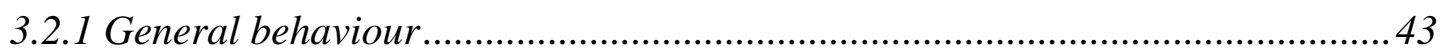

3.2.2 PVC encased walls versus control walls .......................................................... 44

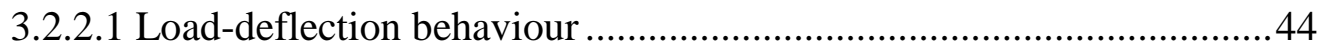

3.2.2.2 Load-strain behaviour ................................................................. 46

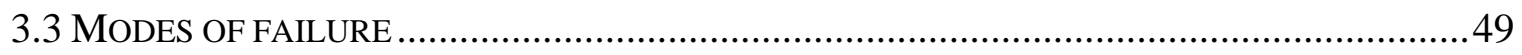

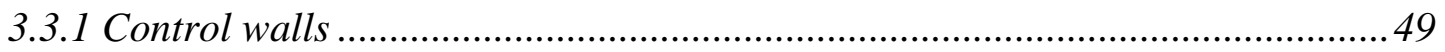

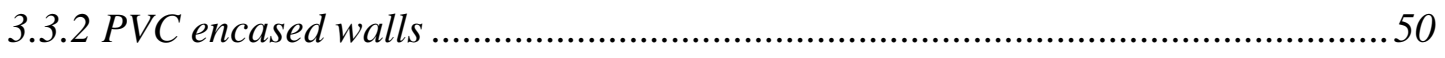

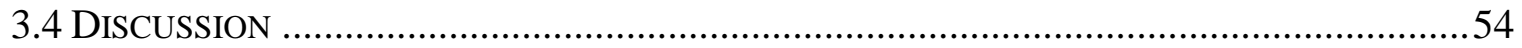

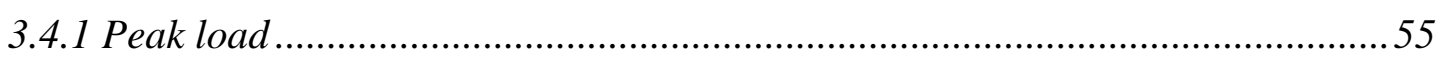

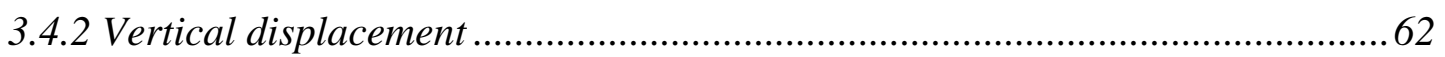

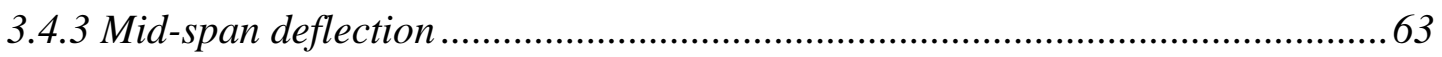

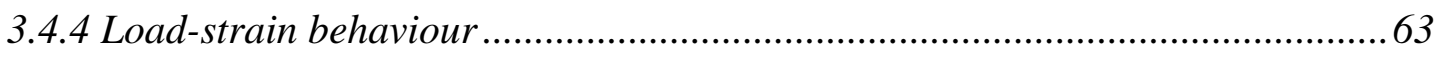

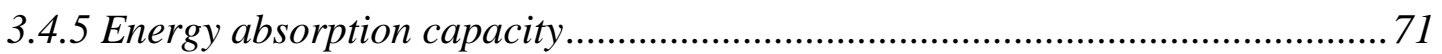

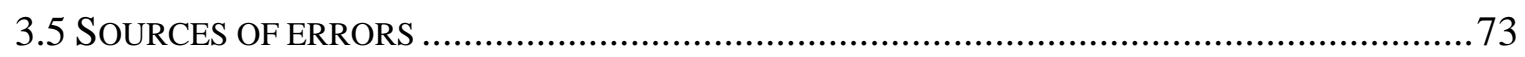

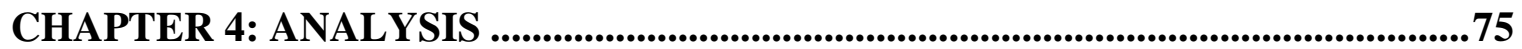

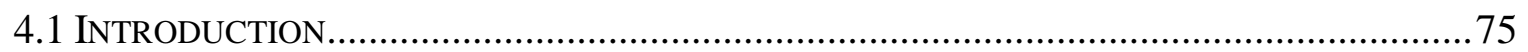

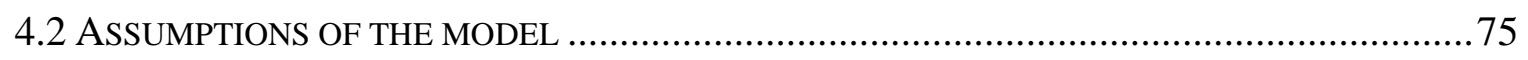

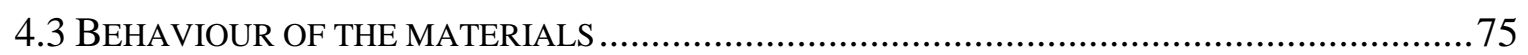

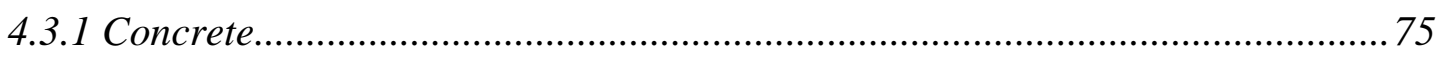

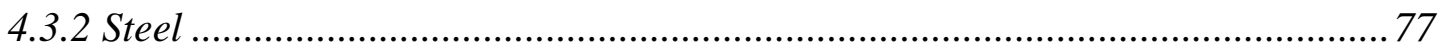

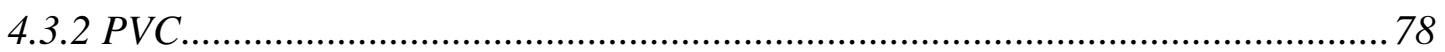

4.4 SECTIONAL ANALYSIS NEGLECTING THE CONFINEMENT EFFECT OF THE PVC

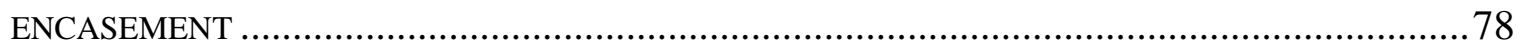

4.5 COMPARISON BETWEEN THE EXPERIMENTAL AND CALCULATED RESULTS ....................... 87

4.6 SECTIONAL ANALYSIS INCLUDING THE PVC CONFINEMENT EFFECT ..............................89

4.7 CALCULATED AND EXPERIMENTAL RESULTS FOR THE PVC ENCASED SPECIMENS ..........95

CHAPTER 5: CONCLUSION AND RECOMMENDATION .....................................98

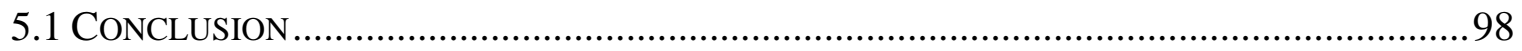

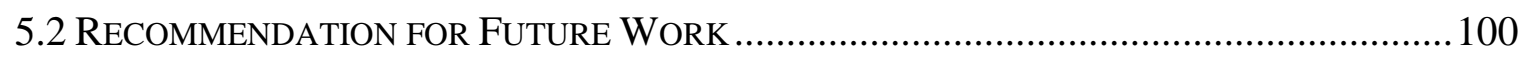

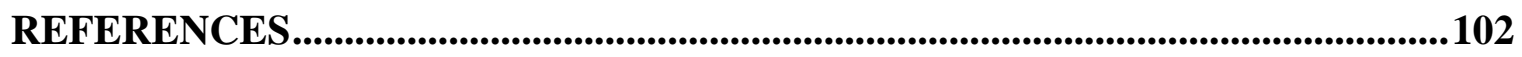

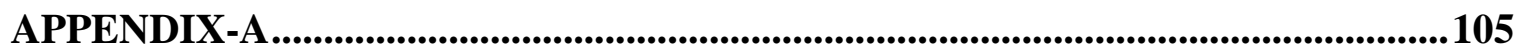




\section{List of Tables}

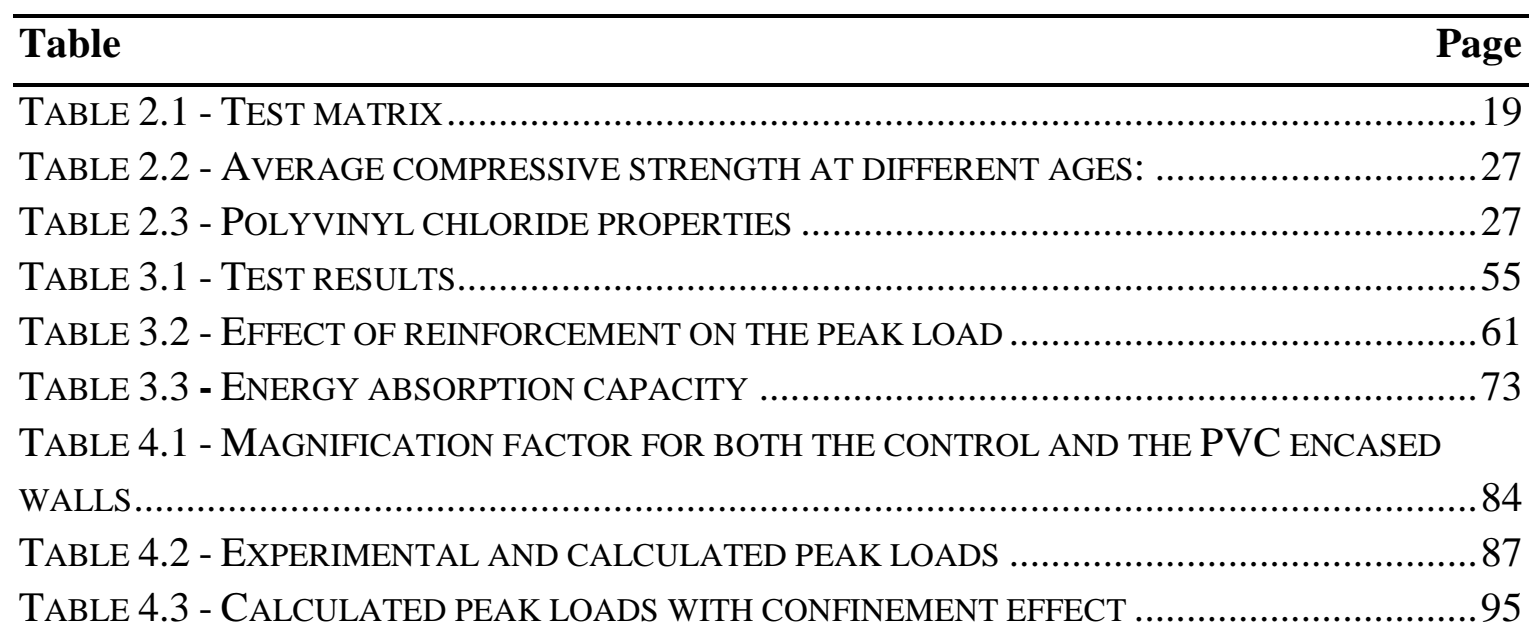




\section{List of Figures}

\begin{tabular}{lc}
\hline Figure & Page \\
\hline
\end{tabular}

FIGURE 1.1 - ELEMENTS USED IN PVC ENCASEMENT 10

FIGURE 1.2 - DIFFERENT CONFIGURATIONS FOR THE PANELS AND CONNECTORS

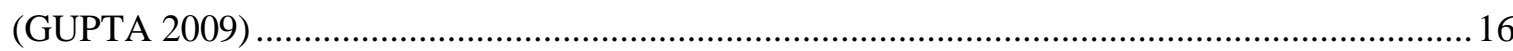

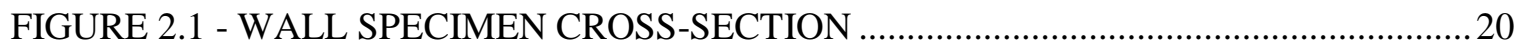

FIGURE 2.2 - FORMWORK AND REINFORCEMENT CONTROL SPECIMENS .................22

FIGURE 2.3 - TOP AND BOTTOM ENDS OF THE CONTROL SPECIMENS ….....................23

FIGURE 2.4 - FORMWORK FOR PVC ENCASED WALL SPECIMENS …..............................24

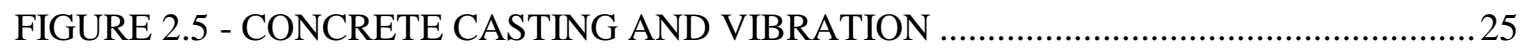

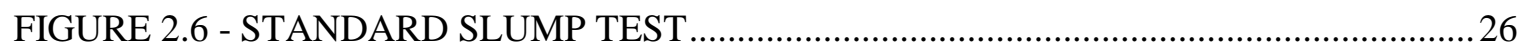

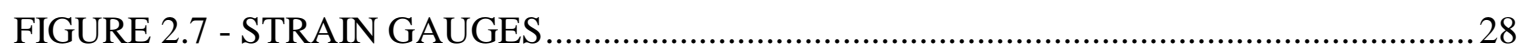

FIGURE 2.8 - END PLATES AND SWIVEL SYSTEM ............................................................... 30

FIGURE 2.9 - FORKLIFT PLACING THE SPECIMEN INSIDE THE FRAME .......................... 31

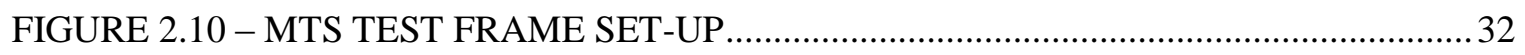

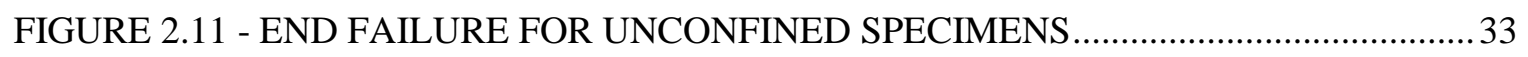

FIGURE 2.12 - SPECIMEN WITH EXTERNAL CONFINEMENT (COLLARS) ........................ 36

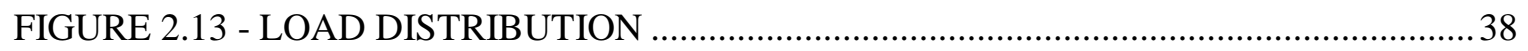

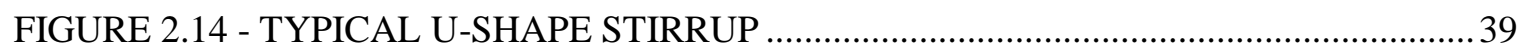

FIGURE 2.15 - FAILURE MODES OF A) UNCONFINED AND B) CONFINED O-E3-15

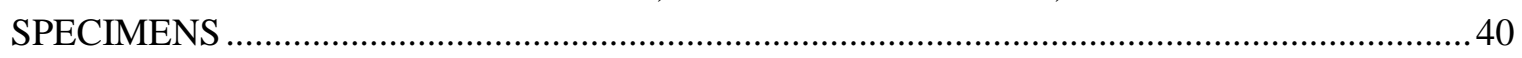

FIGURE 2.16 - LOAD VERSUS DISPLACEMENT FOR UNCONFINED AND CONFINED O-

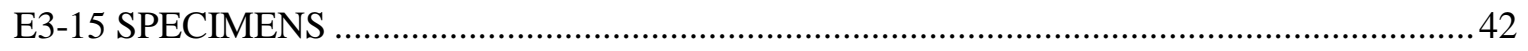

FIGURE 3.1 - LOAD VERSUS VERTICAL DISPLACEMENT FOR O-E3-10 AND C-E3-10

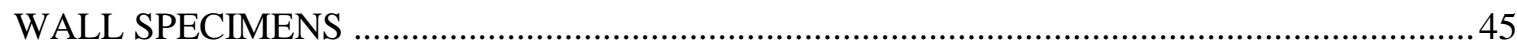

FIGURE 3.2 - LOAD VERSUS MID-SPAN DEFLECTION FOR O-E3-10 AND C-E3-10

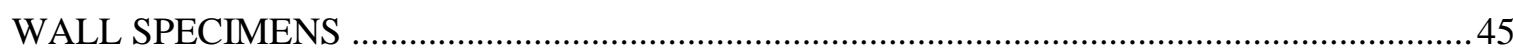

FIGURE 3.3 - LOAD VERSUS TENSION STEEL STRAIN FOR O-E3-10 AND C-E3-10

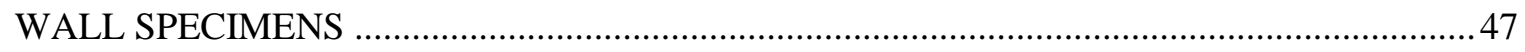

FIGURE 3.4 - LOAD VERSUS CONCRETE STRAIN FOR O-E3-10 AND C-E3-10 WALL SPECIMENS

FIGURE 3.5 - LOAD VERSUS COMPRESSION STEEL STRAIN FOR O-E3-10 AND C-E3-10

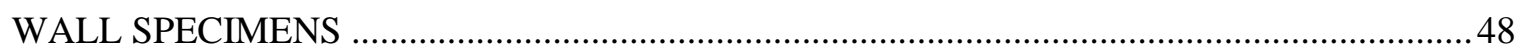

FIGURE 3.6 - LOAD VERSUS STRAIN FOR O-E3-10 WALL SPECIMEN...............................48

FIGURE 3.7 - FAILURES AT THE LOWEST ECCENTRICITY (33.87 MM) .........................51 
FIGURE 3.8 - FAILURES AT THE INTERMEDIATE ECCENTRICITY $(67.73 \mathrm{MM}) \ldots \ldots \ldots \ldots . . . .52$

FIGURE 3.9 - FAILURES AT THE HIGHEST ECCENTRICITY (101.6 MM),..........................53

FIGURE 3.10 - LOAD VERSUS VERTICAL DISPLACEMENT FOR THE CONTROL SPECIMENS REINFORCED WITH 4-10M AT DIFFERENT ECCENTRICITIES ....................58

FIGURE 3.11 - LOAD VERSUS MID-SPAN DEFLECTION FOR THE CONTROL SPECIMENS REINFORCED WITH 4-10M AT DIFFERENT ECCENTRICITIES ..................58

FIGURE 3.12 - LOAD VERSUS VERTICAL DISPLACEMENT FOR THE PVC ENCASED SPECIMENS REINFORCED WITH 4-10M AT DIFFERENT ECCENTRICITIES .59

FIGURE 3.13 - LOAD VERSUS MID-SPAN DEFLECTION FOR THE PVC ENCASED SPECIMENS REINFORCED WITH 4-10M AT DIFFERENT ECCENTRICITIES . .59

FIGURE 3.14 - LOAD VERSUS VERTICAL DISPLACEMENT FOR CONTROL WALL SPECIMENS WITH DIFFERENT REINFORCEMENT (C-E3-10 AND C-E3-15)

FIGURE 3.15 - LOAD VERSUS VERTICAL DISPLACEMENT FOR PVC ENCASED WALL SPECIMENS WITH DIFFERENT REINFORCEMENT (O-E2-10 AND O-E2-10)... .62

FIGURE 3.16 - LOAD VERSUS STRAIN AT MID-SPAN FOR O-E6-10 WALL SPECIMEN 64 FIGURE 3.17 - LOAD VERSUS TENSION STRAIN READINGS FOR THE PVC ENCASED WALL SPECIMEN (O-E3-10)

FIGURE 3.18 - LOAD VERSUS COMPRESSION STRAIN READINGS FOR THE PVC ENCASED WALL SPECIMEN (O-E3-10).

FIGURE 3.19 - LOAD VERSUS TENSION STRAIN READINGS FOR THE PVC ENCASED WALL SPECIMEN (O-E2-10)

FIGURE 3.20 - LOAD VERSUS COMPRESSION STRAIN READINGS FOR THE PVC ENCASED WALL SPECIMEN (O-E2-10).

FIGURE 3.21 - LOAD VERSUS PVC STRAIN GAUGE READINGS AT DIFFERENT ECCENTRICITIES FOR THE WALLS REINFORCED WITH 4-10M. 70

FIGURE 3.22 - LOAD VERSUS PVC STRAIN GAUGE READINGS AT A GIVEN ECCENTRICITY FOR DIFFERENT REINFORCEMENT RATIOS (O-E2-10 AND O-E2-15) 71 FIGURE 4.1 - EQUIVALENT COMPRESSIVE STRESS IN CONCRETE

FIGURE 4.2 - STRESS-STRAIN RELATION FOR THE PVC (WAHAB AND SOUDKI 2013)

FIGURE 4.3 - STRAIN, STRESS AND INTERNAL FORCE DISTRIBUTION FOR SPECIMENS SUBJECTED TO COMBINED FLEXURE AND AXIAL LOADS .80

FIGURE 4.4 - CALCULATION STEPS FOR UNCONFINED WALL SPECIMENS . .86

FIGURE 4.5 - INTERACTION DIAGRAM FOR CONTROL WALLS . .88

FIGURE 4.6 - STRAIN, STRESS AND INTERNAL FORCE DISTRIBUTION FOR PVC ENCASED SPECIMENS SUBJECTED TO COMBINED FLEXURE AND AXIAL LOAD ..... 90 FIGURE 4.7 - CALCULATION STEPS FOR THE PVC ENCASED WALLS ACCOUNTING FOR THE CONFINEMENT EFFECT . .94 FIGURE 4.8 - INTERACTION DIAGRAM FOR PVC ENCASED WALLS .96 
FIGURE 4.9 - CALCULATED INTERACTION DIAGRAMS FOR BOTH CONTROL AND PVC ENCASED WALLS .. 


\section{Chapter 1: Introduction and literature review}

\subsection{Introduction}

Formwork is a general term for either a temporary or permanent system used in casting concrete to form a particular structural shape. The formwork system must be capable of carrying its own weight, the weight developed by fresh concrete, and the live loads associated with the construction process and equipment. The most common formwork system is traditional timber formwork. This system is built on site using plywood sheets to form a certain structural shape. Once the concrete hardens and gains its strength, the formwork is removed. The main drawbacks of that system are Time consuming, relatively short life span and huge labor demand during the process of installation and removal of the formwork

Stay-in-place (SIP) formwork has been lately used as an alternative to the conventional formwork system. Stay-in-place formwork systems are mainly assembled on site, hence simplifying the construction process and reducing the construction time as the removal procedure is eliminated. As well, most of the stay-in-place formwork systems are made of lightweight and prefabricated materials.

Stay-in-place formwork systems are usually designed to be highly durable against environmental influences and enhance constructability and mechanical performance of concrete. In addition, in some cases such as bridge decks constructed over features like railway or heavy traffic highway, the SIP formwork system reduces the safety hazards associated with these projects as the assembly and removal procedure of the formwork are optimized. 
Stay-in-place formwork systems can be divided into two main categories; structural and non-structural formwork, based on their contribution to carrying applied loads. The nonstructural SIP formwork systems are not designed to carry loads, but to resist loads generated by fresh concrete. The main advantage of this type of formwork, besides reducing the construction time, is enhancing the durability of concrete against harsh environmental applications. Also, it improves the efficiency of the structure in terms of acoustic performance and energy.

The second type of SIP formwork systems is structural formwork. In addition to the advantages provided by the non-structural formwork, it contributes to resisting the applied loads in service. This can lead to a more economical solution than the nonstructural formwork, as it results in reducing the cross section and the reinforcement of the structural member (Rteil et al., 2008). It can also enhance the confinement properties of the concrete structural elements.

Several materials have been used for the SIP structural formwork systems and can be summarized into two main groups; metallic and non-metallic materials. Metallic formwork such as steel and aluminum have been widely used in recent decades, especially in bridge construction. Several research projects were carried out to investigate the effect of this formwork on the quality and the performance of the concrete structures. The main drawbacks of using metallic formwork are the susceptibility of these forms to corrosion, the presence of excess moisture content in the concrete due to water entrapment, and the weakness of the interfacial bond between the concrete and the formwork. 
The corrosion problem can be eliminated using SIP non-metallic formwork. A wide range of the non-metallic formwork systems are made of synthetic materials, especially polyvinyl chloride (PVC) and fiber reinforced polymer (FRP).

Recently, polyvinyl chloride (PVC) has been used as a stay-in-place formwork because of its lower cost compared to other materials, durability, and ease to assemble. This type of formwork has been used mainly for walls in commercial, agricultural and industrial buildings. PVC SIP formwork is mainly designed to be highly durable in harsh environmental conditions and to enhance the constructability and the mechanical performance of concrete.

However, in contrast to the FRP SIP formwork, the contribution of the PVC SIP formwork to the structural strength of the formed concrete member is ignored in most cases due to the lack of specified design guidelines for this type of forms. Only few studies have examined the structural behaviour of the composite PVC SIP formed wall elements.

\subsection{Literature review}

\subsubsection{General}

The two main types of the non-metallic structural formwork are the FRP and the PVC stay-in-place formwork. This chapter summarizes the work done on both types of formwork and presents the main findings. 


\subsubsection{FRP structural formwork}

\subsubsection{FRP material}

FRP materials are composite materials which are normally composed of strong fibers embedded in a resin matrix. The applied load is carried mainly by the fibers which provide the strength and stiffness to the composite. The matrix bonds and protects the fibers as well as transferring the stresses from fiber to fiber through shear stresses. The most common fibers are glass, carbon, and aramid. Matrixes are typically epoxies, polyesters, vinylesters, or phenolics (ACI 440R-07).

FRP stay-in-place formwork systems are being widely used in the recent years. There are various types of FRP formwork that have been used for structural concrete members such as; FRP box (rectangular section) having one open side for concrete to be poured, Pultruded FRP panel having a flat continuous base and two T-up stands as shear studs, and Concrete-filled FRP tubes (CFFT). The first and the second are suitable for beams and slabs applications, respectively. The last system is used in piles in corrosive marine environments and as bridge girders, piers, and columns (ACI 440R-07).

The FRP stay-in-place formwork systems can be efficiently used for concrete columns. It can reduce the amount of internal reinforcement, as well as increase the resistance of the concrete members against harsh environmental (Mirmiran 2003).

The advantages of FRP formwork system as summarized by ACI 440 (2007):

The FRP formwork system can offer many solutions. Fiber type, orientation and number of layers can be varied to achieve optimum design. The composite action between the concrete and the FRP can be suited to the type of loading. For the systems subjected to 
flexural load, it is preferable to have the FRP and the concrete fully bonded, but for systems resisting axial loads, un-bonding the FRP from concrete is more desirable. Also, the construction process is simplified and the construction time is reduced since the removal procedure is eliminated. The FRP formwork system can either provide the main flexural reinforcement for the concrete element or the shear and flexural reinforcement combined. Thus, the time required to assemble the reinforcing bars and stirrups in case of the conventional formwork is reduced. Also, the confinement effect of the FRP formwork system protects and isolates the concrete from harsh environment applications.

In addition to the previous FRP formwork systems discussed previously, many other systems were proposed as an alternative to the conventional formwork systems. Hybrid tube system (HTS) is a system that acts as stay-in-place formwork for slabs and beams. It consists of hollow E-glass/carbon hybrid beams, connected along one another from the top using fiber reinforcement concrete deck. Another type of stay-in-place formwork systems is the Carbon Shell system (CSS). The carbon shell consists of carbon fibers in the longitudinal direction and hoop fibers in the transverse direction. Carbon Shell System uses prefabricated filament-wound carbon/epoxy thin shells to be filled on-site with concrete. The system mainly serves as longitudinal and hoop reinforcement and acts as a stay-in-place formwork. The CSS system is used mainly for columns and girders (Van Den Einde et al. 2003).

\subsubsection{Behaviour of the FRP encased columns}

Ozbakkaloglu et al. (2006) investigated the seismic performance and the confinement effect of the stay-in-place FRP formwork for high strength concrete and normal strength concrete. The formwork was proposed as an alternative to the conventional confinement 
reinforcement used for concrete columns. The FRP tubes were made of carbon fiber and epoxy resign. The fibers were placed in the hoop direction to attain an efficient confinement effect. The specimens were $0.27 \mathrm{~m}$ circular cross-section, 1.72 or $0.92 \mathrm{~m}$ length and reinforced with 8-no.15 bars. The variables in this study were the concrete strength, thickness of the FRP tube (number of layers), the level of axial load and the shear span. The specimens were subjected to constant axial compression and incrementally increasing reversals lateral deformation to simulate the seismic action. They concluded that the high strength concrete circular columns confined with stay-inplace FRP formwork showed a significant ductile behaviour under simulated seismic loading. In addition, an increase in the inelastic deformability for the high strength concrete columns was indicated. Also, the stay-in-place formwork showed an effective entire confinement for the whole column section in comparison to the conventional reinforcement confinement where only the core of the concrete column was confined.

Mirmiran et al. (1999) investigated the behaviour of beam-column specimens subjected to uniaxial compression and axial-flexural loading. The specimens were concrete-filled FRP tubes (CFFT). The FRP tubes act as a stay-in-place formwork and a protection shell for the concrete from harsh environmental conditions. All of the specimens were $178 \mathrm{~mm}$ by $178 \mathrm{~mm}$ in cross-section by $1,320 \mathrm{~mm}$ long. The specimens were tested under four point bending, a uniaxial compression load and combined axial-flexural loading. An interaction diagram was established based on the experimental results. They concluded that the CFFT specimens subjected to concentric loads showed a higher capacity (over $75 \%$ ) compared to conventional reinforcement concrete specimens due to the confinement provided by the FRP tubes. The increase in the capacity of the specimens tested under concentric loading was higher than the other CFTT specimens tested under axial-flexural 
loading. They also suggested that the effect of confinement in beam-column specimens is higher in the compression region of the interaction diagram. Moreover, the failure of the specimens encased with CFFT system was more ductile than the conventional reinforced concrete specimens.

Fam et al. (2003) experimentally investigated the behaviour of concrete-filled glass fiber reinforcement polymer tubes. They were subjected to concentric and eccentric axial loads using column specimens and pure bending using beam specimens. Two different types of laminate structures of the glass FRP tubes with different properties were used. The laminates varied in the outer diameter, structural wall thickness, matrix type, elastic modulus-axial, elastic modulus-hoop, axial tensile and compressive strength, hoop tensile strength and Poisson's ratio. All of the specimens had an outer diameter of $326 \mathrm{~mm}$ or $320 \mathrm{~mm}$ based on the type of the laminate. The height of the columns tested concentrically was $0.98 \mathrm{~m}$ or $0.96 \mathrm{~m}$. The height of the columns tested eccentrically was $1.8 \mathrm{~m}$ or $1.75 \mathrm{~m}$. All of the beams had spans of $5.5 \mathrm{~m}$. The applied eccentricity varied between $55 \mathrm{~mm}$ to $839 \mathrm{~mm}$ for type I and $11 \mathrm{~mm}$ to $329 \mathrm{~mm}$ for type II. The objectives of the study were to evaluate the effect of the diameter-to-thickness ratio and laminate structure of the tube on the behaviour of the specimens taking into consideration the different ratios of fiber in the axial and the hoop directions. In addition, they investigated the effect of the confinement at different eccentricities of the applied axial load for different laminate structures. The test results showed that different types of tubes having almost the same wall thickness and diameter had different confinement effects based on the laminate structure. For a given laminate structure, an increase in both bending and axial strength can be achieved by increasing the wall thickness and/or the ratio of fibers in the axial direction. They concluded that depending on the tube thickness, an optimum 
laminate structure for a given eccentricity can be attained by varying the proportion of fibers in the axial and the hoop directions.

Li et al. (2005) conducted an experimental study on the FRP tube-encased concrete columns (FRP/ECCs). The objective of the study was to investigate the effect of the concrete strength on the performance of the FRP tube-encased columns. The specimens were classified into three batches based on the 28-days compressive strength; $35 \mathrm{MPa}, 50$ $\mathrm{MPa}$ and $80 \mathrm{MPa}$. Twenty seven specimens were cast using FRP tubes with $5 \mathrm{~mm}$ wall thickness for the three batches of concrete. The specimens were $101.6 \mathrm{~mm}$ in diameter and $304.8 \mathrm{~mm}$ high. In the four point bending test, the specimen length was increased to $508 \mathrm{~mm}$. For each batch, three specimens were used for each of the uniaxial compression test, the four-bending test and the push-out test. The push-out test was conducted to study the effect of the concrete strength on the interfacial bonding behaviour.

Li et al. (2005) found that for high strength concrete, the interfacial bonding is low. All FRP confined specimens tested under uniaxial compression load showed an increase in the compressive strength compared to the control specimens. The percentage of increase depends on the concrete compression strength. The FRP confined specimens cast with the lowest concrete compressive strength (35 $\mathrm{MPa}$ ) showed an increased compressive strength over their control specimens by 4.35 times. As the concrete strength increased to $50 \mathrm{MPa}$ and $80 \mathrm{MPa}$, the FRP specimens showed an increase in their compressive strength over their control specimens by 3.58 and 2.20 times, respectively. It was concluded that the efficiency of the load carrying capacity of the FRP can be fully utilized at lower concrete strengths due to the early contribution of the FRP tubes. In the Fourpoint bending test, the FRP confined specimens cast with $50 \mathrm{MPa}$ and $80 \mathrm{MPa}$ showed 
almost the same load carrying capacity. On the other hand, the FRP confined specimens cast with the lowest concrete compressive strength (35 MPa) showed lower load carrying capacity. The deflection of the FRP tube-encased concrete columns was affected by the core concrete strength. Four-point bending test results showed that the FRP confined specimens cast with the highest compressive strength $(82 \mathrm{MPa})$ had the smallest deflection due to its high stiffness. They also concluded that the confinement effect of the FRP tubes significantly enhanced the ductility of the columns.

Although, FRP formwork systems have some advantages, there are some limitations on using FRP formwork systems, which are mainly; poor fire resistance and vandalism of accessible FRP. In addition, protection against moisture intrusion is required in case of direct contact between the FRP form and the water. (ACI 440R-07)

\subsubsection{PVC encasement structural formwork}

\subsubsection{PVC material}

The polyvinyl chloride (PVC) stay-in-place formwork consists of interconnected panels and connectors that serve as permanent formwork for the concrete walls. The panels form the outer shell of the PVC encased wall surface. The connectors slide and interlock with the panels. Panels are connected together via a hollow web connector component that holds the forms together as shown in Figure 1.1. The hollow web connectors allow the concrete to flow laterally between adjacent cells. In addition, it facilitates the placement of reinforcing steel. The PVC encasement system may provide additional tension reinforcement and increase the confinement of the concrete, and hence increase the capacity of the concrete walls. 


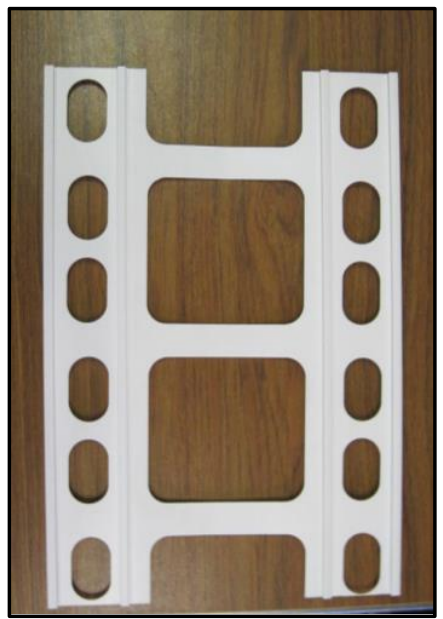

a- Connector

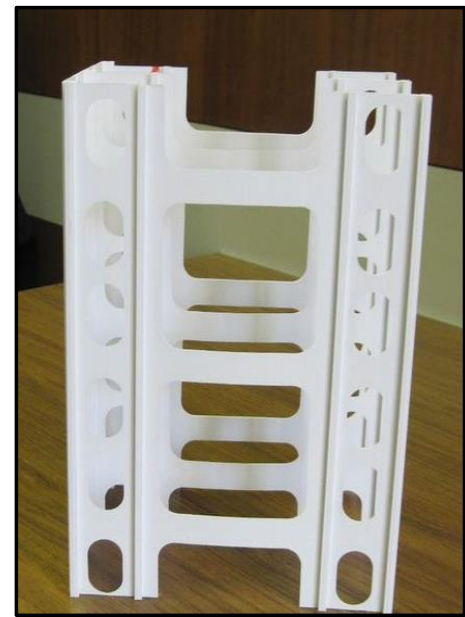

b- Side view of the wall cell

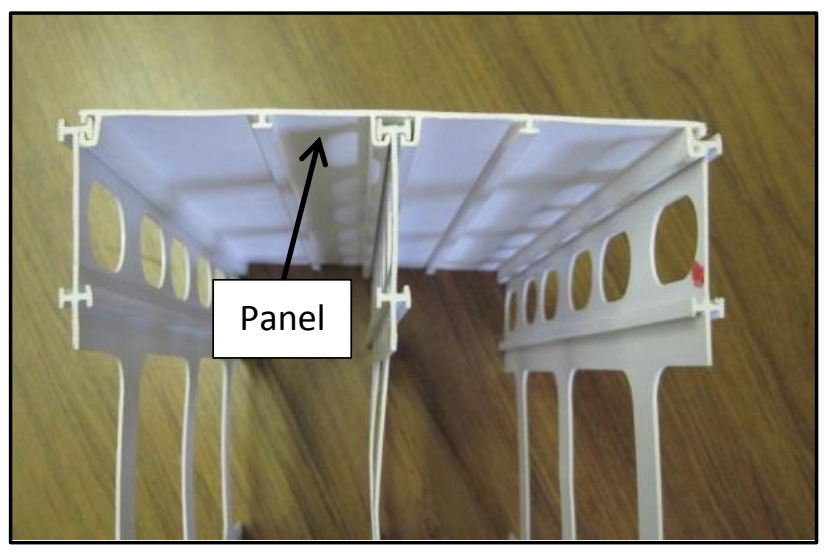

c- Top view of the wall cell

Figure 1.1 - Elements used in PVC encasement

\subsubsection{Behaviour of the PVC encased members}

\section{Effect of PVC as tension reinforcement}

The effect of the PVC as a tensile reinforcement was investigated by testing the walls under pure flexure. Rteil et al. (2008) investigated the effect of the PVC stay-in-place forming system (Octaform) on the flexural behaviour of walls subjected to four point bending tests. A total of twelve (12) specimens were cast and tested. Eight specimens were cast with the PVC forming system. The other four were cast without the PVC forming system to act as control specimens. All specimens had a rectangular cross-section and were $2500 \mathrm{~mm}$ long and $305 \mathrm{~mm}$ wide. The variables of that study were the specimen 
depth (150, and $200 \mathrm{~mm})$, and the connector configuration, middle connectors or inclined $\left(45^{\circ}\right)$ connectors. The specimens were reinforced with two $10 \mathrm{M}$ rebars. Results showed that the PVC did not change the flexural mode of failure of the walls. However, the PVC stay-in-place forming system increased the cracking load, ultimate load capacity and steel yielding by $36 \%, 36 \%$, and $78 \%$, respectively. It also increased the ductility index by $25 \%$. In addition, it was found that encasing a wall specimen with the stay-in-place PVC system allowed reducing the depth of that specimen without affecting the general behaviour of the wall. Also, test results showed that using different connector configurations (middle or inclined) did not affect the performance of the PVC encased walls.

Chahrour et al. (2005) investigated experimentally the flexural behaviour of PVC stay-inplace formwork for concrete walls. They tested a total of 15 wall specimens in flexure under four point bending. The test variables included the wall thickness (100, 150 and $200 \mathrm{~mm}$ ) and the reinforcement ratio (plain and reinforced concrete walls). All of the specimens were simply supported with a clear span of $2000 \mathrm{~mm}$. They reported the rupture of the polymer flange in tension as a mode of failure. They concluded that polymer stay-in-place encased concrete walls tested in flexure exhibited a ductile response that depended on the specimen thickness and steel reinforcement ratio. They did not test control walls (without PVC encasement). Hence, they did not comment on the effect of the PVC encasement on the capacity of the specimen.

Kuder et al. (2009) investigated the flexural behaviour of the PVC-encased specimens. They tested reinforced concrete beams with and without the PVC components. The beams were $152.4 \mathrm{~mm}$ deep, $152.4 \mathrm{~mm}$ wide and $609.6 \mathrm{~mm}$ long. They were reinforced in the 
longitudinal direction with a \#3 rebar $(9.5 \mathrm{~mm}$ diameter). They examined different configurations for the PVC panels and connectors. Their specimens were tested in threepoint bending with a span of $508 \mathrm{~mm}$. The PVC encased specimens showed an increase in the peak load by 39-66\% over the control specimens depending on the PVC configuration. The PVC configuration influenced the extent of the increase of peak load and consequently the toughness.

Wahab and Soudki (2013) experimentally investigated the flexural behaviour of concrete wall strips encased with PVC. They tested 30 PVC encased wall specimens. They were $457 \mathrm{~mm}$ wide by $200 \mathrm{~mm}$ or $250 \mathrm{~mm}$ deep by $3050 \mathrm{~mm}$ long. Their variables were the concrete core thickness $(200 \mathrm{~mm}$ or $250 \mathrm{~mm})$, the reinforcement ratio, and the connector type. The specimens were tested monotonically under four point bending with a shear span of $1150 \mathrm{~mm}$. They concluded that the PVC stay-in-place formwork system enhanced the flexural behaviour of the encased walls. They reported that the contribution of the PVC system to the ultimate load increased as the concrete core thickness decreased. In addition, contribution of the PVC system to the ultimate load increased as the reinforcement ratio decreased. The increase in their ultimate loads due to the PVC stayin-place system ranged from $17.4 \%$ to $37.7 \%$ over the control specimen. They also reported that the PVC stay-in-place system enhanced the ductility by $2.5 \%$ to $134 \%$ over the control specimens.

In summary, the PVC system enhanced the flexural behaviour of the walls under flexure. The ultimate loads for the PVC encased walls were reported to be higher than the control walls, indicating the contribution of the PVC panels as a tensile reinforcement. The 
increase in the peak load depended on the wall thickness, reinforcement and configuration.

\section{Behaviour of PVC encased members under axial load}

Chahrour and Soudki (2006) experimentally investigated the behaviour of the polymer (PVC) encased concrete walls subjected to pure axial load and combined axial and flexural load. Based on the experimental results, a theoretical provision aims to predict the ultimate load capacity of the specimens was conducted taking into consideration the effect of the polymer based stay-in-place formwork system on the capacity of the wall. The theoretical provision was derived based on the moment magnification factor method in which the effect of secondary stresses associated with column deformations was taken into consideration.

A total of 24 specimens were tested under pure axial compression and 14 specimens under combined axial compression and flexure. For the pure axial compression tests, all of the specimens were $300 \mathrm{~mm}$ long, $333 \mathrm{~mm}$ width and either 100 or $150 \mathrm{~mm}$ thick. The specimens were tested under axial concentric load. Similar failure modes were observed for both PVC encased and control specimens. The ultimate load of the polymer encased specimens was only $3 \%$ higher than the control specimens. Results showed a more ductile descending post-failure curve for polymer encased specimens compared to those tested without any confinement (control specimens).

For the combined axial and flexural load tests, the specimens were $3658 \mathrm{~mm}$ long, 333 mm width and either 100 or $150 \mathrm{~mm}$ thick. The eccentricities were applied as a ratio of the specimen's thickness varying from $10 \mathrm{~mm}$ to $75 \mathrm{~mm}$. Failure occurred by disintegration of the polymer in addition to the formation of a large crack around the mid- 
span cross section. The result of the combined axial compression and flexure tests showed a considerable contribution of the polymer to the tensile load capacity of the specimens. In addition, a significant enhancement in the deformability of the polymer encased specimens was noticed. It was found that mid-span deflection up to $200 \mathrm{~mm}$ was achieved while the specimen was still capable of carrying significant loads at such very large midspan deflection levels.

Since confinement improves the compressive behaviour of concrete columns (Richart et al. 1928), Kudr et al. (2006 and 2009) and Gupta at el. (2009) investigated the confining effect of PVC on concrete columns tested under axial load. Concrete expands laterally, as micro-cracks begin to form. If deformation compatibility between the concrete and the confining material exists, lateral stresses are developed in the confining material that opposes the expansion of the concrete. Mirmiran and Shahawy (1997) and Mirmiran et al. (1998) reported that the effectiveness of the confining material depended on the deformation compatibility between the confining material and the concrete, the geometry of the columns and the properties of the confining material.

Kudr et al. (2006 and 2009) investigated the confining effect of the PVC on the concrete. They tested concrete stub columns $152 \mathrm{~mm}$ by $152 \mathrm{~mm}$ by $152 \mathrm{~mm}$ encased in PVC. They investigated the effect of different configurations for the panels and connectors on the capacity of the stub column (Figure 1.2). All stub columns were tested under axial compression load. The concrete strength was $27 \mathrm{MPa}$. They concluded that generally the PVC increased the compressive strength over the control specimens. The increase varied between $4 \%$ and $42 \%$ depending on the configuration of the panels and the connectors. The lowest increase was for the configuration with a maximum number of components. 
They reported that as the number or components increased, the consolidation become more difficult which affected the test results.

Kudr et al. (2006 and 2009) reported that a conical failure was observed in the control specimens with a significant amount of lost concrete. However, for the PVC encased specimens, the PVC still contained the crushed concrete. They also reported that near the peak load, the connectors started de-bonding from the concrete but the panels did not show any signs of de-bonding. Hence, they concluded that the PVC resisted the lateral expansion of the concrete. However, since the connectors had voids in them, they covered less area and allowed the concrete to expand more freely between their openings.

Gupta at el. (2009) also investigated the confining effect of PVC on concrete. They tested concrete columns encased in PVC and compared them to the control specimens. The column cross section was $152 \mathrm{~mm}$ by $152 \mathrm{~mm}$. They investigated three different lengths $(508,915$ and $1828 \mathrm{~mm})$. They investigated the effect of four different configurations (Figure 1.2) on increasing the axial load capacity. The concrete strength was $38 \mathrm{MPa}$. They reported that the PVC encased columns confined the concrete and showed an increase in the peak load up to $31 \%$ over the control columns. They reported an average increase of $12 \%$ for the four configurations. 

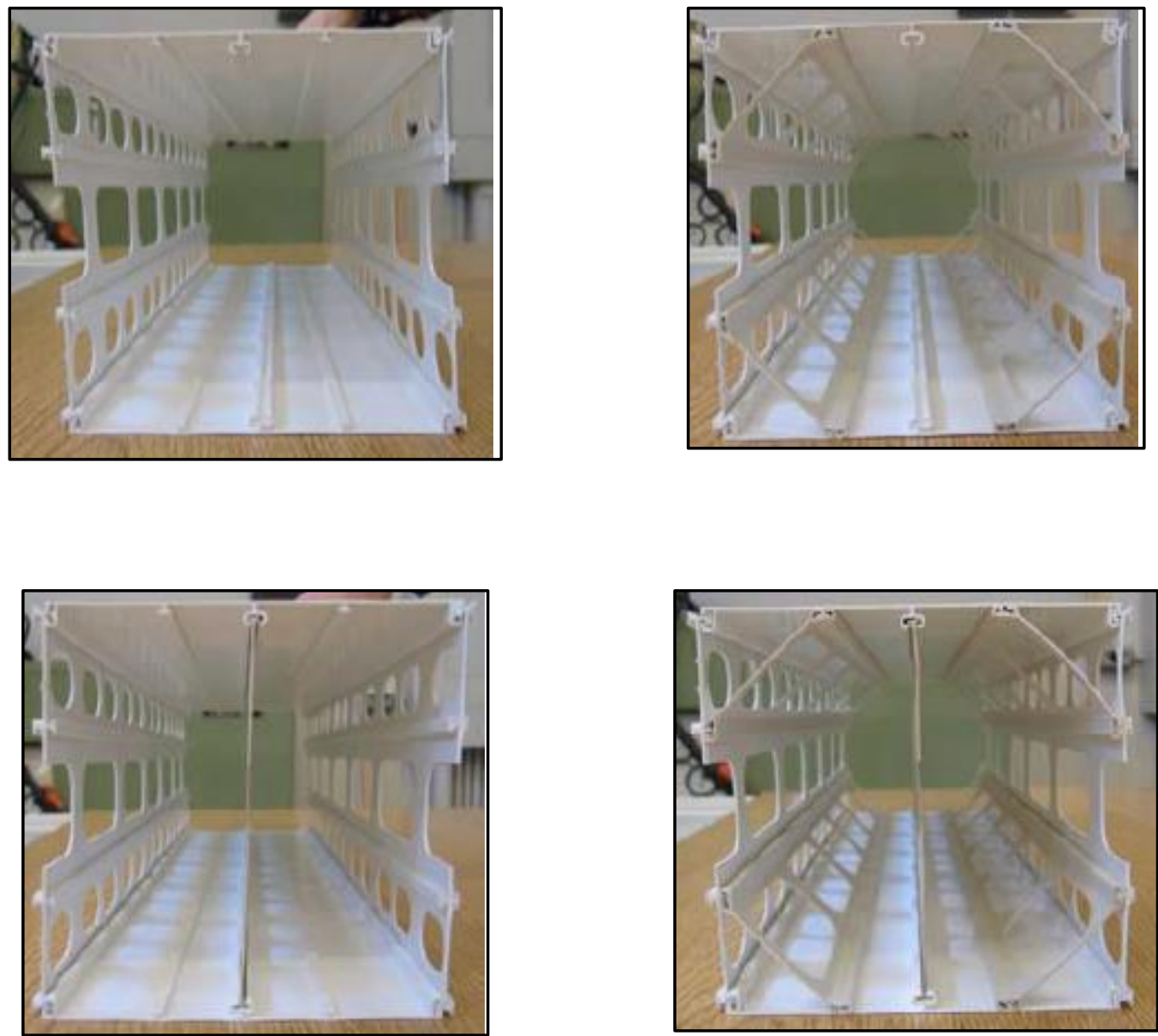

Figure 1.2 - Different configurations for the panels and connectors (Gupta 2009)

In summary, the PVC encasement was proven to be effective in confining the plain concrete columns under axial load. The confinement effect will depend on the configuration of the panels and the connectors. For the plain concrete walls encased with PVC and tested under combined axial and flexure load, the results showed a considerable contribution of the polymer to the tensile load capacity of the specimens.

\subsection{Objectives of the study}

The PVC encased system has been used extensively to form foundation walls, retaining walls, walls in water and waste treatment tanks and walls for swimming pools. In these applications, the walls are resisting axial load and bending moment. They might also be subjected to eccentric axial load. In this study the load is applied at different eccentricities 
for concrete walls with different reinforcement ratios. The behaviour of the PVC encased specimens is compared to the control specimens (without PVC) to assess the contribution of the PVC. The main objectives of this study are:

- Investigate the characteristic behavior of the PVC encased walls subjected to axial compression and flexural loading

- Compare the behaviour of the PVC encased walls to the control concrete walls.

- Investigate the contribution of the PVC encased system under different reinforcement ratios.

- Investigate the contribution of the PVC encased system under different applied eccentricities.

\subsection{Thesis structure}

The thesis is divided into five chapters. Chapter one provides an introduction, description of the objectives of this study, organization of the thesis and summarizes the work done by other researchers on similar topics and presents their main findings. Chapter two describes the experimental program, specimen fabrication, test instrumentation and test set-up. Chapter three discusses the results obtained from testing the reinforced concrete walls. Chapter four presents a model that calculates the capacity of the PVC encased walls. Conclusions, recommendations and future work are provided in Chapter five. 


\section{Chapter 2: Experimental program}

\subsection{Overview}

This chapter presents the test program for the control reinforced concrete walls and the polyvinyl chloride (PVC) encased walls. Sections 2.2 and 2.3 describe the test matrix and the test specimen. Sections 2.4 and 2.5 discuss the specimen fabrication and the casting of the concrete. Section 2.6 presents the material properties. The instrumentation and the test procedure are described in Section 2.7. Finally, Section 2.8 illustrates the effect of the confining system for the wall specimens.

\subsection{Experimental program}

Eighteen reinforced concrete walls were cast and tested at the structural laboratory at University of Waterloo. The variables in this study were the type of the specimen (PVC encased or control), amount of the longitudinal reinforcement (4-10M or $4-15 \mathrm{M}$ rebars) and the eccentricity of the applied load $(33.87 \mathrm{~mm}, 67.73 \mathrm{~mm}, 101.6 \mathrm{~mm})$. Six specimens acted as control specimens (without PVC encasement) and twelve specimens were PVC encased walls with middle connectors. The walls were cast in two batches. In the first batch, the control walls and six PVC encased walls were cast. In the second batch, the remaining PVC encased walls were cast.

Table 2.1 shows the test matrix. The notation is as follows; the first letter stands for the wall type; PVC encased wall (O) or control wall (C) (without PVC encasement). The following letter represents the eccentricity, where e6, e3 and e2 represent an eccentricity ratio of $1 / 6,1 / 3$ and $1 / 2$ of the specimen's thickness ( $t$ ), respectively. The last number represents the diameter of the reinforcement rebar. For instance; O-e3-15 is a PVC 
encased wall reinforced with 4-15 $\mathrm{M}$ and subjected to an eccentric compression load applied at $1 / 3$ of the specimen's thickness.

Table 2.1 - Test matrix

\begin{tabular}{|c|c|c|c|c|c|}
\hline Specimen & $\begin{array}{c}\text { Connector } \\
\text { type }\end{array}$ & Reinforcement & $\begin{array}{c}\text { Reinforcement } \\
\text { ratio }\end{array}$ & $\begin{array}{l}\text { Eccentricity } \\
(\mathbf{m m})\end{array}$ & $\begin{array}{c}\text { Number } \\
\text { of } \\
\text { specimens }\end{array}$ \\
\hline C-e6-10 & \multirow{3}{*}{ NA } & \multirow{3}{*}{$4-10 \mathrm{M}$} & \multirow{3}{*}{0.65} & $\mathrm{t} / 6=33.87$ & \multirow{6}{*}{6} \\
\hline C-e3-10 & & & & $t / 3=67.73$ & \\
\hline C-e2-10 & & & & $\mathrm{t} / 2=101.6$ & \\
\hline C-e6-15 & \multirow{3}{*}{ NA } & \multirow{3}{*}{$4-15 \mathrm{M}$} & \multirow{3}{*}{1.3} & $t / 6=33.87$ & \\
\hline C-e3-15 & & & & $t / 3=67.73$ & \\
\hline C-e2-15 & & & & $\mathrm{t} / 2=101.6$ & \\
\hline O-e6-10 & \multirow{3}{*}{ Middle } & \multirow{3}{*}{$4-10 \mathrm{M}$} & \multirow{3}{*}{0.65} & $t / 6=33.87$ & \multirow{6}{*}{12} \\
\hline O-e3-10 & & & & $\mathrm{t} / 3=67.73$ & \\
\hline O-e2-10 & & & & $t / 2=101.60$ & \\
\hline O-e6-15 & \multirow{3}{*}{ Middle } & \multirow{3}{*}{$4-15 \mathrm{M}$} & \multirow{3}{*}{1.3} & $\mathrm{t} / 6=33.87$ & \\
\hline O-e3-15 & & & & $\mathrm{t} / 3=67.73$ & \\
\hline O-e2-15 & & & & $\mathrm{t} / 2=101.60$ & \\
\hline
\end{tabular}

\subsection{Test specimen}

All specimens had a rectangular cross section $304.8 \mathrm{~mm}$ wide by $203.2 \mathrm{~mm}$ thick and $1829 \mathrm{~mm}$ long. All of the walls were reinforced in the longitudinal direction with 4 steel rebars $(10 \mathrm{M}$ or $15 \mathrm{M})$. The amount of reinforcement was chosen based on the typical reinforcement used for walls encased with PVC. Two rebars were placed on the tension side and two rebars were placed on the compression side. In the transverse direction, two $10 \mathrm{M}$ stirrups were used at each end of the wall in the first batch and five $10 \mathrm{M}$ stirrups were used at each end of the wall in the second batch to increase the confinement as explained at the end of the chapter. Also, the specimens were reinforced with 3 rebars $(10 \mathrm{M})$ in the middle section to simulate the transverse reinforcement used in practice. The longitudinal and transverse reinforcement were tied together using spiral ties. The clear concrete cover on both the tension and the compression sides was $40 \mathrm{~mm}$. 
The PVC encased specimens consisted of two main elements; panels and middle connectors as shown in Figure 2.1. The panels were $150 \mathrm{~mm}$ wide and $1.2 \mathrm{~mm}$ thick. The middle connectors were $200 \mathrm{~mm}$ wide and $1.2 \mathrm{~mm}$ thick. Each PVC encased wall consisted of two panels on each face of the wall and five middle connectors. The PVC encased system used here is known commercially as Octaform. Figure 2.1 shows a top view of an assembled PVC encased wall.
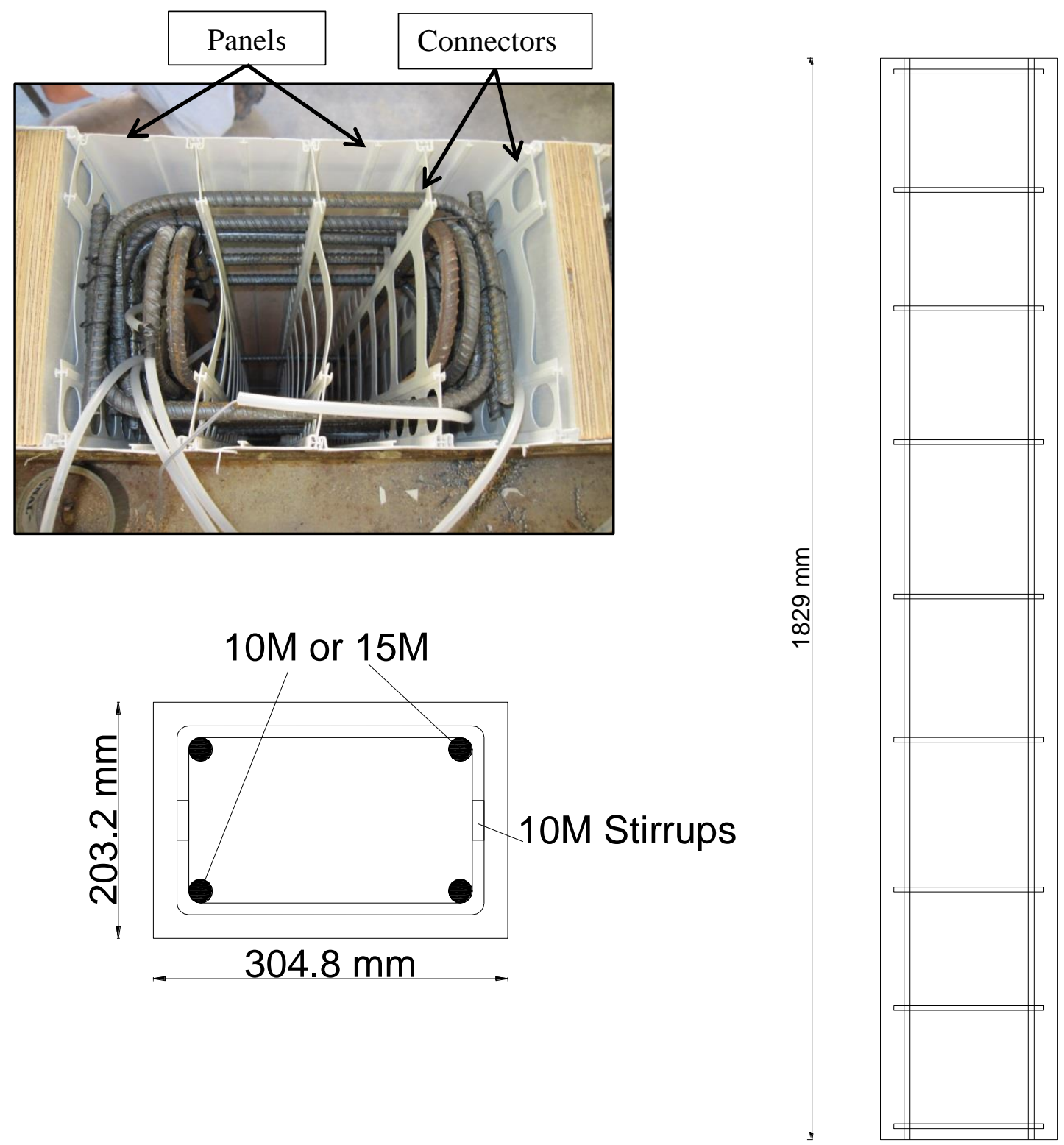

Figure 2.1 - wall specimen cross-section 


\subsection{Specimen fabrication}

\subsubsection{Control walls}

Six control specimens were cast using two wooden boxes. Each box held three specimens. The faces of the boxes were made from a single layer $3 / 4$ inch ply-wood. Double layers of $3 / 4$ inch ply-wood were used as separators between the specimens in one box. The longitudinal reinforcement was fixed to the base of the wooden boxes to avoid any movement during casting. Plastic chairs were used at both ends and at mid-span of the control specimens to ensure that the steel cage remains vertical with a constant concrete cover. Figure 2.2 shows the boxes for the control specimens. Two straight coil loop inserts were used at each end of the wall specimen to facilitate lifting the specimen. The straight coil loop insert was fabricated with one straight loop strut resistance welded to a coil as shown in Figure 2.3.

Bracing of the boxes was critical for the control walls to avoid concrete blowing out during casting. All of the boxes were braced using 2 inch $x 4$ inch lumber spaced at 400 $\mathrm{mm}$ as shown in Figure 2.2. At each level, the longitudinal and the transverse lumber were bolted together using $3 / 4$ inch bolts to avoid any failures at the corner of the formwork. 


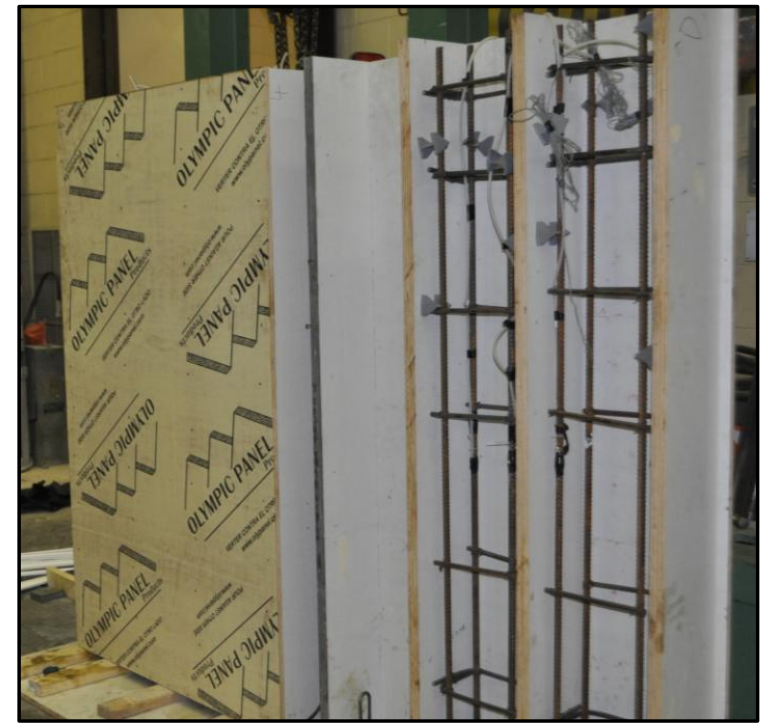

a- Boxes for the control specimens before bracing

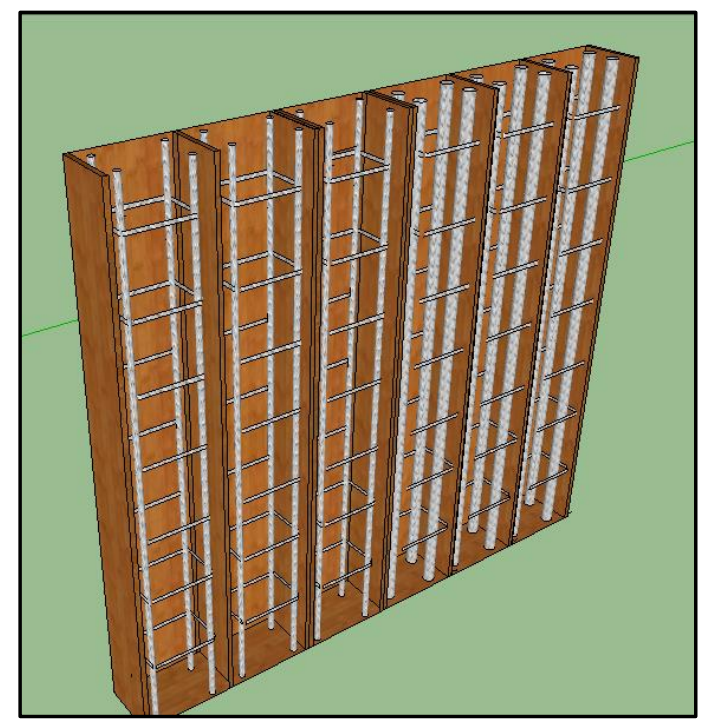

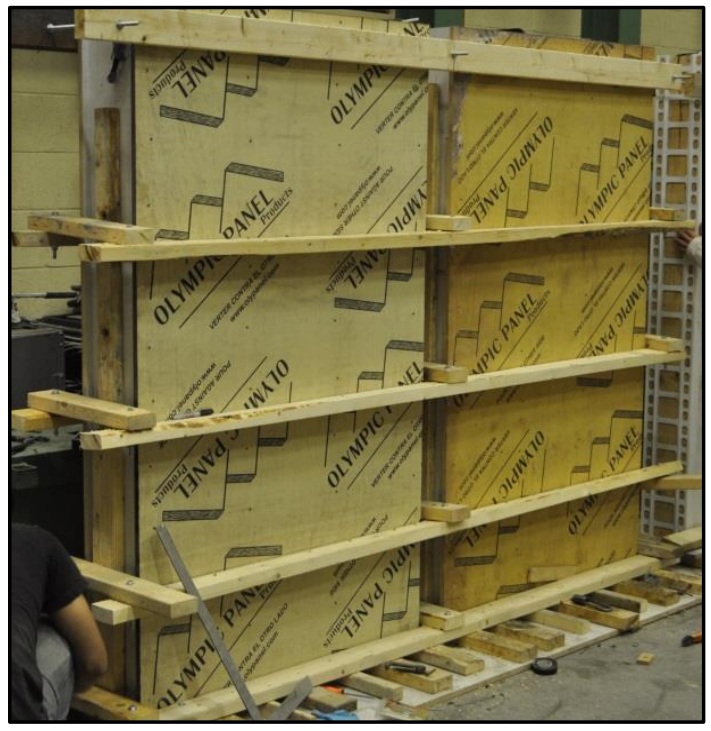

b- Boxes for the control specimens after bracing

c- 3D drawing showing the control boxes with steel cages

Figure 2.2 - Formwork and reinforcement control specimens 


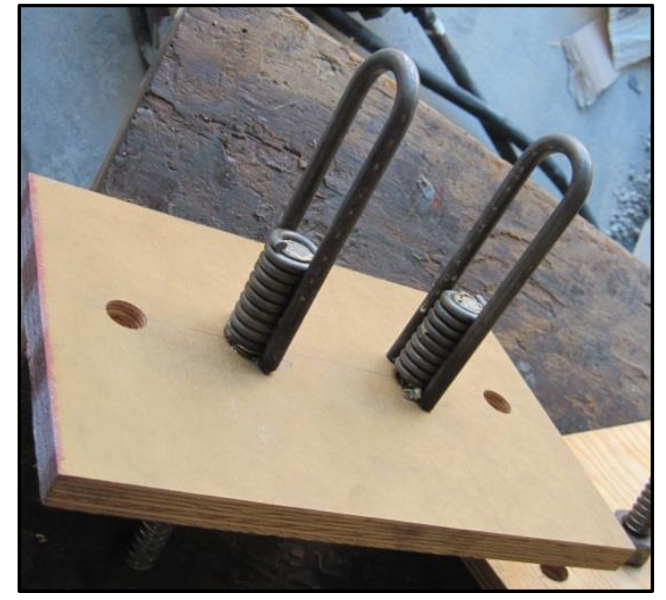

a- Top end plates with straight coil loop inserts

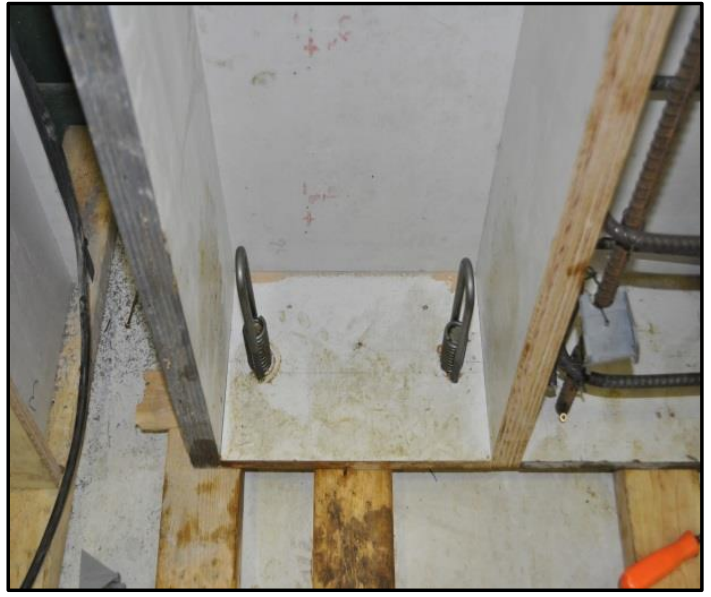

b- Base of the box with straight coil loop inserts

Figure 2.3 - Top and bottom ends of the control specimens

\subsubsection{PVC encased concrete walls}

The PVC encased concrete walls were assembled horizontally by sliding the bottom panels along the middle connectors (Figure 2.4). Then, the longitudinal (10M or $15 \mathrm{M}$ rebars) and the transverse reinforcement (10M rebars) were placed at specified locations and tied together. Plastic chairs were used at both ends and at mid-span of the specimens to guarantee constant concrete cover along the PVC encased wall. The walls were flipped vertically to their final casting position and placed next to one another. Every two walls were separated by a sheet of ply-wood. Finally, the top panels were slid to form the outer surface of the wall. The PVC encased walls were braced by 2 inch $\mathrm{x} 4$ inch lumber at the top and the bottom of the specimens as shown in Figure 2.4. The walls were cast in one row as shown in the figure. 


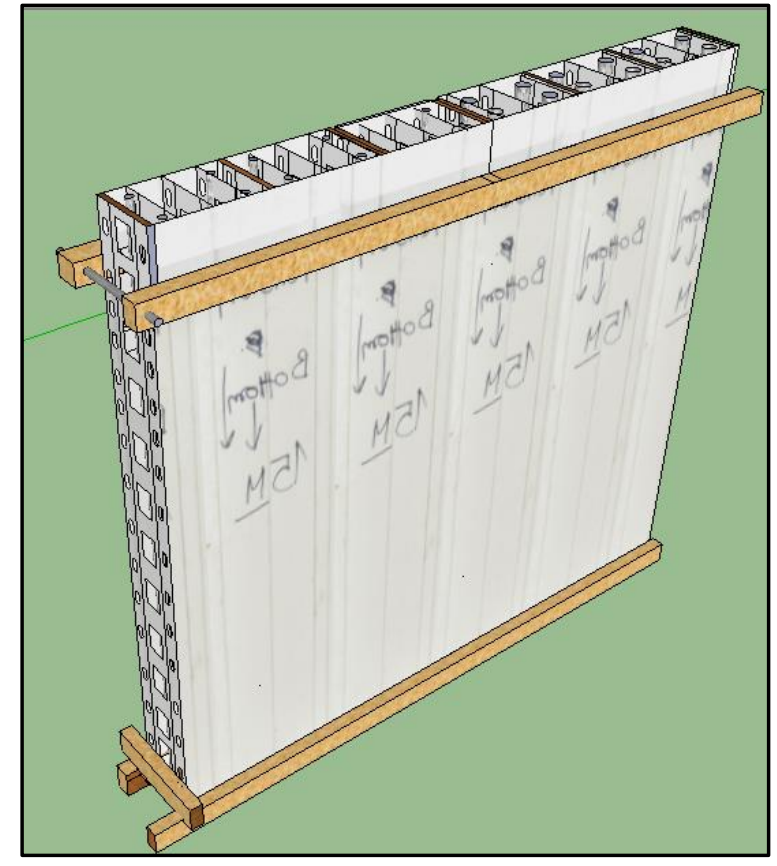

a- 3D for the PVC encased wall specimens

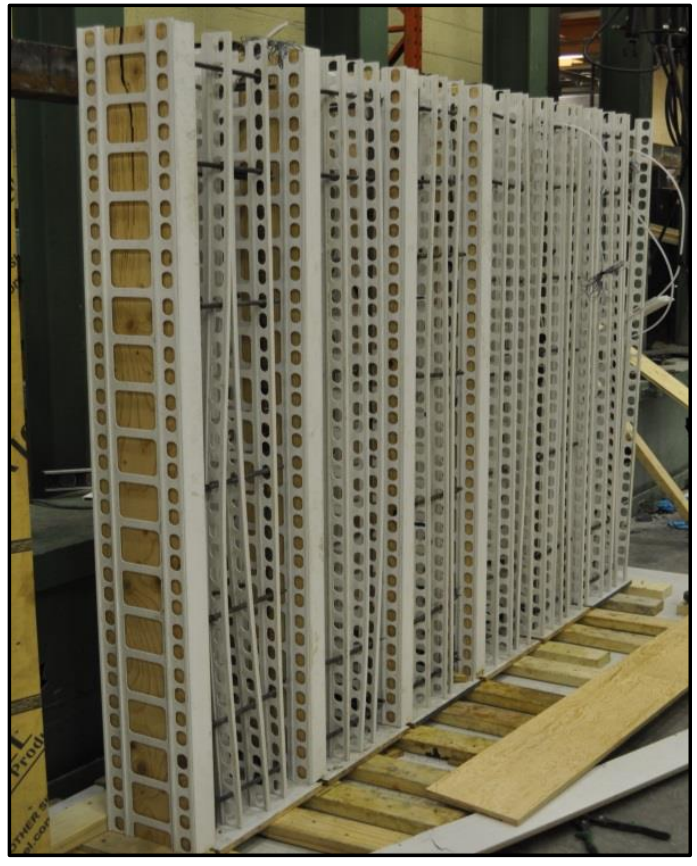

b- Assembling the PVC encased wall specimens

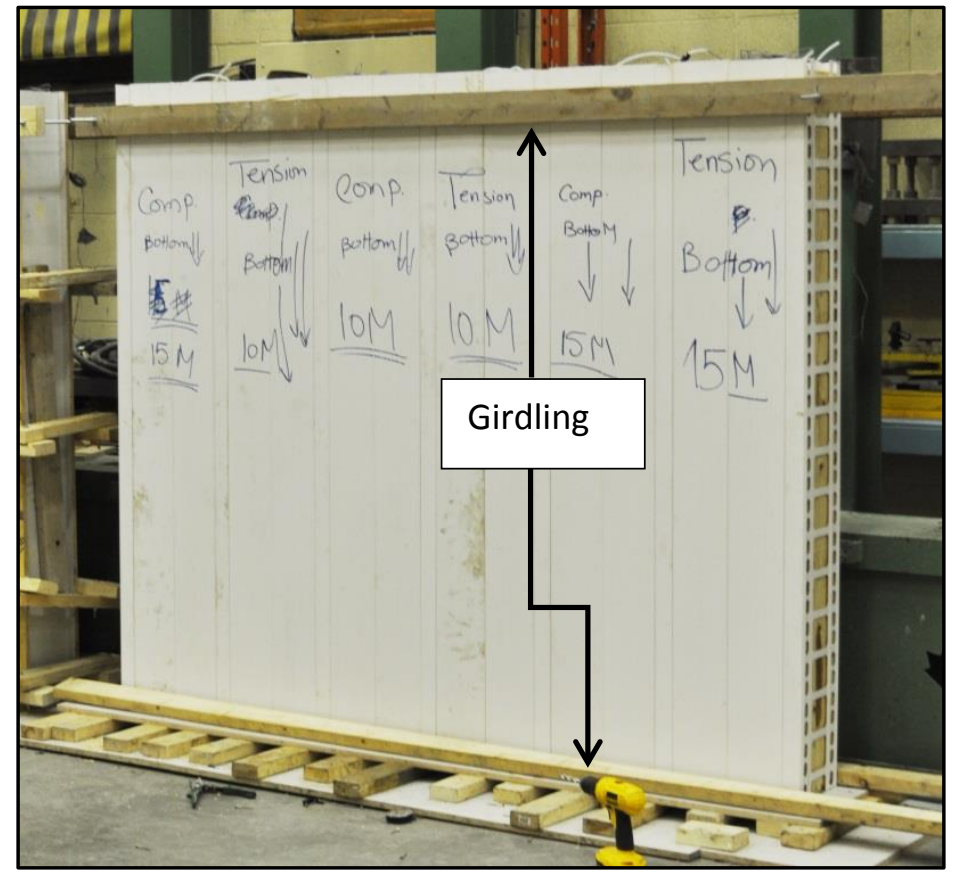

c- PVC encased wall specimens before casting

Figure 2.4 - Formwork for PVC encased wall specimens 


\subsection{Casting the concrete}

The concrete mix was supplied by a local ready mix plant. A conveyor belt was used to convey the concrete horizontally at the wall level as shown in Figure 2.5-a. The concrete was poured in 3 lifts, almost half a metre each using a tremie tube. After each lift, the concrete was vibrated using a three metre long vibrator to guarantee a thorough consolidation as shown in Figure 2.5-b. Thirty five cylinders (100 mm in diameter x 200 $\mathrm{mm}$ long) were cast at the beginning, middle and end of the pour to determine the actual concrete compressive strength (Figure 2.5-c). After filling the walls with concrete, the end plates with two straight coil loop inserts were placed on the top surface of the walls (Figure 2.5-d).

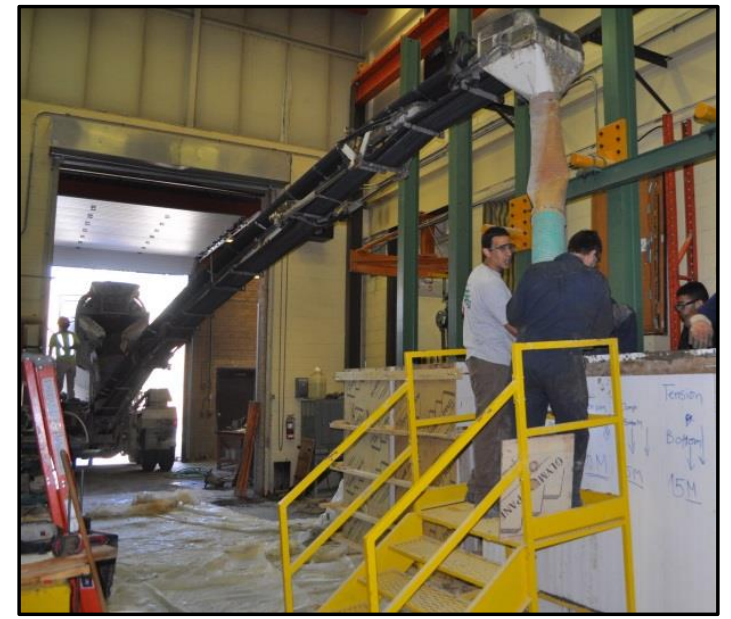

a- Casting the concrete using conveyor belt

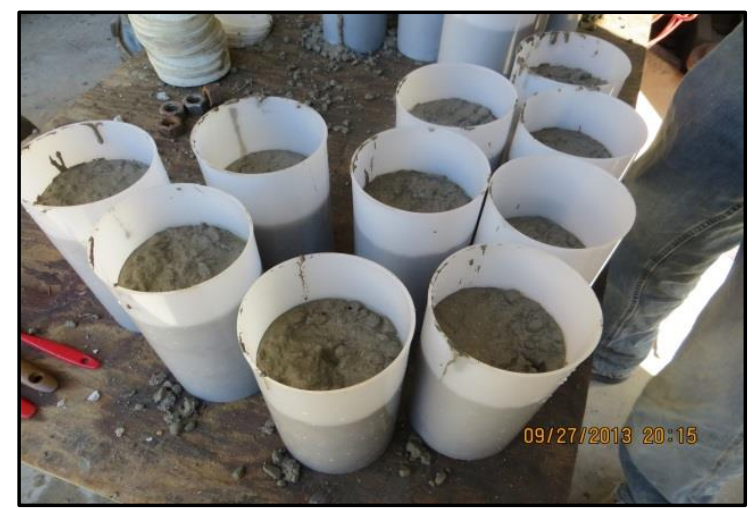

c- Concrete cylinders

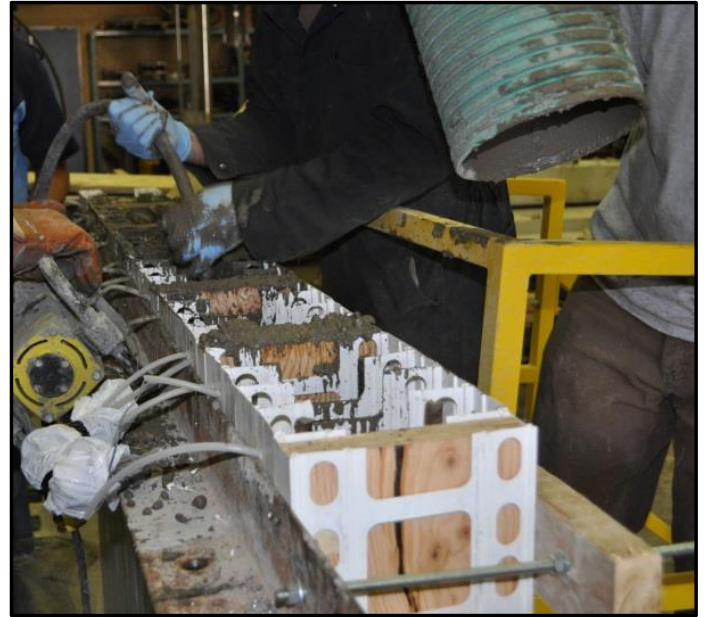

b- Vibrating the concrete

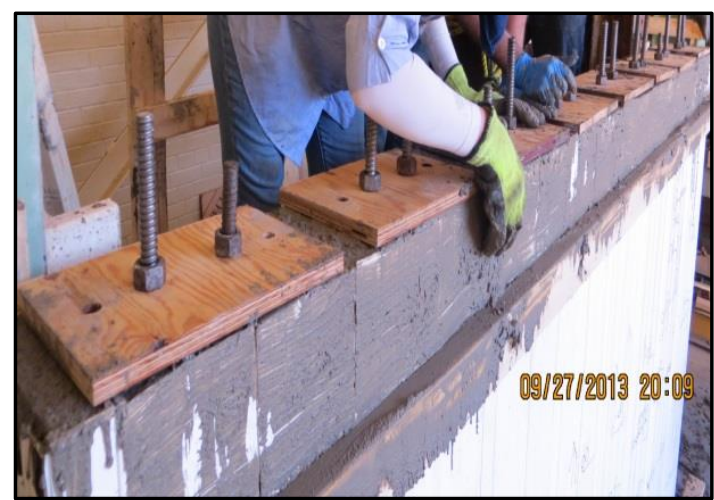

d- Placing the end plates after casting

Figure 2.5 - Concrete casting and vibration 
After forty minutes from the end of the cast, the specimens were covered with wet burlap and plastic sheets in order to control the moisture loss from the concrete. The specimens were cured for 7 days by spraying them with water twice a day and covering them with wet burlap and plastic sheets. After 7 days, six cylinders were tested to ensure attaining an adequate concrete strength prior to stripping off the formwork. The control specimens were stripped off and the PVC encased specimens were separated. Then, all specimens were stored horizontally on top of one another to be tested at 28 days.

\subsection{Material properties}

\subsubsection{Concrete}

The concrete mix had $10 \mathrm{~mm}$ maximum aggregate size. The slump was $170 \mathrm{~mm}$ as shown in Figure 2.6. Compressive strength tests were conducted on the concrete cylinders at 3 days, 7 days, 21 days and 28 days. Six cylinders were tested at each time. Then, the minimum and the maximum compressive strength values were excluded. The average value was based on the average strength of four cylinders. In the first batch, the actual average compressive strength was $37.81 \mathrm{MPa}$. The same mix was used for casting the second batch. Table 2.2 illustrates the actual average compressive strength at 7, 21 and 28 days for both batches.

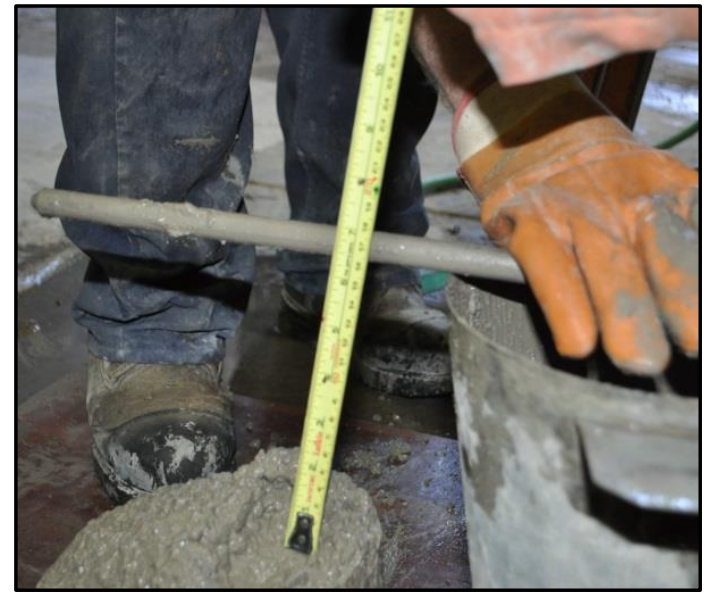

Figure 2.6 - Standard slump test 
Table 2.2 - Average compressive strength at different ages:

\begin{tabular}{|c|c|c|}
\hline \multirow{2}{*}{ Age } & \multicolumn{2}{|c|}{$\mathrm{f}^{\prime} \mathrm{c}(\mathrm{MPa})$} \\
\hline & Batch 1 & Batch 2 \\
\hline 7 days & $25.90 \pm 1.18$ & $23.70 \pm 0.3$ \\
\hline 21 days & $34.1 \pm 1.1$ & -----* \\
\hline 28 days & $37.91 \pm 1.09$ & $39.19 \pm 0.15$ \\
\hline
\end{tabular}

*: Missing data

\subsubsection{Steel}

Steel rebars $10 \mathrm{M}$ and $15 \mathrm{M}$ were used. As provided by the manufacturer, the average yield strength of the $10 \mathrm{M}$ and $15 \mathrm{M}$ rebars was $478 \mathrm{MPa}$ and $490 \mathrm{MPa}$, respectively. The average ultimate strength of the $10 \mathrm{M}$ and $15 \mathrm{M}$ rebars was $702 \mathrm{MPa}$ and $597 \mathrm{MPa}$, respectively.

\subsubsection{Polyvinyl Chloride (PVC)}

The properties of the polyvinyl chloride (PVC) as provided by the manufacturer are given in Table 2.3.

Table 2.3 - Polyvinyl chloride properties

\begin{tabular}{|c|c|}
\hline Property & Value (MPa) \\
\hline Tensile strength & 45.9 \\
\hline Tensile modulus & 2,896 \\
\hline
\end{tabular}

\subsection{Instrumentation and test procedure}

Two strain gauges were mounted on the tension reinforcement at mid-span for all of the concrete walls. In addition, one strain gauge was mounted on the compression reinforcement at mid-span. For the walls cast in the second batch, an additional strain gauge was mounted on the tension steel at a distance equal to $300 \mathrm{~mm}$ from the top end of 
the specimen in order to capture the strains in the steel when failure occurred at the uppermost portion of the wall. The gauges were locally protected, as shown in Figure 2.7, in order to maintain the bond between the steel reinforcement and the concrete.

Before testing the specimens, two $5 \mathrm{~mm}$ long strain gauges were mounted on the PVC panels at mid-span. One gauge was mounted on the compression side and another on the tension side. Also, a cut was made in the PVC panel at mid-span and a $60 \mathrm{~mm}$ long strain gauge was mounted on the concrete compression side of the wall as shown in Figure 2.7. All of the strain gauges were supplied by Tokyo Sokki Kenkyujo Co., Ltd.

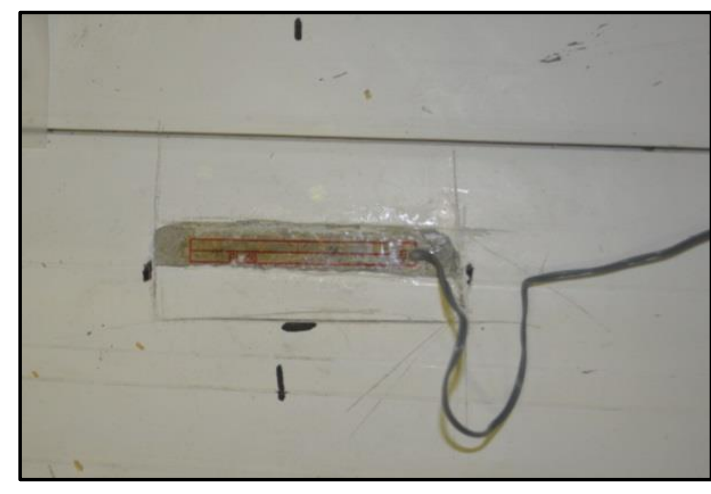

a- Strain gauge mounted on the concrete

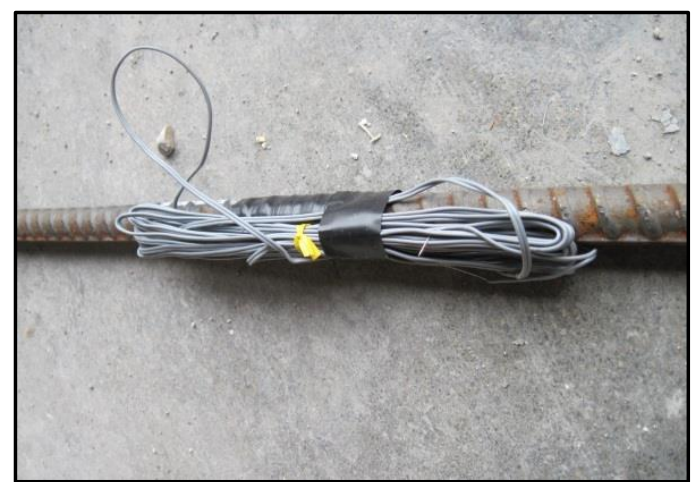

b- Strain gauge mounted on the steel

Figure 2.7 - Strain gauges

To apply the load eccentrically on the wall, a system was created at each end of the wall consisting of a steel plate (Figure 2.8-a) and a swivel (Figure 2.8-b). The steel plate was $38 \mathrm{~mm}$ thick by $400 \mathrm{~mm}$ wide by $600 \mathrm{~mm}$ long as shown in Figure 2.8 -a. The plates had six threaded holes to accommodate different eccentricities of the applied load. The plate was placed on the specimen where the dotted line represented the specimen (Figure 2.8a). Hydrostone was used as a filler material between the plate and the specimen to ensure that the ends were perfectly flat and leveled. Then, threaded rods (19 $\mathrm{mm}$ in diameter) were used to anchor the plates to the specimens. Once the plates were fixed to the 
specimens, the forklift was used to place the specimen inside the testing frame as shown in Figure 2.9.

Prior to placing the specimen inside the frame, the swivel system (pin supports) was connected to the movable crosshead and the fixed platen. Once the specimen was inside the frame, the swivel was bolted to the end plates to apply the load at the desired eccentricity. In Figure 2.8, the holes used to bolt the swivel to the end plate and apply a given eccentricity are given the same notation. For instance; e33 represents the two holes used when applying an eccentricity of $33 \mathrm{~mm}$.

The specimens were tested in a displacement-controlled mode using a servo- hydraulic actuator controlled by a MTS 311 controller. The capacity of the frame was $1500 \mathrm{kN}$. The MTS load frame consisted of four vertical columns that connected a movable crosshead and a fixed platen as shown in Figure 2.10-a. The load was measured using a load cell attached to the movable crosshead. The displacement was recorded using the internal LVDT. In addition, two string-pots were used to measure the specimen's lateral displacement and the specimen's vertical displacement. To measure the lateral displacement, the string pot was attached to the compression side of the specimen at midspan, Figure 2.10-b. The data was recorded using a data acquisition system. The specimens were loaded monotonically at a rate of $0.5 \mathrm{~mm}$ per minute until failure occurred. 

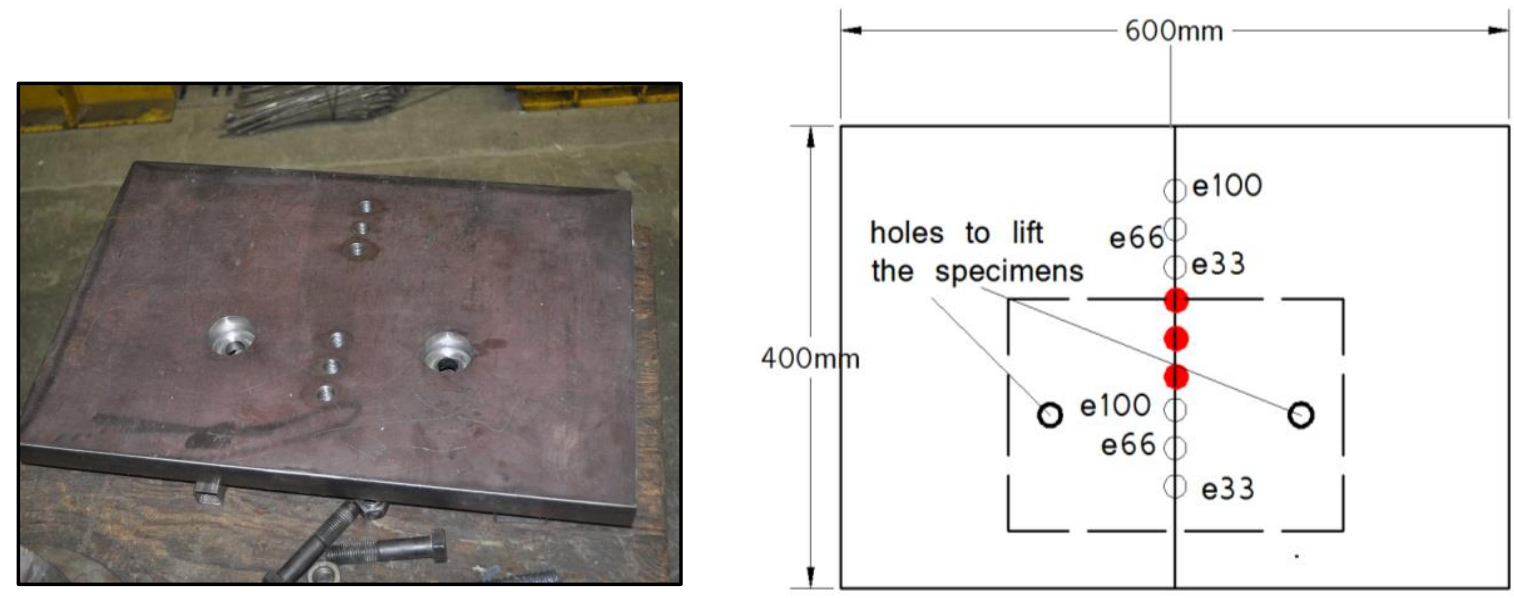

a- End plates
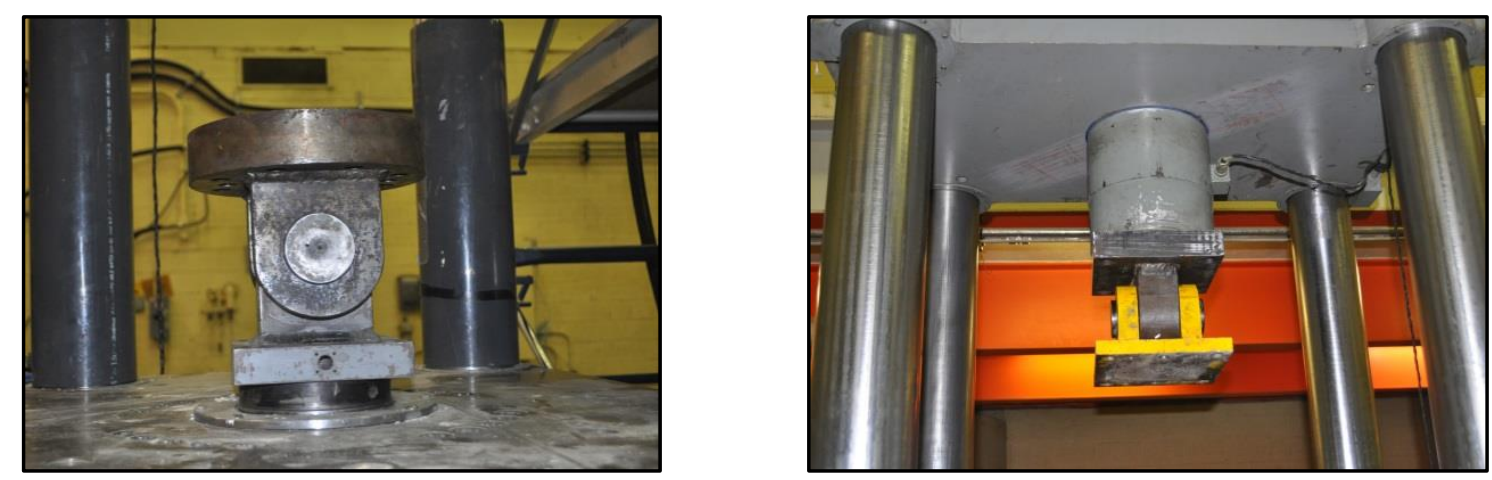

b- Swivel system

Figure 2.8 - End plates and swivel system 


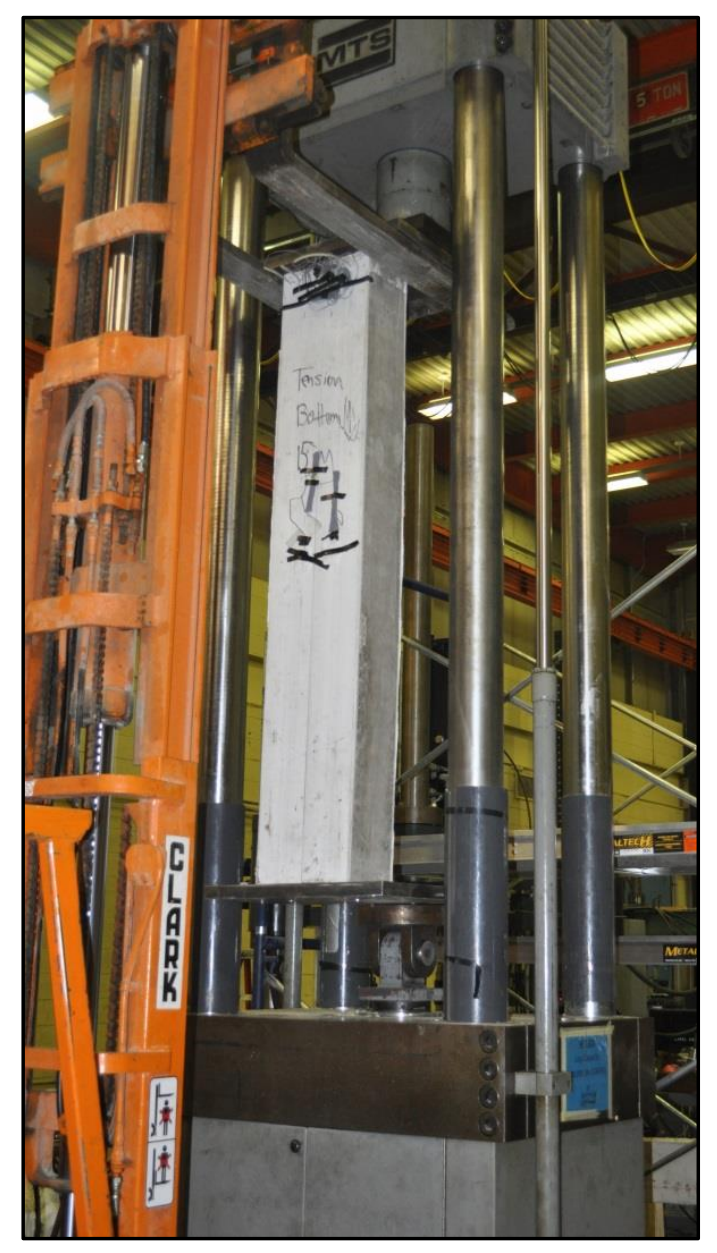

Figure 2.9 - Forklift placing the specimen inside the frame 


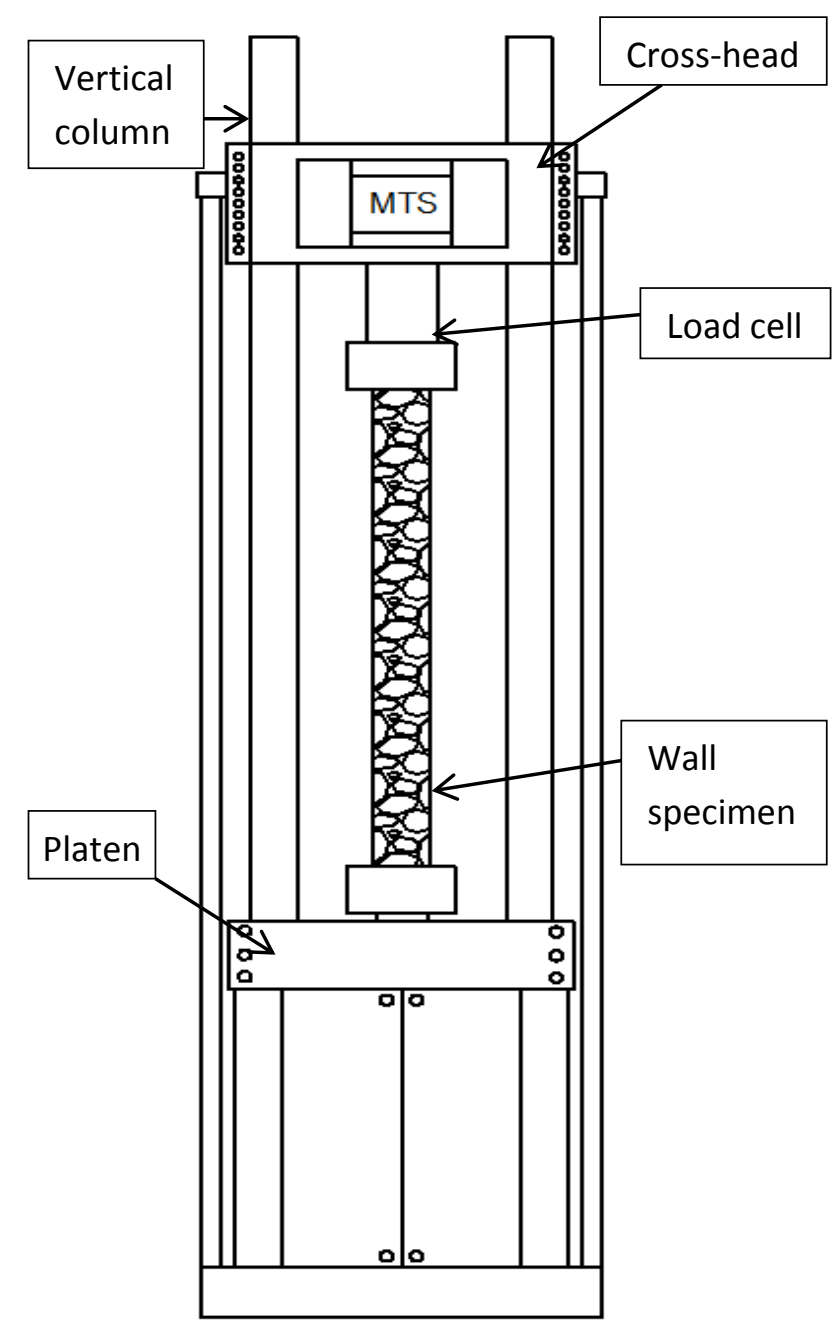

a- Schematic for the MTS load frame

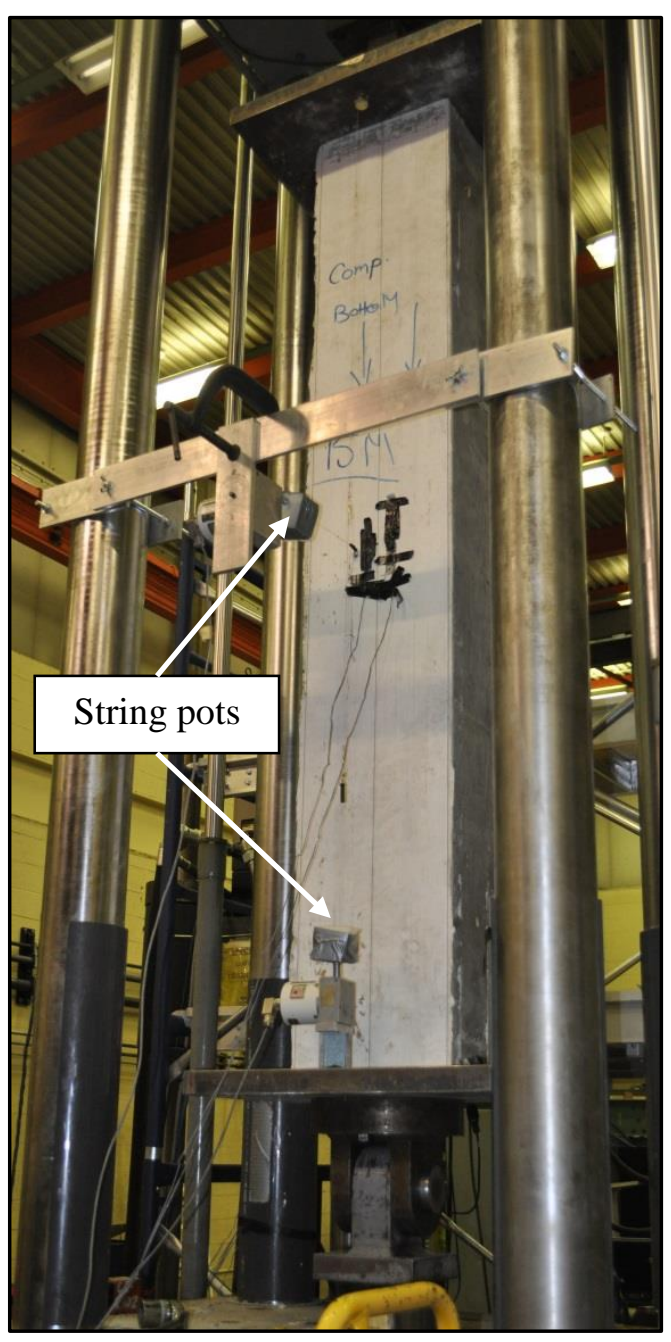

b- Specimen before testing

Figure 2.10 - MTS test frame set-up

\subsection{End confinement system}

When the concrete columns were subjected to an axial compression loading, they tended to expand in the direction perpendicular to the load application direction owing to Poisson's effect; the applied compressive stresses produced lateral tensile stresses (horizontal direction). When the tensile stresses exceeded the tensile strength of the concrete, bursting cracks occurred, unless appropriate transverse reinforcement and confinement were provided. Thus, the ends of the specimens were subjected to two main types of stresses; compressive stresses and tensile bursting stresses. The high compressive 
stresses were directly below the loading point followed by tensile bursting stresses. This behaviour was manifested in the mode of failure of the two specimens O-e3-15 and C-e615 (Figure 2.11). Failure occurred at the ends where the compressive stresses created transverse tensile stresses causing premature failure by splitting of the concrete. A detailed analysis was carried out for the stresses in the end zones as presented below. Extra confinement was used for the remaining specimens as presented at the end of this section.

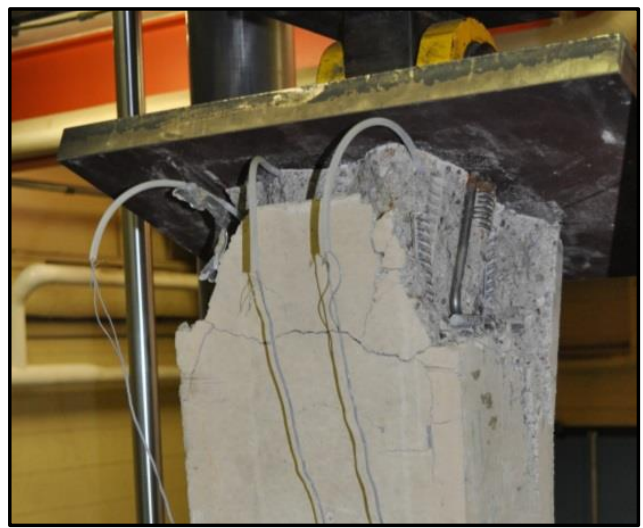

a- Unconfined C-e6-15 specimen

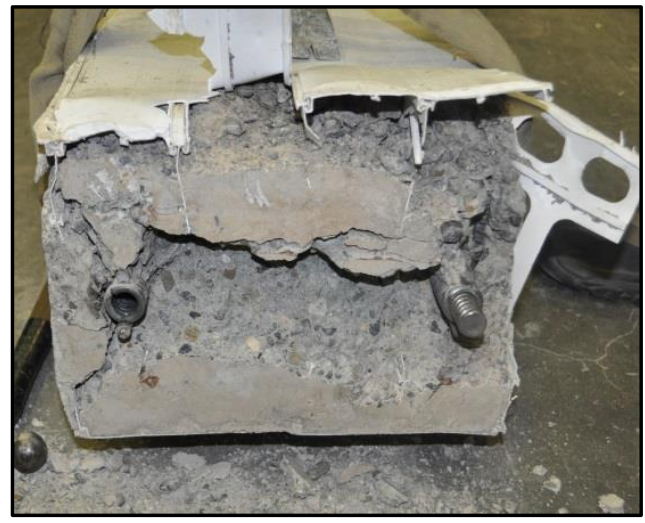

b- Unconfined O-e3-15 specimen

Figure 2.11 - End failure for unconfined specimens

Richart et al. (1928) reported that the strength, ductility and capacity of the column could be significantly enhanced in presence of a tri-axial state of compression. This could be achieved by applying a proper confinement for the concrete to counteract the expansion. There were two types of confinement; internal and external. The internal confinement was attained by providing transverse reinforcement in the form of stirrups. The external confinement was attained via a collar consisting of four steel plates. 


\subsubsection{Internal confinement}

The confining reinforcement in the region close to the end bearing plates had to be chosen to prevent bursting and splitting produced by the high concentrated compressive forces. In addition, the bearing stresses on the concrete at the loading point had to be less than the allowable compressive bearing capacity of the concrete. To improve the resistance of the specimens to each of these stresses, the bearing stresses were checked and a proper local confinement of the specimens was provided.

\section{a- Bursting stresses}

The tensile stresses occurred over a relatively short length of the member. This length was estimated to be equal to the depth of the cross-section $(203.2 \mathrm{~mm})$ in the direction considered. The location of the concrete bursting stresses and the resulting bursting cracks depended mainly on the location and the distribution of the concentrated compressive force applied to the end bearing plates. Since the member had a rectangular cross-section with no discontinuities along the span, a simplified equation was used to compute the magnitude of the bursting force $\left(T_{\text {burst }}\right.$ ), as shown in Equation 2.1 (Nawy 2006).

Eq. 2.1

$$
T_{\text {burst }}=0.25 \sum P_{s u}\left(1-\frac{a}{h}\right)
$$

Where;

$T_{\text {burst }}$ : Bursting force, $\mathrm{kN}$

$P_{s u}:$ Maximum axial load to be applied on the specimen, $\mathrm{kN}$

$a:$ Roller width in the direction considered, $\mathrm{mm}$

$h$ : Depth of the cross-section in the direction considered, $\mathrm{mm}$ 
Proper local confinement of the concrete was required to resist the bursting force and increase the compressive load that could be applied at the ends before failure was attained. Spiral stirrups provided the highest confinement in those areas. However, since the PVC encased specimens had middle connectors, it was impossible to use spiral stirrups. Rectangular stirrups were provided instead. For the walls cast in the second batch, five closed (M10) U-shaped stirrups were provided over a $200 \mathrm{~mm}$ distance, measured from the end of the specimen. Detailed calculations are provided in Section 2.8.3.

\section{b- Bearing stresses}

The maximum allowable bearing stresses at the ends of the specimen should not exceed the smaller of the two values given by Equation 2.2 and Equation 2.3 (Nawy 2006).

$$
\begin{array}{rr}
\text { Eq. } 2.2 & f_{b} \leq 0.7 f^{\prime}{ }_{c} \sqrt{A / A_{g}} \\
\text { Eq. } 2.3 & f_{b} \leq 2.25 f^{\prime}{ }_{c}
\end{array}
$$

Where;

$f_{b}:$ the bearing stress, $\mathrm{MPa}$

$A_{g}:$ the gross area of the bearing surface, $\mathrm{mm}^{2}$

$A:$ the maximum area of portion of the supporting surface that is geometrically similar to the loaded area and concentric with it, with the upper base being the loaded surface area of the concrete and sloping sideway with a slope of 1 vertical to 2 horizontal, $\mathrm{mm}^{2}$

\subsubsection{External confinement}

To avoid end failures completely, additional external confinement was provided at each end using four steel plates $(25 \mathrm{~mm}$ thick $\times 200 \mathrm{~mm}$ wide) bolted together with high strength bolts (19 mm diameter) to form a collar (Figure 2.12). First, epoxy (Sikadur 31) 
was applied as a filler material on the surfaces of the specimen. Then, the collar was placed and the bolts were tightened with an air gun. The bolts were tightened until the epoxy started flowing outside the collar to ensure that the collar was in full contact with the specimens.

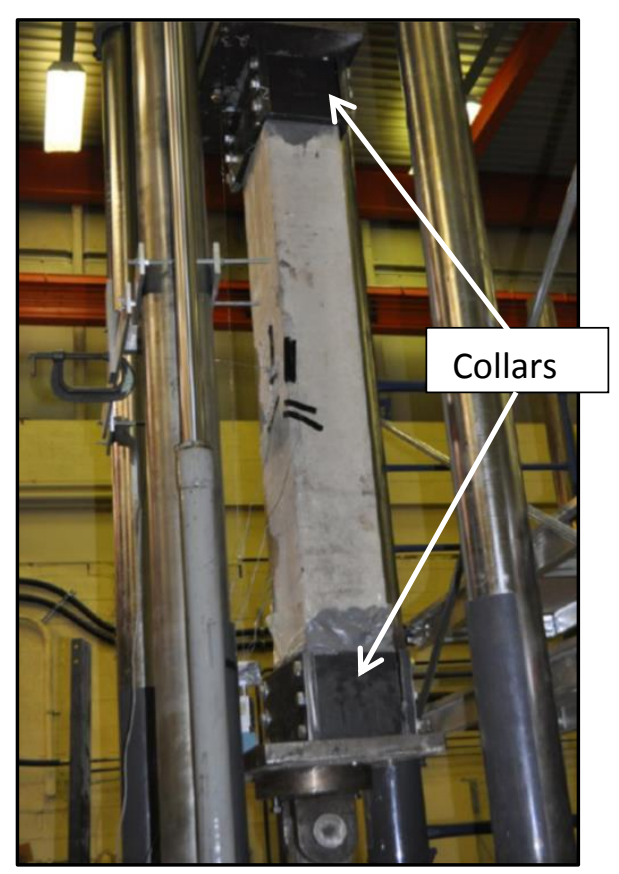

Figure 2.12 - Specimen with external confinement (collars) 


\subsubsection{Calculations for the internal reinforcement using the Approximate Method}

\section{a- Bursting stresses}

Using Equation 2.1, the bursting force could be computed. The depth of the cross section (h) was equal to $203.2 \mathrm{~mm}$. The width of the roller was known and equal to 76.2 $\mathrm{mm}$. The maximum applied load was taken equal to the maximum frame capacity 1500 $\mathrm{kN}$. Thus, the bursting force was equal to $234.38 \mathrm{kN}$.

$$
\begin{gathered}
T_{\text {burst }}=0.25 \sum P_{s u}\left(1-\frac{a}{h}\right) \\
a=76.2 \mathrm{~mm} \\
h=203.2 \mathrm{~mm} \\
P_{\text {su }}=1500 \mathrm{kN} \\
T_{\text {burst }}=234.38 \mathrm{kN}
\end{gathered}
$$

Using a maximum steel stress equal to the yield stress, the area of stirrups required to resist the bursting force was computed.

$$
\begin{gathered}
\qquad f_{y}=474 \mathrm{MPa} \\
\qquad A_{t}=\frac{234380}{474}=494.47 \mathrm{~mm}^{2} \\
\text { For 10M stirrups, } A_{s}=2 \times 100=200 \mathrm{~mm}^{2} \\
\text { Required number of stirrups }=\frac{494.47}{200}=3 \text { stirrups, }
\end{gathered}
$$

Hence, five stirrups were used; four inside the collar over a length equal to $203.2 \mathrm{~mm}$ (h) and one just underneath the collar. 
Assuming that the load was distributed with a slope of 2 vertical to 1 horizontal (Figure $2.13)$, then at a distance of $101.6 \mathrm{~mm}(0.5 \mathrm{~h})$, the dimensions of the concrete zone that required confinement was:

In plane:

$$
\begin{aligned}
& d=X_{1}+X_{2}+a \\
& d=50.8+50.8+76.2=177.8 \mathrm{~mm}
\end{aligned}
$$

Therefore, the width was take equal to $160 \mathrm{~mm}$ for constructability

Out of plane:

$$
d=X_{1}+X_{2}+a
$$

$d=76.2+76.2+200=352.4 \mathrm{~mm}>300 \mathrm{~mm}$ - the maximum allowable width

Therefore, the width was take equal to $260 \mathrm{~mm}$

A typical U shaped stirrup is shown in Figure 2.14.

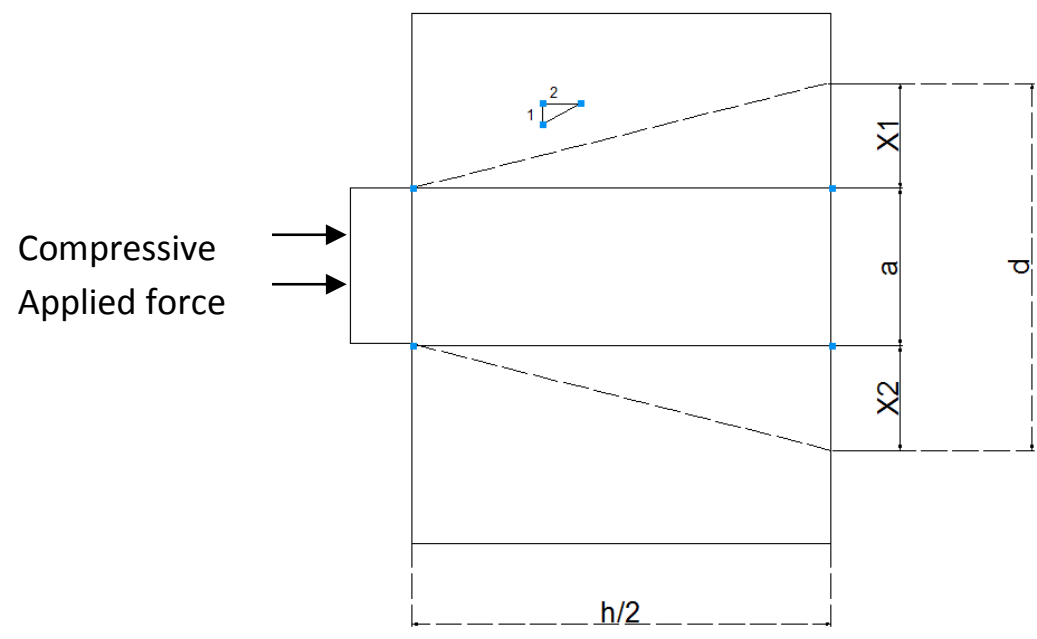

Figure 2.13 - Load distribution 


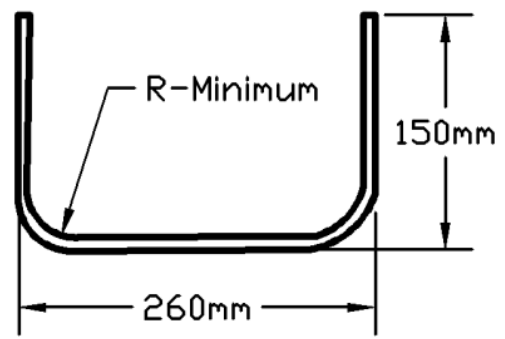

Figure 2.14 - Typical U-shape stirrup

\section{b- Bearing stresses}

Actual bearing stress $=\frac{\text { capacity of the frame }}{\text { Area of end plate }}=\frac{1500000}{200 * 300}=25 \mathrm{MPa}$

$$
f_{b} \leq 0.7 f^{\prime}{ }_{c} \sqrt{A / A_{g}}
$$

To be more conservative, assume $\sqrt{A / A_{g}}=1$

$$
\begin{gathered}
{f^{\prime}}^{\prime}=40 \mathrm{MPa} \text { (at testing day) } \\
f_{b}=0.7 \times 40 \times 1=28 \mathrm{MPa} \\
f_{b} \leq 2.25{f^{\prime}}^{\prime} \\
f=2.25 \times 40=90 \mathrm{MPa}
\end{gathered}
$$

Therefore, it is safe.

\subsubsection{Confinement effect}

Figure 2.15 shows the failure for two identical PVC encased walls reinforced with 4-15 $\mathrm{M}$ and subjected to an eccentricity of $67.73 \mathrm{~mm}$. It is worth mentioning that both walls were from the same batch (first batch). One wall was tested without the external confinement (collar) and the other was tested with the collar. Both walls failed by crushing of concrete followed by buckling of the PVC. However, the failed section 
shifted from the bottom end of the specimen to a distance of $500 \mathrm{~mm}$ from the end of the specimen for the unconfined and confined specimens, respectively.

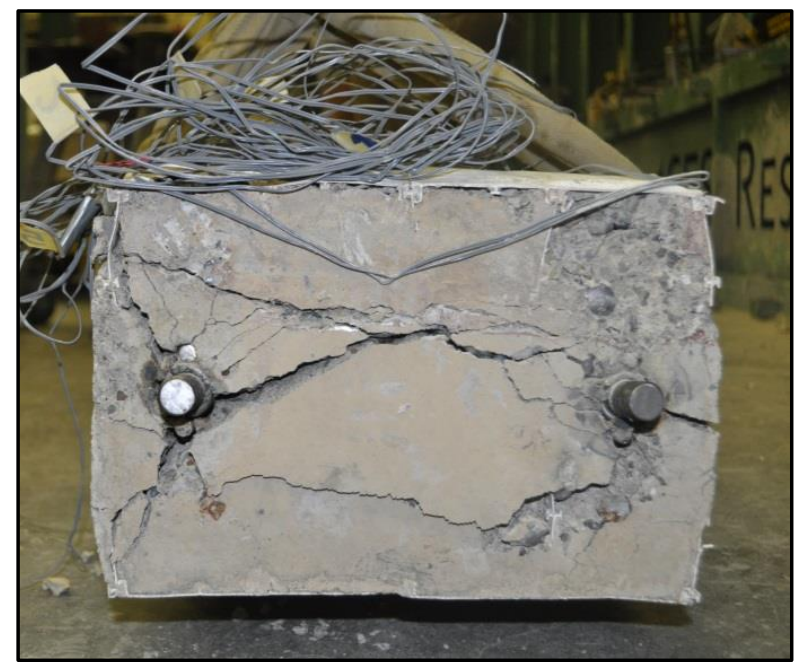

End of the specimen after failure

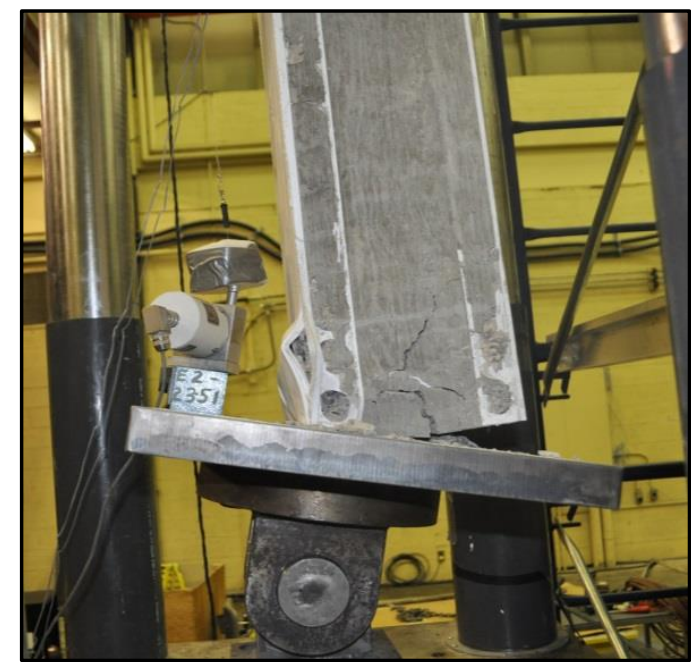

Specimen during testing (at failure) a- Unconfined specimen

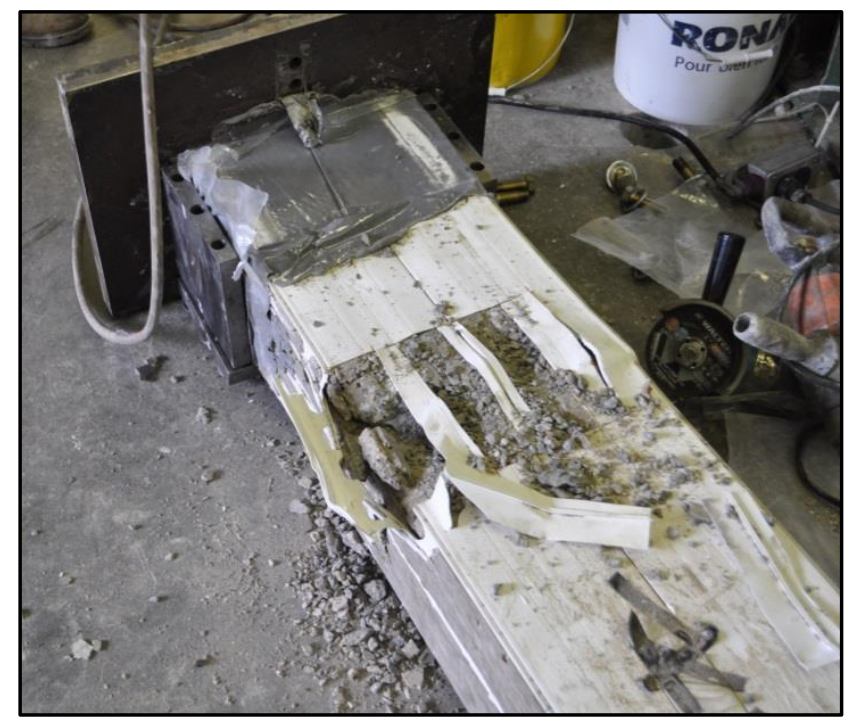

b- Confined specimen after failure

Figure 2.15 - Failure modes of a) Unconfined and b) Confined O-e3-15 specimens

Figure 2.16 shows the load versus deflection for the two specimens O-e3-15; unconfined and confined. For the same eccentricity $(67.73 \mathrm{~mm})$, the confined wall specimen showed a peak load of $984 \mathrm{kN}$ as opposed to $624.6 \mathrm{kN}$ for the unconfined wall specimen. That 
was equivalent to a $57.54 \%$ increase in the ultimate capacity. The substantial increase in the ultimate capacity demonstrated the significant contribution of the confining system to prevent premature failure of the specimens and attain the full capacity of the wall. In addition, at the peak load, the confined wall showed an increase of $139 \%$ and $49 \%$ in the horizontal mid-span deflection and the vertical displacement, respectively over the unconfined specimen. 


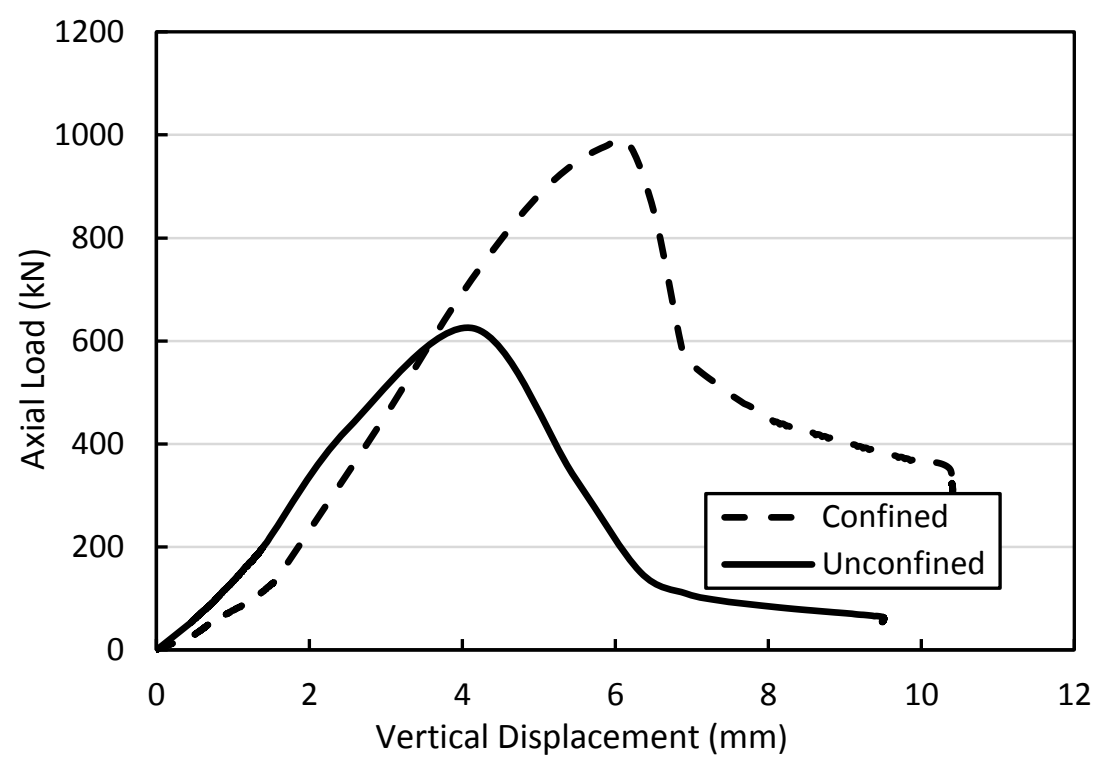

a- Vertical displacement

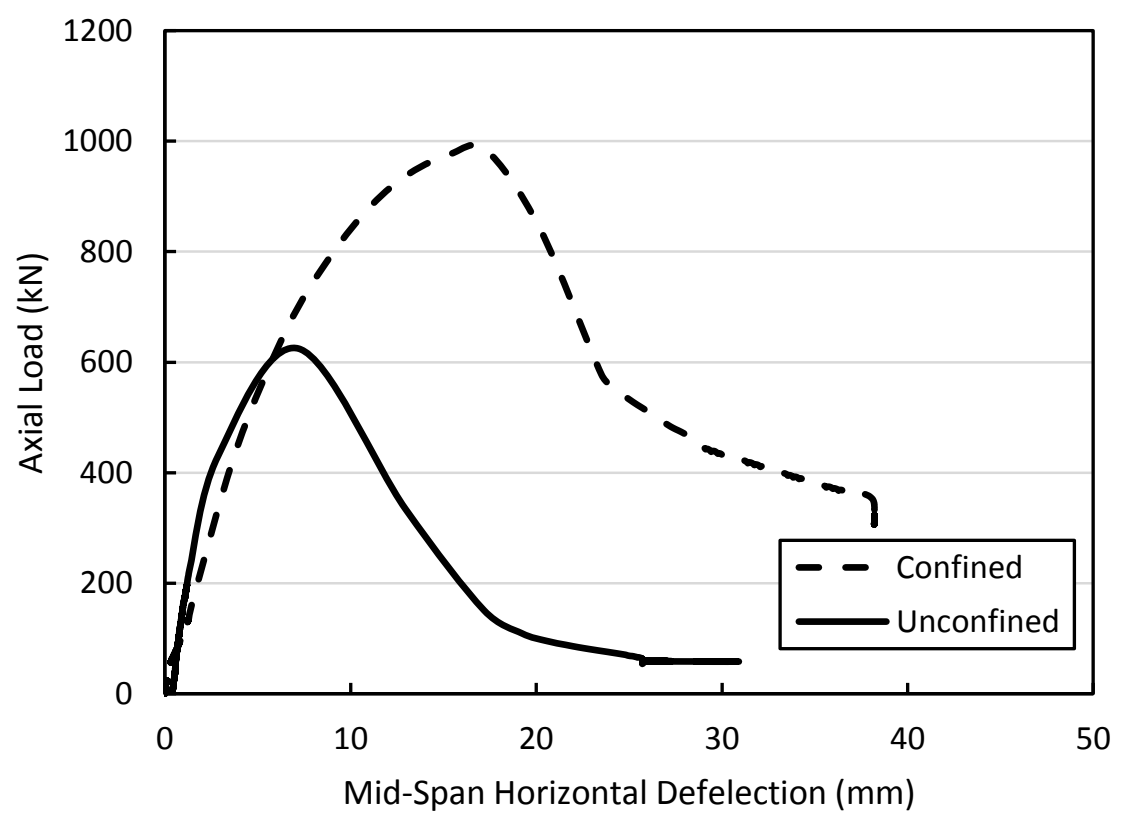

b- Mid-span displacement

Figure 2.16 - Load versus displacement for unconfined and confined O-e3-15 specimens 


\section{Chapter 3: Experimental test results}

\subsection{Introduction}

This chapter presents the experimental results for the control wall specimens and the PVC encased walls. The results presented in this chapter are based on the observations and the data collected during the tests. The discussion focuses on the mode of failure, loaddeflection and load-strain behaviour for the different components. Also, the effect of reinforcement ratio, PVC encasement and different applied eccentricities are discussed.

\subsection{Experimental test results}

\subsubsection{General behaviour}

As the specimens were loaded there were three distinct phases. At the beginning, the load increased at a slow rate without any signs of cracking until reaching about $130 \mathrm{kN}$. This phase lasted for 7 minutes approximately. Then, it was noticed that the load increased at a higher rate until reaching the peak load within 1 to 2 minutes. During the testing, close from reaching the peak load, stretch marks appeared on the tension side of the PVC panels near the mid-height or the top section of the encased wall depending on the failure location. At the peak load, crushing of the concrete was heard. For the PVC encased walls, crushing of concrete was accompanied with popping sounds of the PVC encasement followed by buckling of the PVC panels. The failure of the walls was marked clearly by one or more of the following; crushing of concrete or buckling of the PVC. Past the peak load, the load dropped abruptly and the cracks grew deeper and wider. The test continued after the load dropped to assess the effect of the PVC on the post peak response. 


\subsubsection{PVC encased walls versus control walls}

All of the control and the PVC encased walls with the same reinforcement and tested at the same eccentricity showed similar behaviour. Figures 3.1 to 3.6 show typical test results for a control and a PVC encased wall specimen. Both specimens were reinforced with $4-10 \mathrm{M}$ and subjected to an axial load applied at an eccentricity of $67.73 \mathrm{~mm}$. Figures 3.1 and 3.2 show the typical load versus the vertical and the horizontal mid-span deflection, respectively, for the control and the PVC encased walls. Similarly, Figures 3.3, 3.4 and 3.5 show the typical load versus the strain in the tension steel, concrete and the compression steel reinforcement, respectively, for both walls. Figure 3.6 shows the typical tensile and compressive strains in the PVC panels at the mid-span of a PVC encased wall specimen and compares them to the strain readings in the tension steel reinforcement and the concrete.

\subsubsection{Load-deflection behaviour}

In Figures 3.1 and 3.2, the vertical axis represents the load $(\mathrm{kN})$ and the horizontal axis represents the deflection (mm). All specimens showed the same load versus deflection behaviour. The load increased with deflection until failure where the load dropped abruptly and the deflection increased. It is clear from Figures 3.1 and 3.2 that the PVC encased specimen was stiffer than the control specimens, where the slope of the load versus deflection increased compared to the control specimen. 


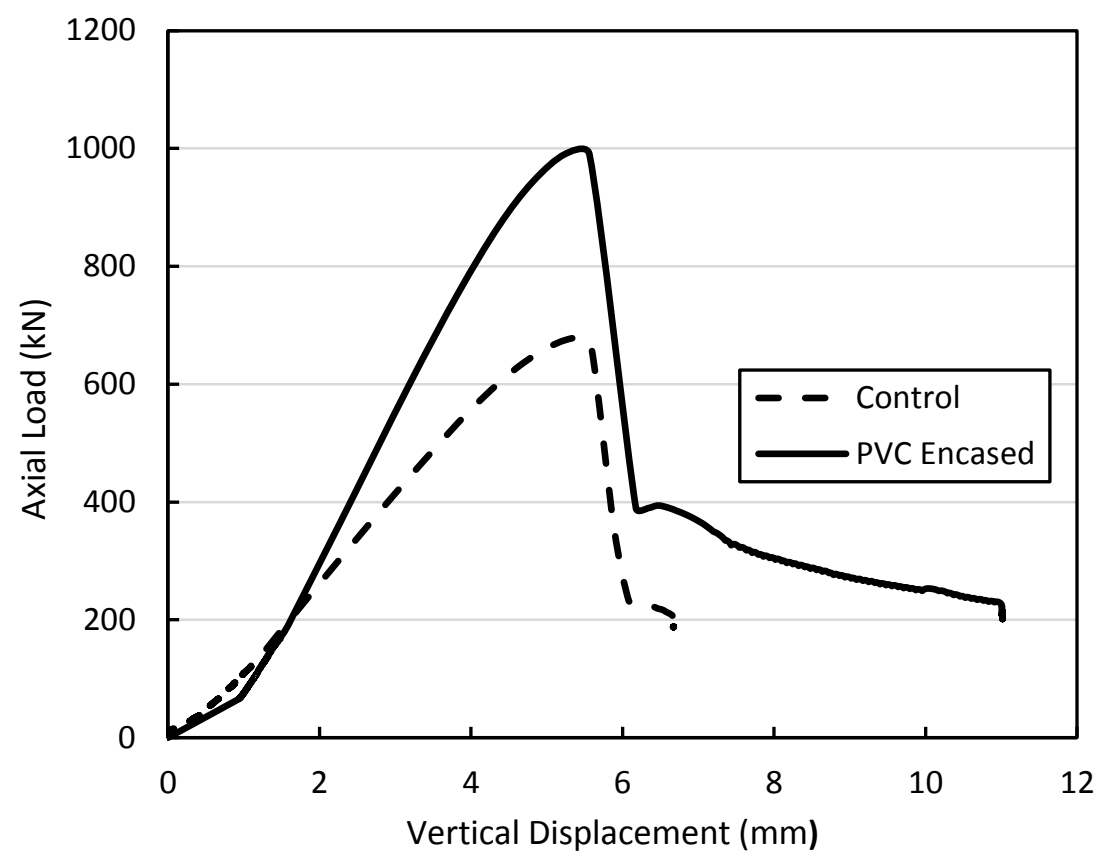

Figure 3.1 - Load versus vertical displacement for O-e3-10 and C-e3-10 wall specimens

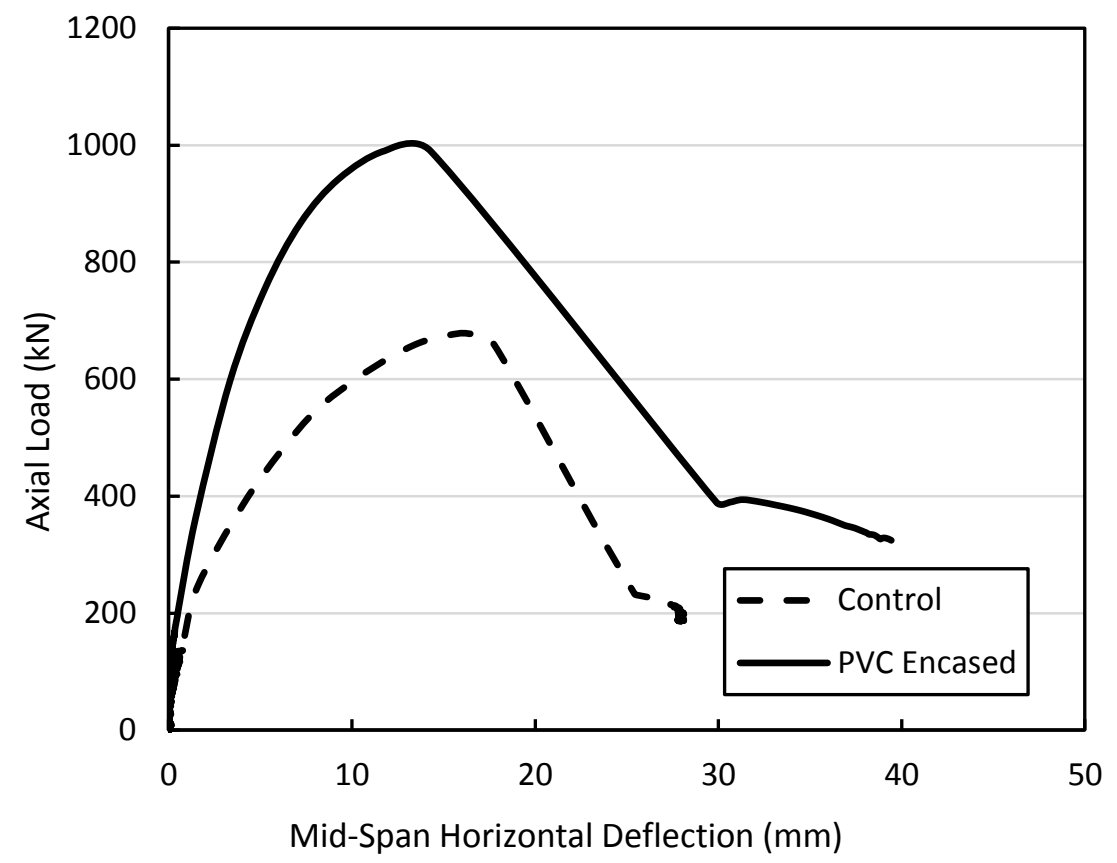

Figure 3.2 - Load versus mid-span deflection for O-e3-10 and C-e3-10 wall specimens 


\subsubsection{Load-strain behaviour}

For both the control and the PVC encased specimens, the behaviour of the load versus strain of steel, concrete and PVC was characterized by an ascending curve until failure where the load dropped with an increase in measured strain, resulting in the descending part of the curve (Figures 3.3, 3.4 and 3.5). It is clear that at any given load value, the strain gauge readings for the control specimen were higher than the PVC encased wall, but the PVC encased wall failed at a higher peak load. Therefore, the PVC encased wall can resist the applied load with decreased strain readings compared to the control walls.

Strain gauge readings for both the tension steel and the PVC panels were compatible until reaching the peak load, where the strains in the steel showed lower values compared to the PVC panels. Past the peak load, the strain gauge readings for both the PVC panel and the tension steel reinforcement increased. However, the PVC panel showed more ductile behaviour, demonstrated by the longer descending branch of the curve, compared to the steel where a sharp drop was observed as shown in Figure 3.6.

Similar to the tensile strain readings, the compressive strain readings for both the concrete and the PVC panel were compatible until reaching a load of $596 \mathrm{kN}$. Past that load until reaching the peak load, the PVC strain was slightly higher than the concrete strain. Past the peak load, the concrete strain dropped as the concrete crushed and the forces were transmitted to the PVC panel. The PVC strain readings continued to increase as shown in Figure 3.6. 


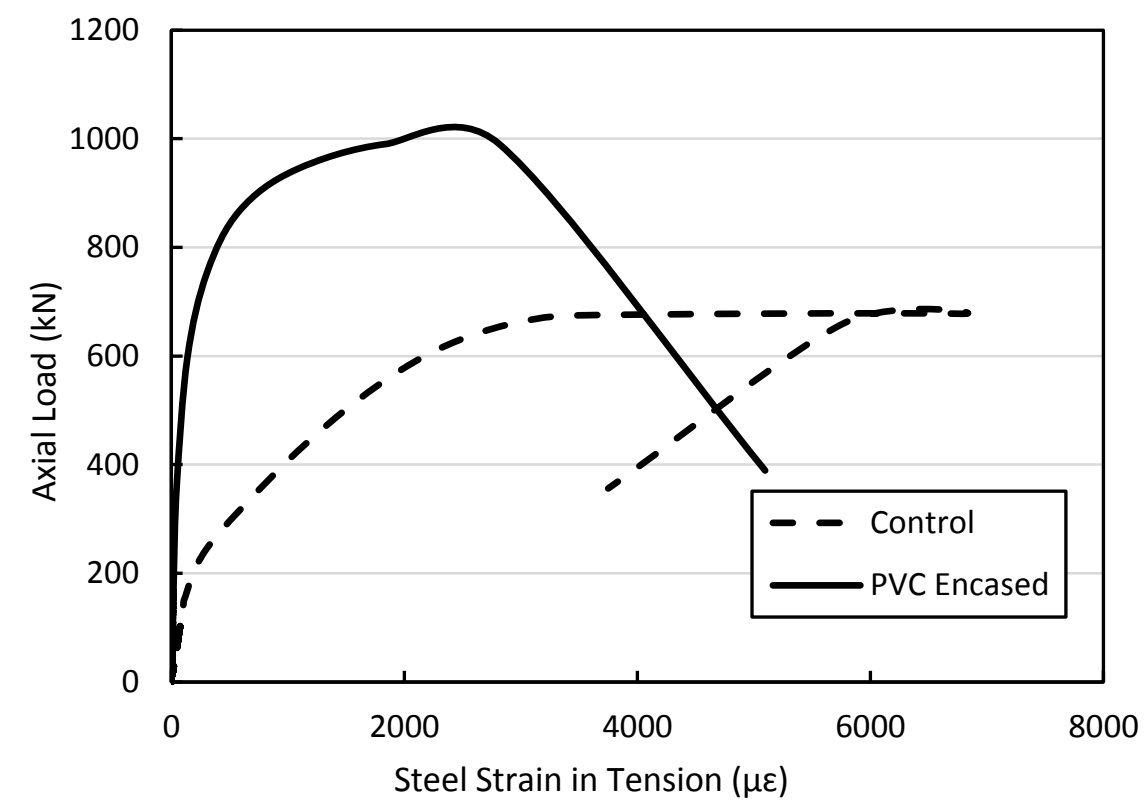

Figure 3.3 - Load versus tension steel strain for O-e3-10 and C-e3-10 wall specimens

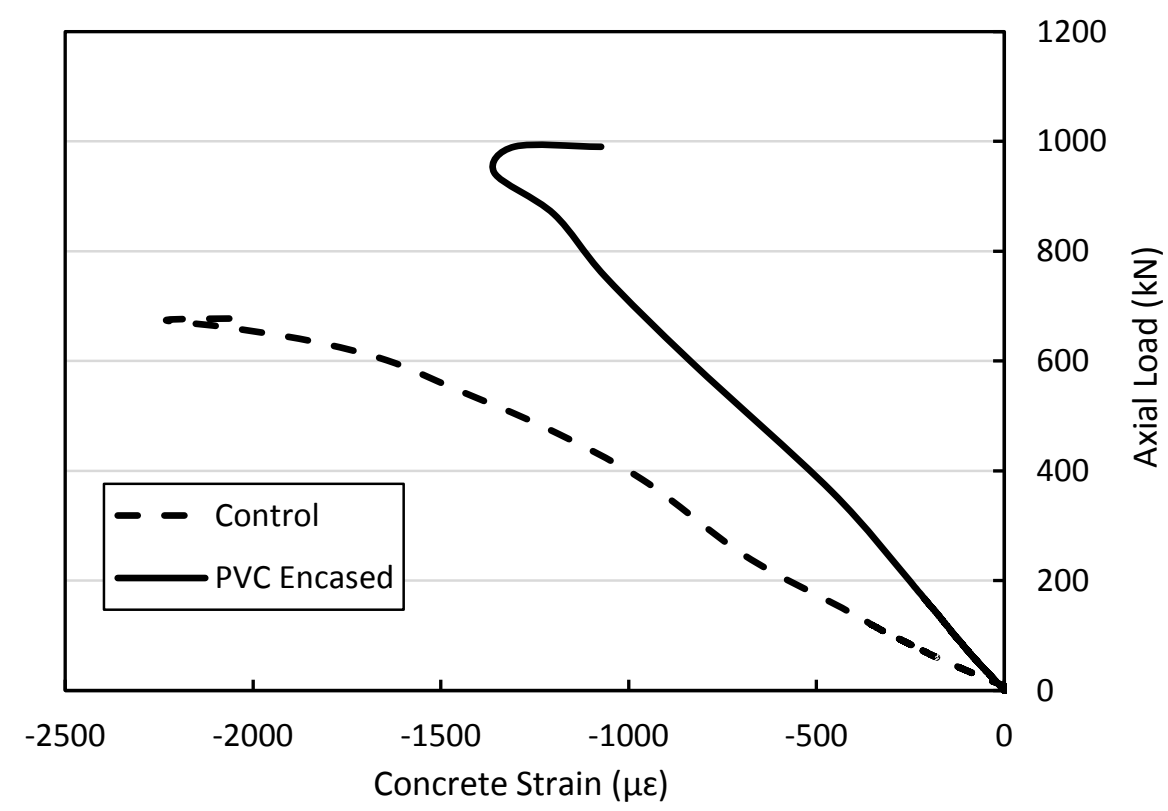

Figure 3.4 - Load versus concrete strain for O-e3-10 and C-e3-10 wall specimens 


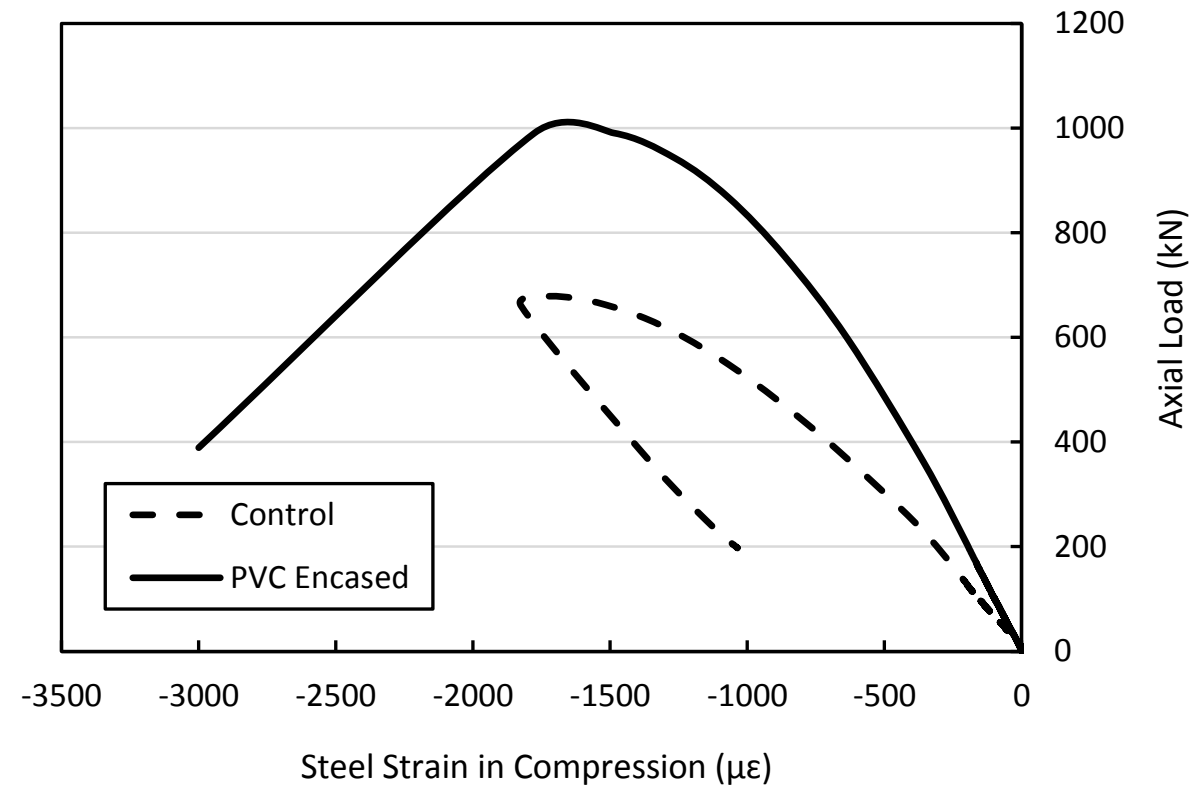

Figure 3.5 - Load versus compression steel strain for O-e3-10 and C-e3-10 wall specimens

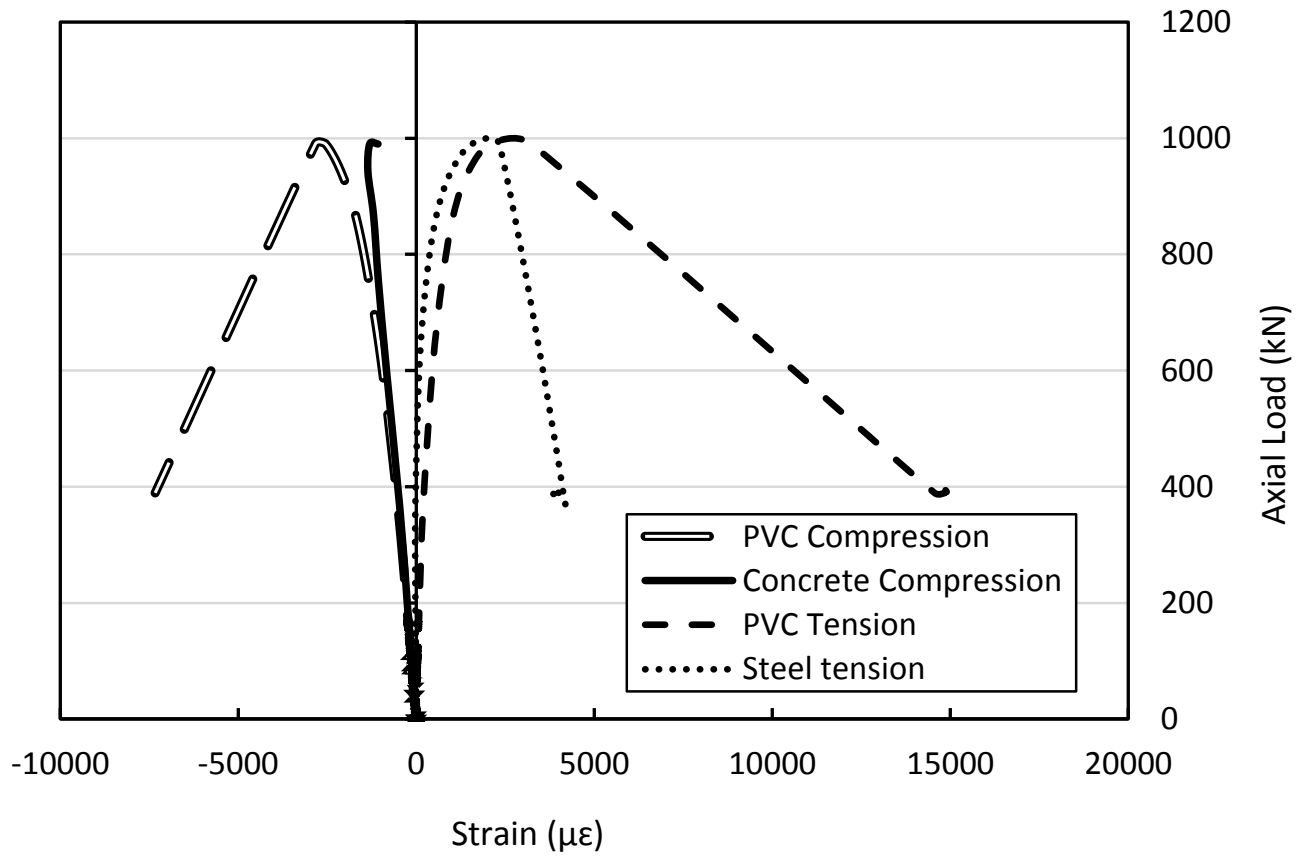

Figure 3.6 - Load versus strain for O-e3-10 wall specimen 


\subsection{Modes of failure}

\subsubsection{Control walls}

Based on the applied eccentricities, the control specimens showed mainly three modes of failure; concrete crushing without yielding of tension steel, concrete crushing accompanied with compression steel buckling, and tension steel yielding followed by crushing of the concrete. At the lowest eccentricity $(33.87 \mathrm{~mm})$, the collar-confined wall reinforced with $10 \mathrm{M}$ failed by concrete crushing accompanied by compression steel buckling (Figure 3.7-a). At the intermediate eccentricity $(67.73 \mathrm{~mm})$, the wall reinforced with $10 \mathrm{M}$ failed by tension steel yielding followed by crushing of the concrete but the wall reinforced with $15 \mathrm{M}$ failed by crushing of concrete without yielding of the steel (Figure 3.8-a). At the highest eccentricity $(101.6 \mathrm{~mm})$, both walls failed by tension steel yielding followed by crushing of the concrete, regardless of the reinforcement $(10 \mathrm{M}$ or $15 \mathrm{M})$ (Figure 3.9-a). It is worth mentioning that prior to using the confined system (collar), one wall reinforced with $15 \mathrm{M}$ and tested at the lowest eccentricity $(33.87 \mathrm{~mm})$ failed at the end.

The failed sections for the confined specimens varied between $300 \mathrm{~mm}$ and $1000 \mathrm{~mm}$ measured from the top end of the wall. The top end of the wall represents the furthest section of the wall from the ground during casting. Failure occurred at these sections due to variation in the compressive strength of the concrete in the upper most portions of the wall where these sections had the lowest compressive strength as reported by Petersons (1964). The lower sections of the column (sections cast at the beginning) showed a higher compressive strength than the upper sections of the column. These sections were confined between the lower and the upper portions, which prevented them from drying out too early. In addition, the lower sections had been subjected throughout the hardening period 
to pressure exerted by the concrete in the upper portions causing the lower sections to have a higher compressive strength. In addition, Petersons (1964) reported that within the upper most portions of the wall, the variation in strength of the concrete could be due to the increase in the water content of the fresh concrete. This could cause a reduction in the compressive strength and a decrease in the weight per unit volume of the hardened concrete. This had been confirmed in the current study by flipping some of the wall specimens before testing to ensure that the specimen failed at sections close to the same end (upper end).

\subsubsection{PVC encased walls}

The PVC encased specimens showed mainly two modes of failure; concrete crushing followed by PVC buckling and tension steel yielding followed by crushing of the concrete then buckling of the PVC.

The confined wall reinforced with $4-10 \mathrm{M}$ failed by compression steel yielding followed by concrete crushing then buckling of PVC. The failed section was at $400 \mathrm{~mm}$ from the top end of the wall. At failure, it is clear that the confined control wall specimens tested at the lowest eccentricity $(33.87 \mathrm{~mm})$ experienced significant concrete spalling at the failed section when reaching the ultimate load as shown in Figure 3.7-a. However, the confined PVC encased specimens tested at the same eccentricity did not show any spalling of concrete at ultimate load. After reaching the ultimate load, the PVC buckled as shown in Figure 3.7-b then the load started to drop. It is worth mentioning that at the lowest eccentricity $(33.87 \mathrm{~mm})$, regardless of the reinforcement $(10 \mathrm{M}$ or $15 \mathrm{M})$, the unconfined walls failed by concrete crushing followed by PVC buckling. The failed sections varied between zero and $200 \mathrm{~mm}$ from the end of the wall. 


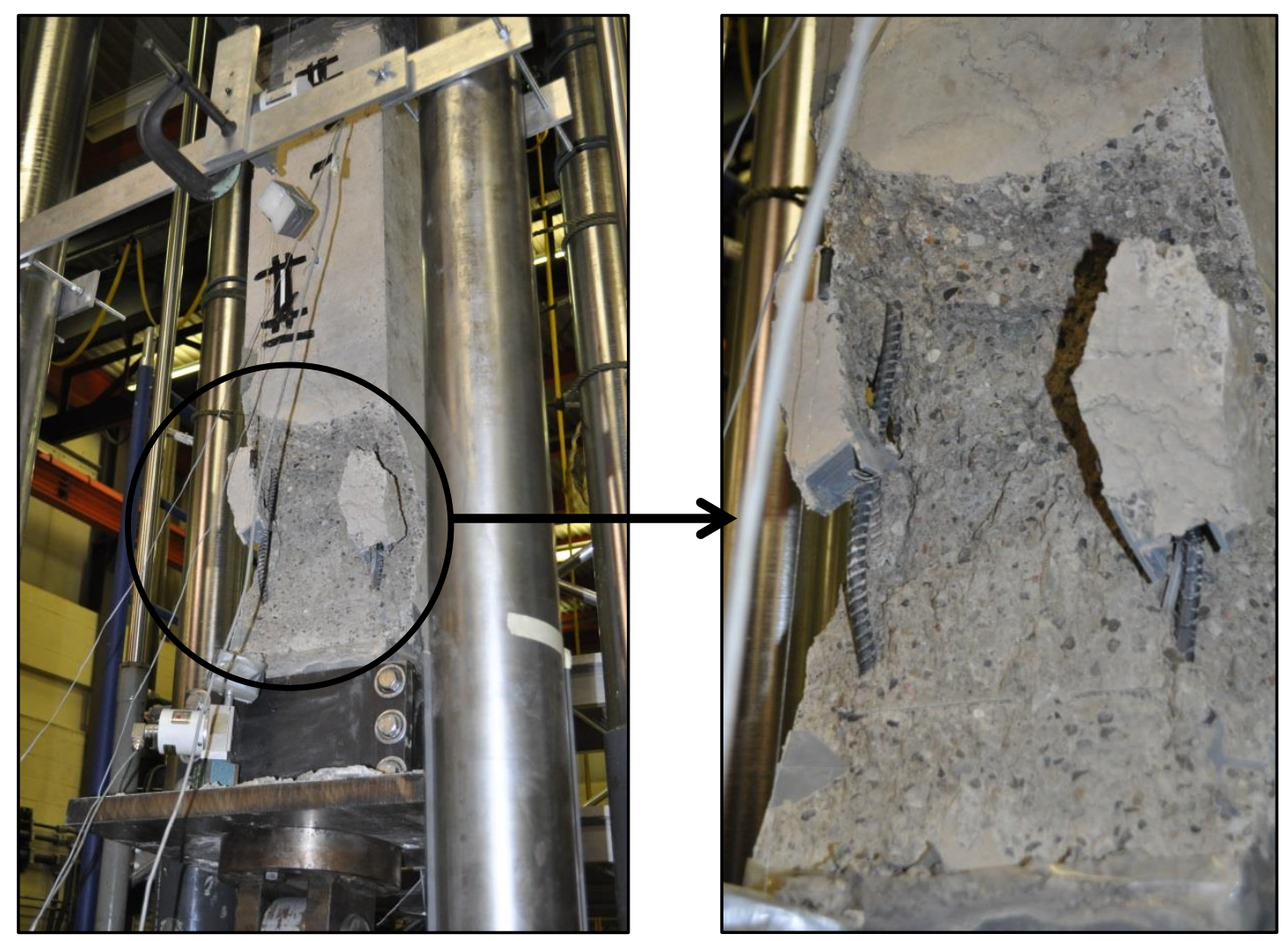

a- C-e6-10 wall specimen
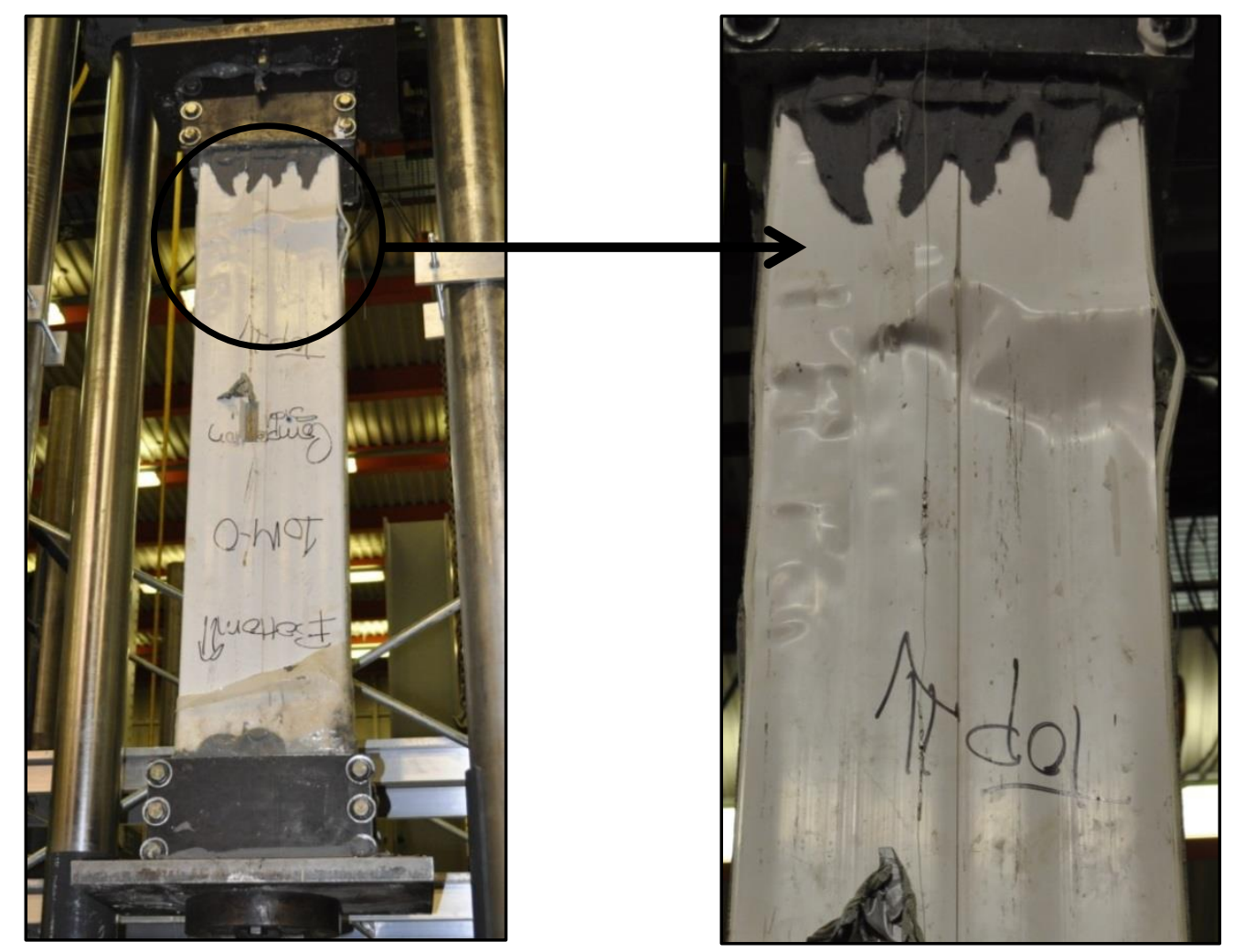

b- O-e6-10 wall specimen

Figure 3.7 - Failures at the lowest eccentricity $(33.87 \mathrm{~mm})$ 
At the intermediate eccentricity $(67.73 \mathrm{~mm})$, the wall reinforced with $4-10 \mathrm{M}$ failed by tension steel yielding and crushing of the concrete at ultimate load followed by buckling of the PVC. The wall reinforced with $4-15 \mathrm{M}$ failed by crushing of the concrete followed by buckling of the PVC (Figure 3.8-b). At the highest eccentricity (101.6 mm), the walls failed by tension steel yielding followed by crushing of the concrete then buckling of the PVC, regardless of the reinforcement (10M or 15M) (Figure 3.9-b).

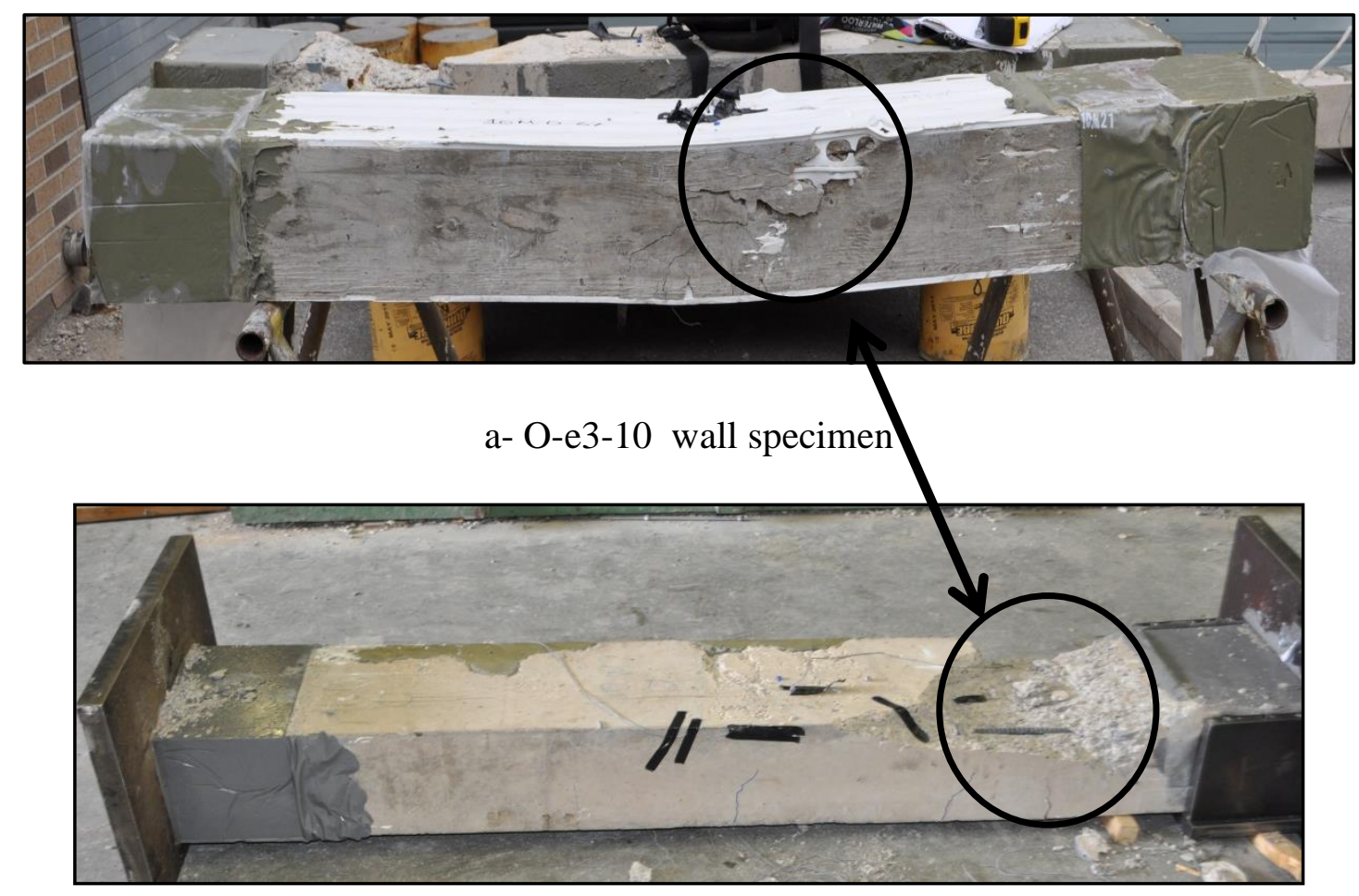

b- C-e3-10 wall specimen

Figure 3.8 - Failures at the intermediate eccentricity $(67.73 \mathrm{~mm})$ 


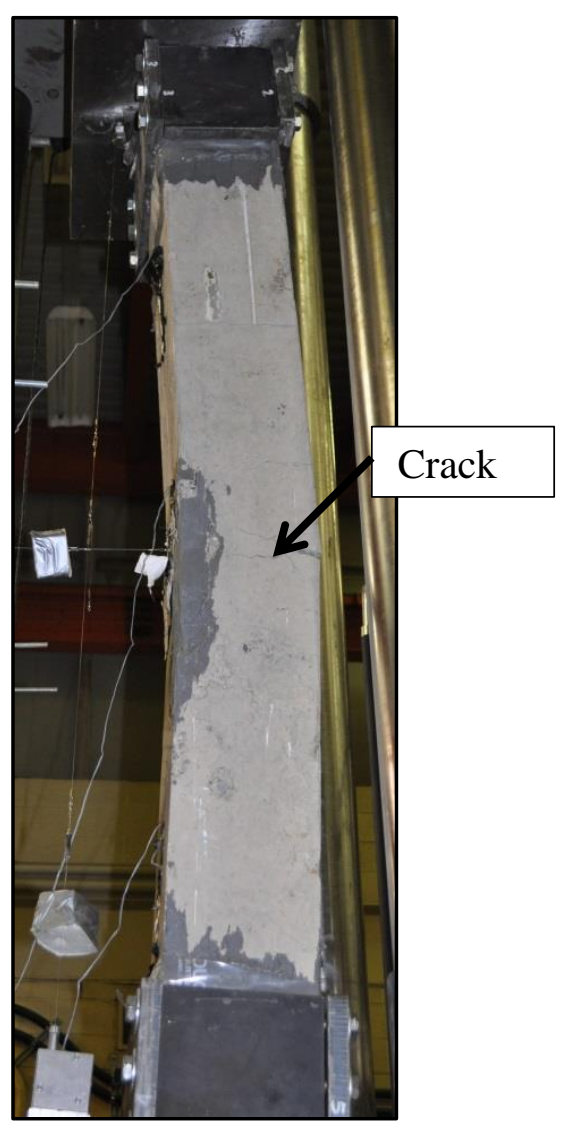

a- Side view

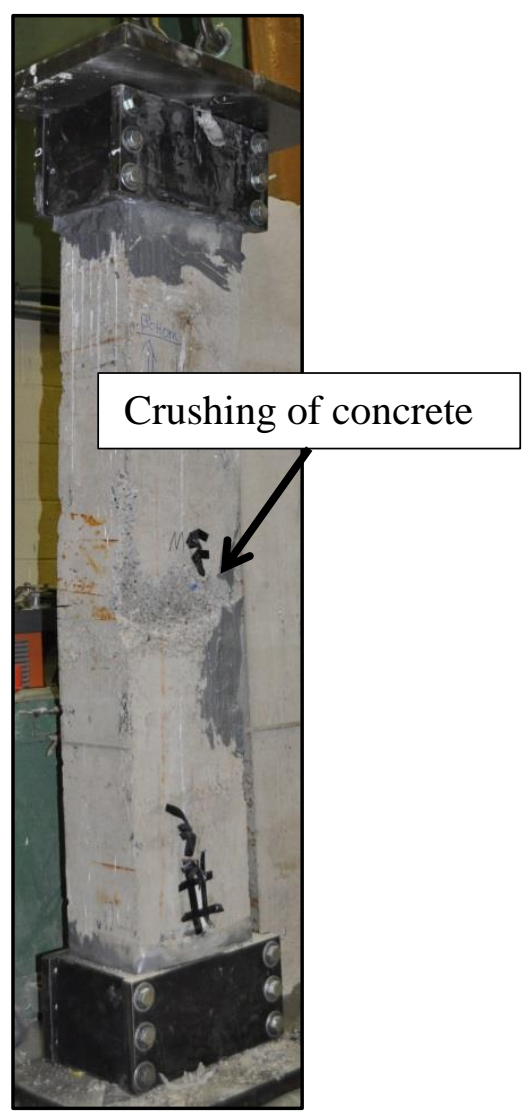

b- Front view

a- C-e2-10 wall specimen

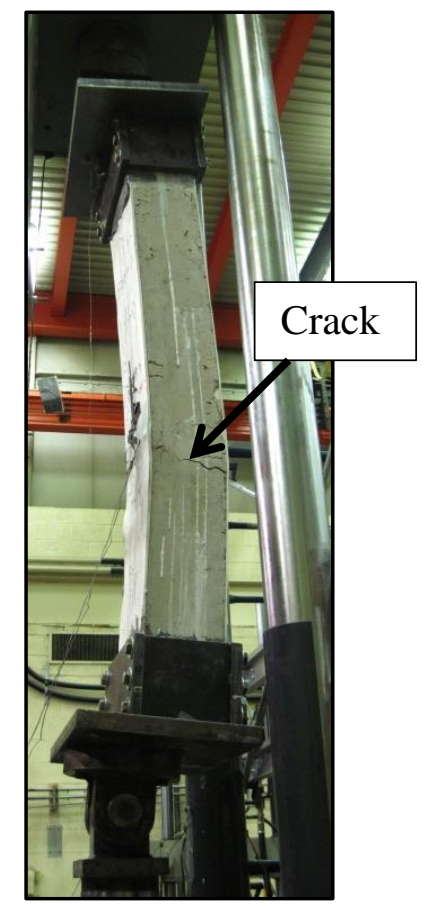

a- Side view

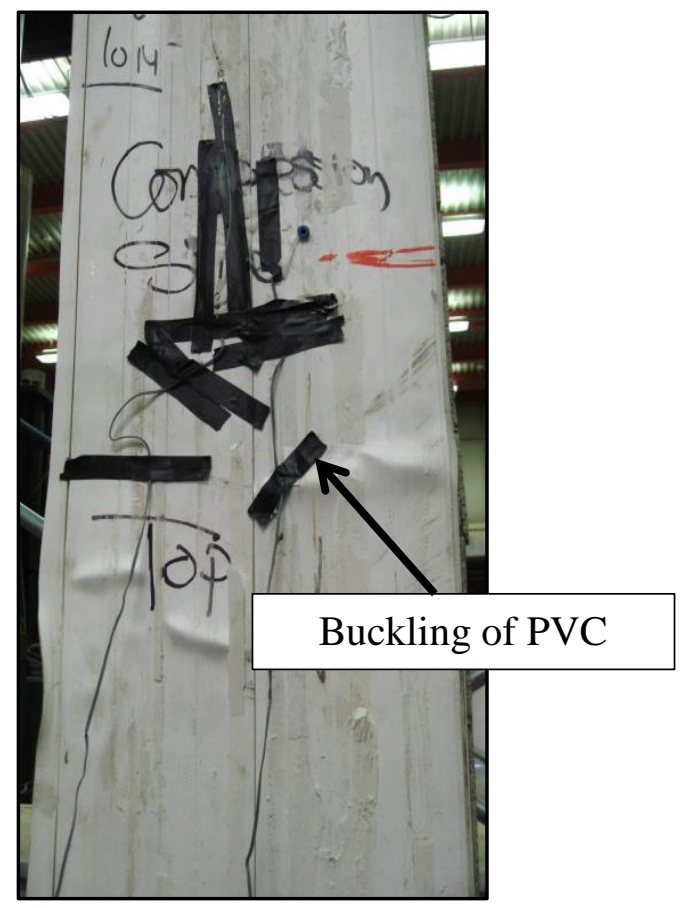

b- Front view

a- C-e2-10 wall specimen

Figure 3.9 - Failures at the highest eccentricity $(101.6 \mathrm{~mm})$ 
When comparing the modes of failure for both the PVC encased wall and control wall reinforced with $4-10 \mathrm{M}$ and tested at the intermediate eccentricity $(67.73 \mathrm{~mm})$, it was noticed that the presence of the PVC delayed the yielding of the tension steel. The tension steel reinforcement in the PVC encased wall yielded right at the ultimate capacity of the wall as opposed to yielding at $94 \%$ of the ultimate load in the control specimen. In other words, the mode of failure shifted from tension failure for the control walls to close to the balanced failure for the PVC encased walls.

At the lowest eccentricity $(33.87 \mathrm{~mm})$, the presence of the PVC encasement did not affect the location of failure. The failure was captured at a distance of $360 \mathrm{~mm}$ for the specimen O-e6-10, but for the specimen O-e6-15 failure started at the top end and extended to 200 $\mathrm{mm}$. For the intermediate eccentricity, the presence of the PVC encasement shifted the failure location towards the mid-span for some specimens. The PVC encased wall (O-e310) failed at $720 \mathrm{~mm}$ from the top end of the specimen as opposed to failing at $370 \mathrm{~mm}$ from the top end of the specimen for the equivalent control wall (C-e3-10) as shown in Figure 3.8. However, for the same specimens reinforced with $15 \mathrm{M}$, both the control and the PVC encased walls failed almost at the same section (on average $590 \mathrm{~mm}$ ) from the top end of the specimen. At the highest eccentricity, all control and PVC encased walls failed almost at mid span.

\subsection{Discussion}

Table 3.1 shows the peak load, mid-span deflection, vertical displacement and mode of failure for the control walls and the PVC encased walls for both end-confined (collar) and unconfined walls. 
Table 3.1 - Test results

\begin{tabular}{|c|c|c|c|c|c|c|}
\hline & Specimen** & Batch & Collar & $\begin{array}{l}\text { Peak } \\
\text { Load } \\
(\mathrm{kN})\end{array}$ & $\begin{array}{c}\text { Mid-span } \\
\text { Deflection } \\
(\mathrm{mm}) \\
\end{array}$ & $\begin{array}{c}\text { Vertical } \\
\text { Displacement } \\
(\mathrm{mm})\end{array}$ \\
\hline \multirow{8}{*}{$\frac{\sum}{\substack{1 \\
\dot{y}}}$} & C-e6-10 & Batch1 & Present & 1445.1 & 9 & 5.1 \\
\hline & O-e6-10 & Batch1 & Absent & 1339.7 & 5.6 & 6.8 \\
\hline & O-e6-10 & Batch 2 & Present & 1475.9 & 7.3 & 5.7 \\
\hline & C-e3-10 & Batch1 & Present & 677.9 & 16.4 & 5.4 \\
\hline & O-e3-10 & Batch1 & Present & 990.3 & 11.8 & 5.2 \\
\hline & O-e3-10 & Batch 2 & Present & 869.3 & 13.4 & 5.2 \\
\hline & C-e2-10 & Batch1 & Present & 374.8 & 20.9 & 5 \\
\hline & O-e2-10 & Batch 2 & Present & 438.9 & 22.7 & 5.3 \\
\hline \multirow{8}{*}{$\frac{\sum_{n}}{\frac{1}{+}}$} & C-e6-15 & Batch1 & Absent & 1266.7 & 8.3 & 6.7 \\
\hline & O-e6-15 & Batch1 & Absent & 1393.5 & 7.5 & 5.8 \\
\hline & C-e3-15 & Batch1 & Present & 856 & 15.4 & 6.3 \\
\hline & O-e3-15 & Batch1 & Absent & 624.6 & 7.2 & 4.1 \\
\hline & O-e3-15* & Batch1 & Present & 984 & 17.2 & 6.2 \\
\hline & O-e3-15 & Batch 2 & Present & 905 & 14.3 & 5.4 \\
\hline & C-e2-15 & Batch1 & Present & 504.1 & 23.2 & 7.3 \\
\hline & O-e2-15 & Batch 2 & Present & 557.9 & 20.3 & 7 \\
\hline
\end{tabular}

* Repeated twice in batch1 due to the premature failure of the specimen during the first test

** Two specimens were excluded due to their damage during test set-up

\subsubsection{Peak load}

The confined control walls reinforced with $4-10 \mathrm{M}$ and tested at an eccentricity of 33.87 $\mathrm{mm}, 67.73 \mathrm{~mm}$ and $101.6 \mathrm{~mm}$ showed a peak load of $1445.1 \mathrm{kN}, 677.9 \mathrm{kN}$ and $374.8 \mathrm{kN}$, respectively. On the other hand, their equivalent PVC encased walls showed a peak load of $1475.9 \mathrm{kN}, 929.79 \mathrm{kN}$ (average) and $438.9 \mathrm{kN}$ at an applied eccentricity of $33.87 \mathrm{~mm}$, $67.73 \mathrm{~mm}$ and $101.6 \mathrm{~mm}$, respectively. Hence, the PVC encased walls showed an increase in the peak load of $2.14 \%, 37.2 \%$ and $17.1 \%$ at $33.87 \mathrm{~mm}, 67.73 \mathrm{~mm}$ and $101.6 \mathrm{~mm}$ eccentricity, respectively. It can be concluded that for the low reinforcement 
ratio $(4-10 \mathrm{M})$, the effect of the PVC on increasing the axial capacity was noticeable at the high eccentricities $(67.73 \mathrm{~mm}$ and $101.6 \mathrm{~mm})$. These results are in good agreement with the findings of Chahroor et al. (2009). It was reported that the PVC encased system showed a significant contribution to the strength enhancement at high eccentricities where the PVC panels contributed to resisting the tensile forces.

The unconfined PVC encased wall reinforced with 4-10M and tested at the lowest eccentricity $(33.87 \mathrm{~mm})$ showed a peak load of $1339.7 \mathrm{kN}$ which was less than its equivalent confined control and PVC encased walls. This emphasized the effect of the collar on increasing the peak axial load and developing the full capacity of the wall. In addition, although the same concrete mix was used for the two batches, the two confined PVC encased walls cast in two different batches and tested at an eccentricity of $67.73 \mathrm{~mm}$ showed a difference in peak load of $121 \mathrm{kN}$. The wall tested from the second batch showed a decreased axial capacity. This finding was also consistent for the duplicate PVC encased walls reinforced with $15 \mathrm{M}$ and tested at an eccentricity of $67.73 \mathrm{~mm}$. It is also worth mentioning that the confined control and PVC encased walls tested at an eccentricity of $33.87 \mathrm{~mm}$ were cast in two different batches. If both walls were cast from the same batch, it is expected that the contribution of the PVC would have been higher than the reported value $(2.14 \%)$.

The control walls reinforced with $4-15 \mathrm{M}$ and tested at an eccentricity of $33.87 \mathrm{~mm}, 67.73$ $\mathrm{mm}$ and $101.6 \mathrm{~mm}$ showed a peak load of $1266.7 \mathrm{kN}, 856 \mathrm{kN}$ and $504.1 \mathrm{kN}$, respectively. It can be observed that the control wall reinforced with 4-15M and tested under $33.87 \mathrm{~mm}$ eccentricity specimen showed a peak load less than its peer specimen reinforced with 4$10 \mathrm{M}$ due to the absence of the confinement system (collar). The equivalent PVC encased 
walls showed a peak load of $1393.5 \mathrm{kN}, 944.5 \mathrm{kN}$ and $557.9 \mathrm{kN}$ at an applied eccentricity of $33.87 \mathrm{~mm}, 67.73 \mathrm{~mm}$ and $101.6 \mathrm{~mm}$. Hence, the PVC encased walls showed an increase in the peak load of $10 \%, 10.34 \%$ and $10.67 \%$ at $33.87 \mathrm{~mm}, 67.73 \mathrm{~mm}$ and 101.6 mm eccentricity, respectively. It is worth mentioning that the two walls tested at the lowest eccentricity of $33.87 \mathrm{~mm}$ were both unconfined. Yet, the PVC encasement enhanced the peak load by $10 \%$. Similar to the duplicate confined specimens cast in two separate batches and reinforced with 4-10M (O-e3-10), the duplicate confined specimens reinforced with $4-15 \mathrm{M}$ and tested at an eccentricity of $67.73 \mathrm{~mm}$ showed a difference in peak load of $79 \mathrm{kN}$. The peak load of the specimen from batch 2 was $79 \mathrm{kN}$ less than the peak load of the specimen from batch 1. It can be concluded that for the high reinforcement ratio $(4-15 \mathrm{M})$, the effect of PVC on increasing the ultimate capacity was much less than the low reinforcement ratio $(4-10 \mathrm{M})$. This indicated that the contribution of the PVC was more significant at lower reinforcement ratios. This finding is consistent with the literature reported on testing the PVC encased walls with different reinforcement ratios under pure bending (Rteil and Soudki 2008, Wahab and Soudki 2013).

Figures 3.10 to 3.13 show the effect of the eccentricity on the peak load for both the control and the PVC encased specimens reinforced with 4-10M. The walls reinforced with $4-15 \mathrm{M}$ behaved in a similar manner to those with $4-10 \mathrm{M}$ reinforcement. For both reinforcement ratios, as the eccentricity increased the peak load of the specimens decreased due to the increase in curvature and the additional moment caused by the eccentric loading. 


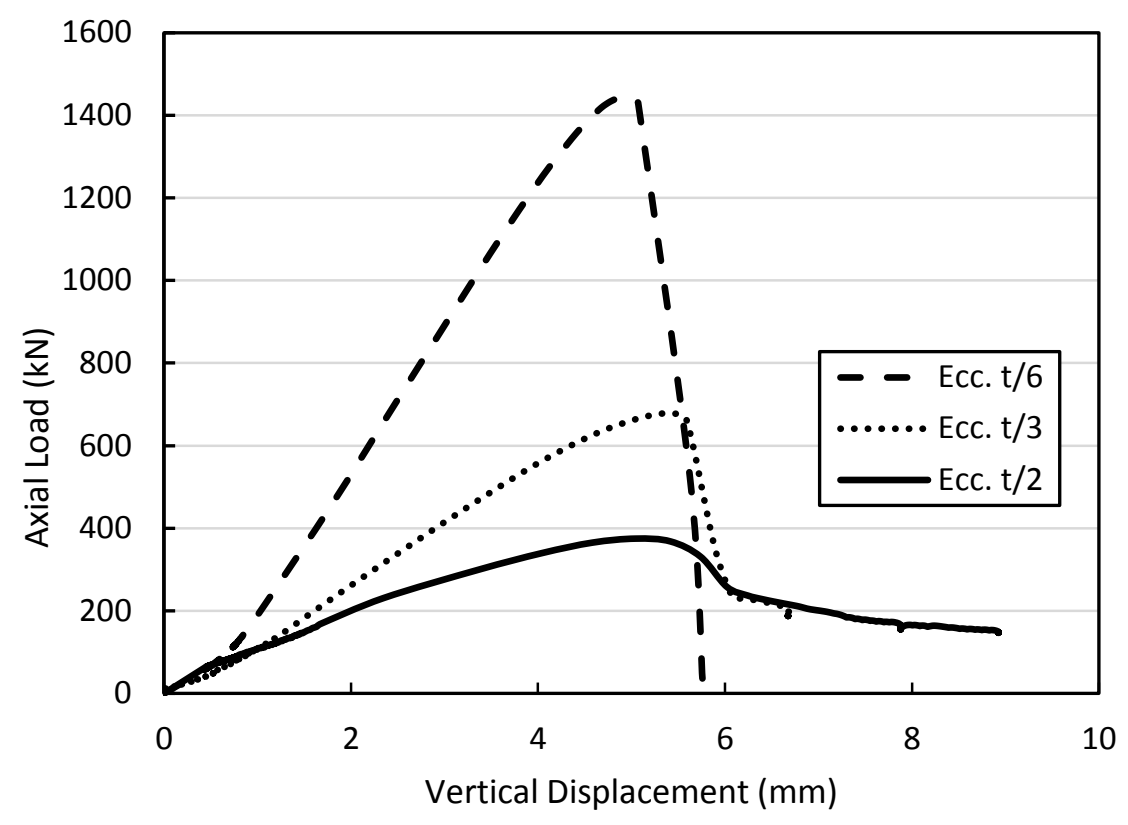

Figure 3.10 - Load versus vertical displacement for the control specimens reinforced with 4-10M at different eccentricities

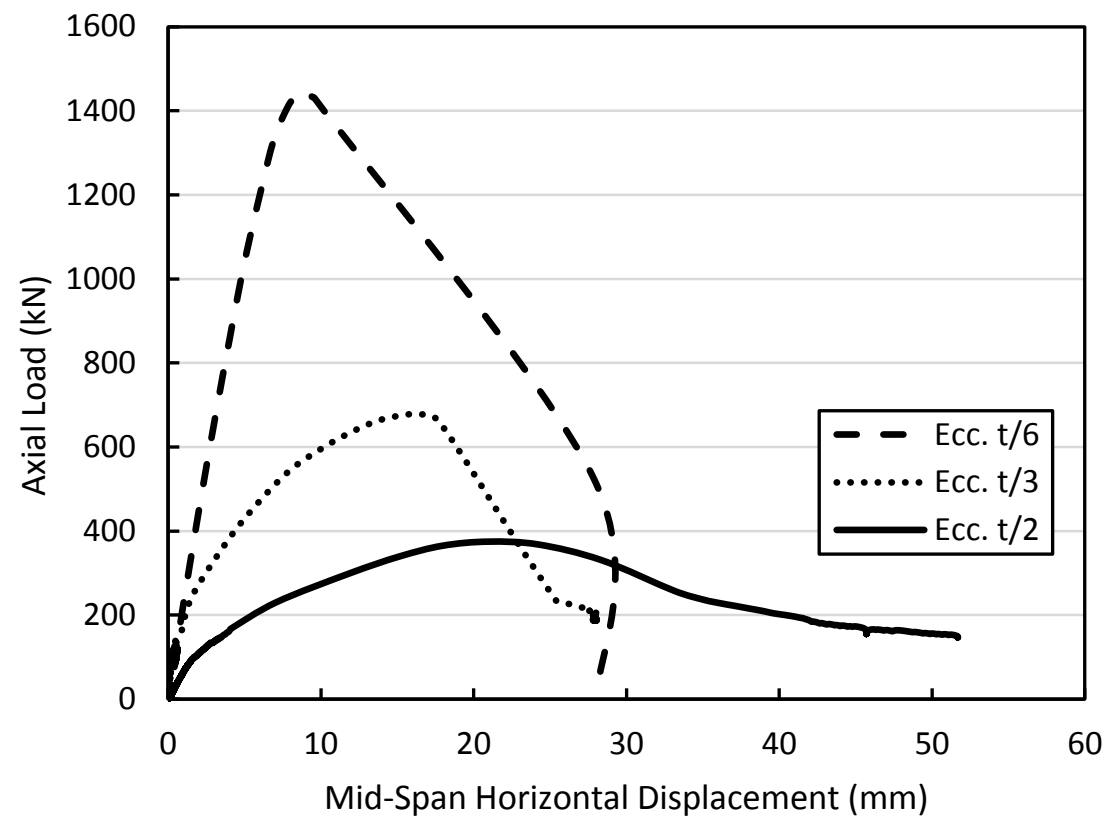

Figure 3.11 - Load versus mid-span deflection for the control specimens reinforced with 4-10M at different eccentricities 


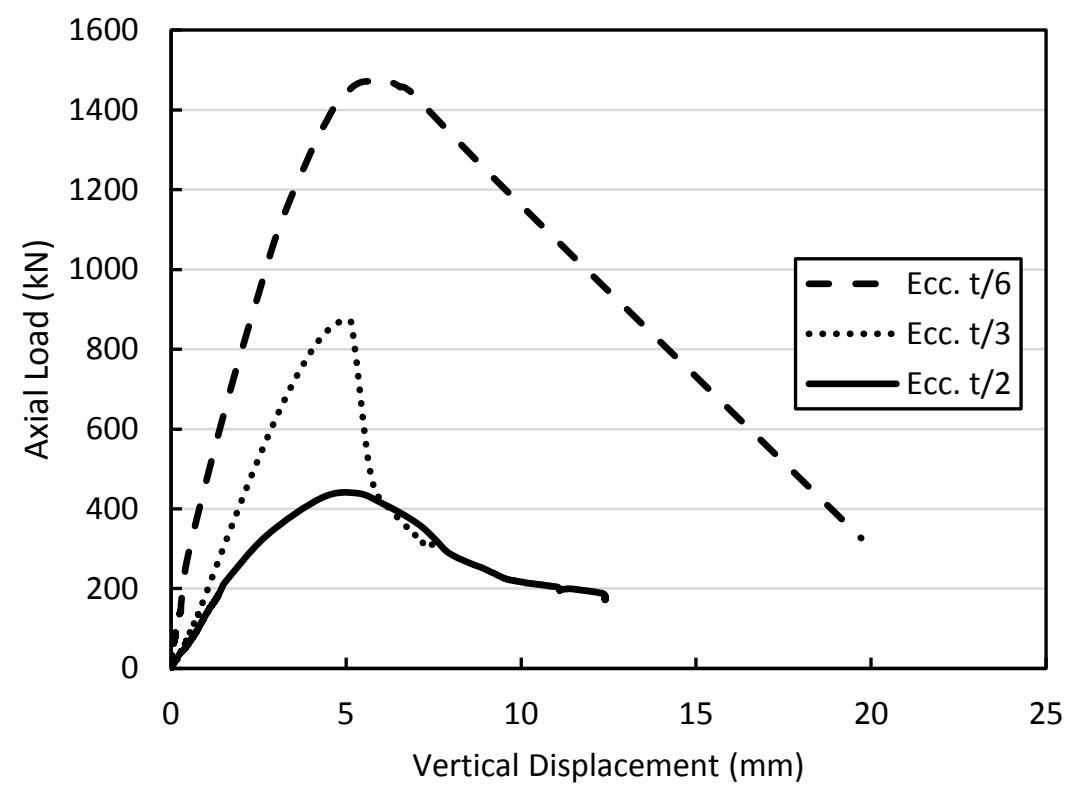

Figure 3.12 - Load versus vertical displacement for the PVC encased specimens reinforced with 4-10M at different eccentricities

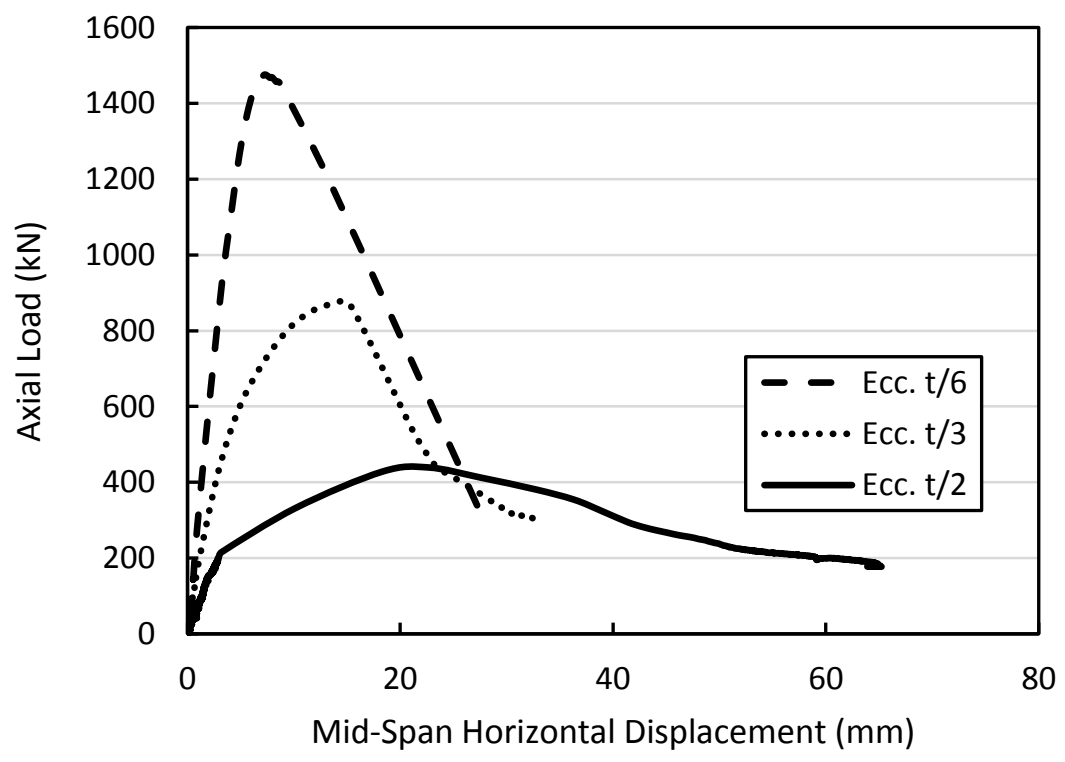

Figure 3.13 - Load versus mid-span deflection for the PVC encased specimens reinforced with 4-10M at different eccentricities 
Table 3.2 shows the effect of the reinforcement (4-10M versus $4-15 \mathrm{M})$ on the peak load for both the control and the PVC encased wall specimens tested at two eccentricities of $67.73 \mathrm{~mm}$ and $101.6 \mathrm{~mm}$. The specimens tested at an eccentricity of $33.87 \mathrm{~mm}$ were excluded from this comparison as the specimens reinforced with $4-15 \mathrm{M}$ were tested without the confinement (collar) system. Typical load versus vertical displacement are provided in Figures 3.14 and 3.15 to show the effect of the reinforcement ratio on the peak load for control specimens and PVC encased specimens, respectively.

The control and the PVC encased specimens reinforced with $4-15 \mathrm{M}$ and tested at an eccentricity of $67.73 \mathrm{~mm}$ showed an increase in the peak load of $26.3 \%$ and $1.6 \%$, respectively, over those reinforced with $4-10 \mathrm{M}$. The difference in the reinforcement effect on the peak load for the control and the PVC encased walls is explained by the different modes of failure. At failure of both the control and the PVC encased walls reinforced with 4-15M, the concrete crushed without yielding of the tension reinforcement. On the other hand, for the control wall reinforced with $4-10 \mathrm{M}$, the steel yielded at about $94 \%$ of the peak load then the concrete crushed at the peak load. Yet, the PVC encased wall reinforced with $4-10 \mathrm{M}$ failed by steel yielding and concrete crushing at the peak load as explained earlier in Section 3.3.2. For the highest eccentricity $(101.6 \mathrm{~mm})$, the control and the PVC encased specimens reinforced with 4-15M showed an increase in the peak load of $34.5 . \%$ and $27.1 \%$, respectively, over those reinforced with $4-10 \mathrm{M}$. The effect of the reinforcement on the peak load is similar in this case as all of the specimens showed same modes of failure. Based on Table 3.2, it is clear that at the same eccentricity the effect of the reinforcement was more noticeable for the control specimens compared to the PVC encased specimens. 
Table 3.2 - Effect of reinforcement on the peak load

\begin{tabular}{|c|c|c|}
\hline Specimen & $\begin{array}{c}\text { Peak load } \\
(\mathrm{kN})\end{array}$ & $\begin{array}{c}\text { Percentage of increase } \\
(\%)\end{array}$ \\
\hline \multicolumn{3}{|c|}{ Eccentricity= t/3 $(67.73 \mathrm{~mm})$} \\
\hline C-e3-10 & 677.85 & \multirow{2}{*}{26.3} \\
\hline C-e3-15 & 856 & \multirow{2}{*}{1.6} \\
\hline O-e3-10 & 929.8 & \multirow{2}{*}{34.5} \\
\hline O-e3-15 & 944.5 & 27.1 \\
\hline \multicolumn{3}{|c|}{ Eccentricity= t/2 (101.6 mm) } \\
\hline C-e2-10 & 374.83 & \\
\hline C-e2-15 & 504.1 & \\
\hline O-e2-10 & 438.9 & \\
\hline O-e2-15 & 557.88 & \\
\hline
\end{tabular}

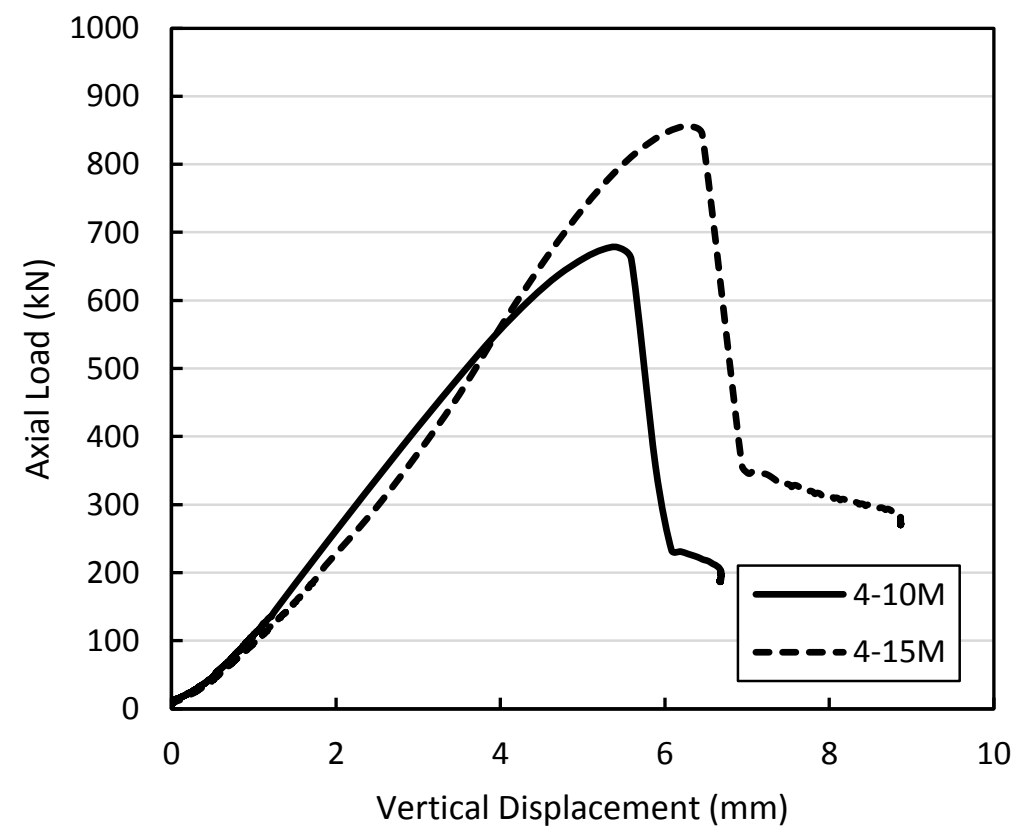

Figure 3.14 - Load versus vertical displacement for control wall specimens with different reinforcement (C-e3-10 and C-e3-15) 


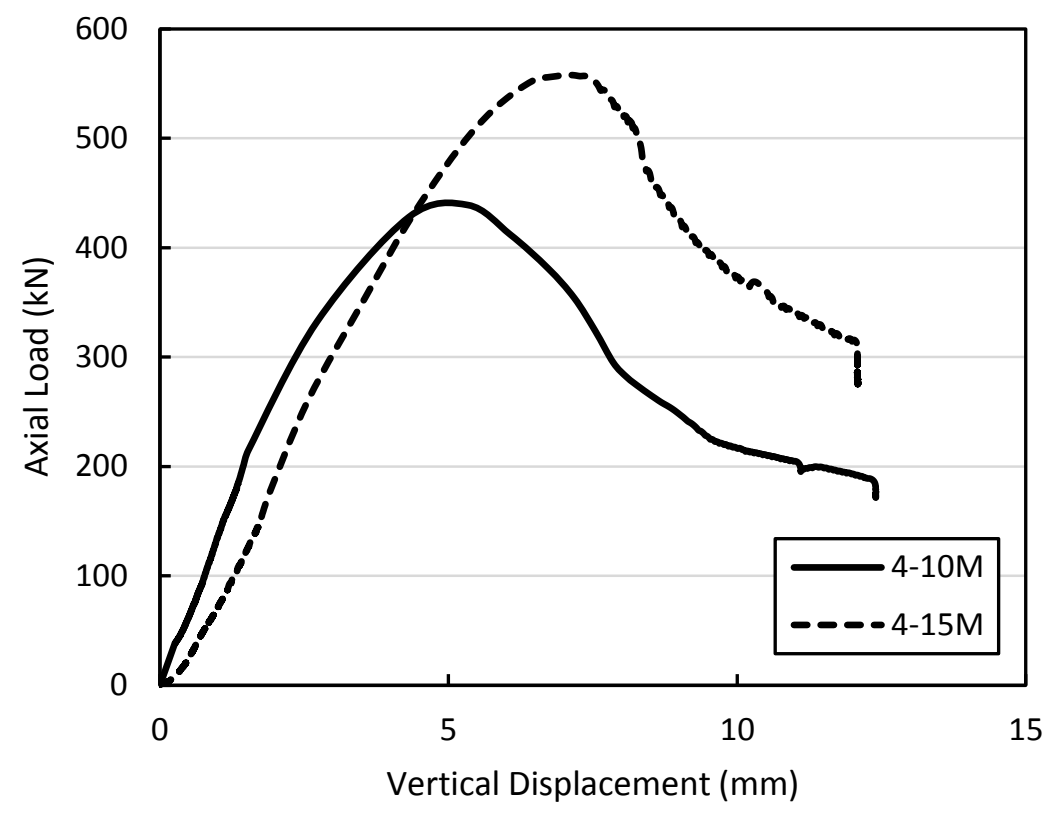

Figure 3.15 - Load versus vertical displacement for PVC encased wall specimens with different reinforcement (O-e2-10 and O-e2-10)

\subsubsection{Vertical displacement}

The control walls reinforced with $4-10 \mathrm{M}$ and tested at an eccentricity of $33.87 \mathrm{~mm}, 67.73$ $\mathrm{mm}$ and $101.6 \mathrm{~mm}$ showed a vertical displacement at peak load of $5.1 \mathrm{~mm}, 5.4 \mathrm{~mm}$ and 5 $\mathrm{mm}$, respectively. Similarly, their equivalent confined PVC encased walls showed a vertical displacement of $5.6 \mathrm{~mm}, 5.2 \mathrm{~mm}$ and $5.3 \mathrm{~mm}$, respectively at peak load. It is clear that the PVC encased specimens had almost the same vertical displacement as the control specimens but at a higher peak load. Similar behaviour was noticed for the walls reinforced with $4-15 \mathrm{M}$ as shown in Table 3.1. It can be concluded that using the PVC encasement with different eccentricities and different reinforcement ratios did not affect the vertical displacement at failure. 


\subsubsection{Mid-span deflection}

For both reinforcement ratios $(4-10 \mathrm{M}$ and $4-15 \mathrm{M})$, it was clear that as the eccentricity increased the mid-span deflection increased. The control walls reinforced with $4-10 \mathrm{M}$ and tested at an eccentricity of $33.87 \mathrm{~mm}, 67.73 \mathrm{~mm}$ and $101.6 \mathrm{~mm}$ showed a horizontal midspan deflection of $9 \mathrm{~mm}, 16.4 \mathrm{~mm}$ and $20.9 \mathrm{~mm}$, respectively at failure, On the other hand, their equivalent PVC encased walls showed a horizontal mid-span deflection of 7.3 $\mathrm{mm}, 12.6 \mathrm{~mm}$ and $22.7 \mathrm{~mm}$ at an applied eccentricity of $33.87 \mathrm{~mm}, 67.73 \mathrm{~mm}$ and 101.6 mm, respectively. Hence, the PVC encased walls showed almost the same horizontal midspan deflection as the control walls at different eccentricities.

For the higher reinforcement ratio $(4-15 \mathrm{M})$, the control walls tested at an eccentricity of $33.87 \mathrm{~mm}, 67.73 \mathrm{~mm}$ and $101.6 \mathrm{~mm}$ showed a horizontal mid-span deflection of $8.3 \mathrm{~mm}$, $15.4 \mathrm{~mm}$ and $23.2 \mathrm{~mm}$, respectively. Their equivalent PVC encased walls showed a horizontal mid-span deflection of $7.5 \mathrm{~mm}, 15.7 \mathrm{~mm}$ and 20.3 at an applied eccentricity of $33.87 \mathrm{~mm}, 67.73 \mathrm{~mm}$ and $101.6 \mathrm{~mm}$, respectively. Similar to the low reinforcement ratio, the control and the PVC encased walls showed almost the same horizontal mid-span deflection at different eccentricities.

\subsubsection{Load-strain behaviour}

The eccentricity and the reinforcement ratio were the dominant factors in defining the load-strain behaviour for the wall specimens. All of the specimens (control and PVC encased walls) tested under the lowest eccentricity $(33.87 \mathrm{~mm})$ showed a similar load versus strain behaviour in steel, concrete and polymer. Figure 3.16 shows typical test results for a confined PVC encased wall specimen reinforced with 4-10M and tested under the lowest eccentricity. The vertical axis represents the axial load and the horizontal 
axis represents the strain in all materials. The positive readings indicate tensile strains and the negative readings indicate compressive strains. The tension forces in the wall cross section were resisted mainly by the steel reinforcement and the PVC panel on the tension side. The compression forces were resisted by the concrete, the steel reinforcement and the PVC panels. It is worth mentioning that the readings of the strain gauges were affected by the location of the gauge with respect to the failure location. The closer the gauge was to the failure location, the higher the recorded measured readings at failure.

From Figure 3.16, it is clear that strain gauge readings on both tension and compression steel reinforcement were negative, with lower strain values for the tension steel compared to the compression steel. This indicated that the whole section was under compression at the peak load due to the low applied eccentricity $(33.87 \mathrm{~mm})$. Also, the PVC panels on the tension side showed negligible positive strain gauge readings (less than 300 microstrains).

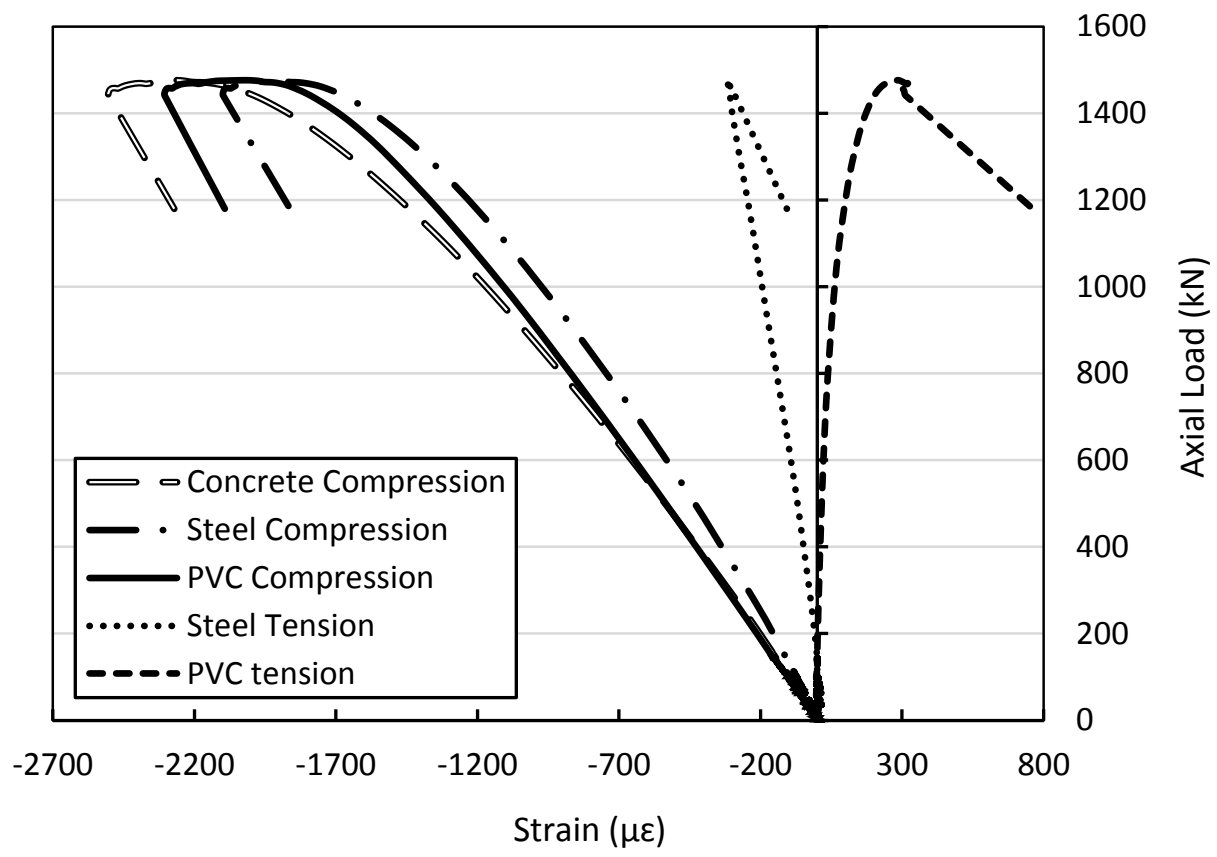

Figure 3.16 - Load versus strain at mid-span for O-e6-10 wall specimen 
At the intermediate eccentricity $(67.73 \mathrm{~mm})$, the specimens showed a load versus strain behaviour similar to those tested under the lowest eccentricity but with different peak values. The readings of the strain gauges were in a good agreement with the mode of failure for all of the specimens tested at the intermediate eccentricity. Figures 3.17 and 3.18 show the load versus strain behaviour for the PVC encased wall (O-e3-10) reinforced with 4-10M and tested at an applied eccentricity of $67.73 \mathrm{~mm}$. This specimen failed by steel yielding and concrete crushing followed by buckling of the PVC panel on the compression side.

From Figure 3.17, strain readings for both the steel reinforcement and the PVC panels on the tension face were compatible until reaching the peak load, where the steel strains showed slightly lower values compared to the PVC strain readings. The strain readings of the tension steel reinforcement and the PVC panels increased until the steel yielded at the peak load. Past the peak load, the strains readings for both the PVC panels and the tension steel reinforcement increased as the load dropped. However, the strain readings of the PVC panels showed more ductile behaviour, demonstrated by the longer descending tail, compared to the steel where a sharp drop was observed as shown in Figure 3.17.

Strain gauge readings for both the concrete and the PVC panels on compression side were almost the same until reaching a load of $596 \mathrm{kN}$, as shown in Figure 3.18. Past that load until reaching the peak load, the PVC strain readings were slightly higher than the concrete strain readings. In addition, the strain readings of the concrete and the compression steel reinforcement were compatible until reaching a load of about $800 \mathrm{kN}$, where the strain readings of the steel reinforcement were less than the strain readings of the concrete. Beyond $800 \mathrm{kN}$, the concrete strain gauge was not functioning properly. 
Past the peak load, the concrete strain readings dropped and the forces were transmitted to the PVC panel. The PVC strain readings continued to increase as shown in Figure 3.18. It is worth mentioning that the strain gauges on the concrete and the PVC panels were located at the mid-span section, about $200 \mathrm{~mm}$ from the failed section.

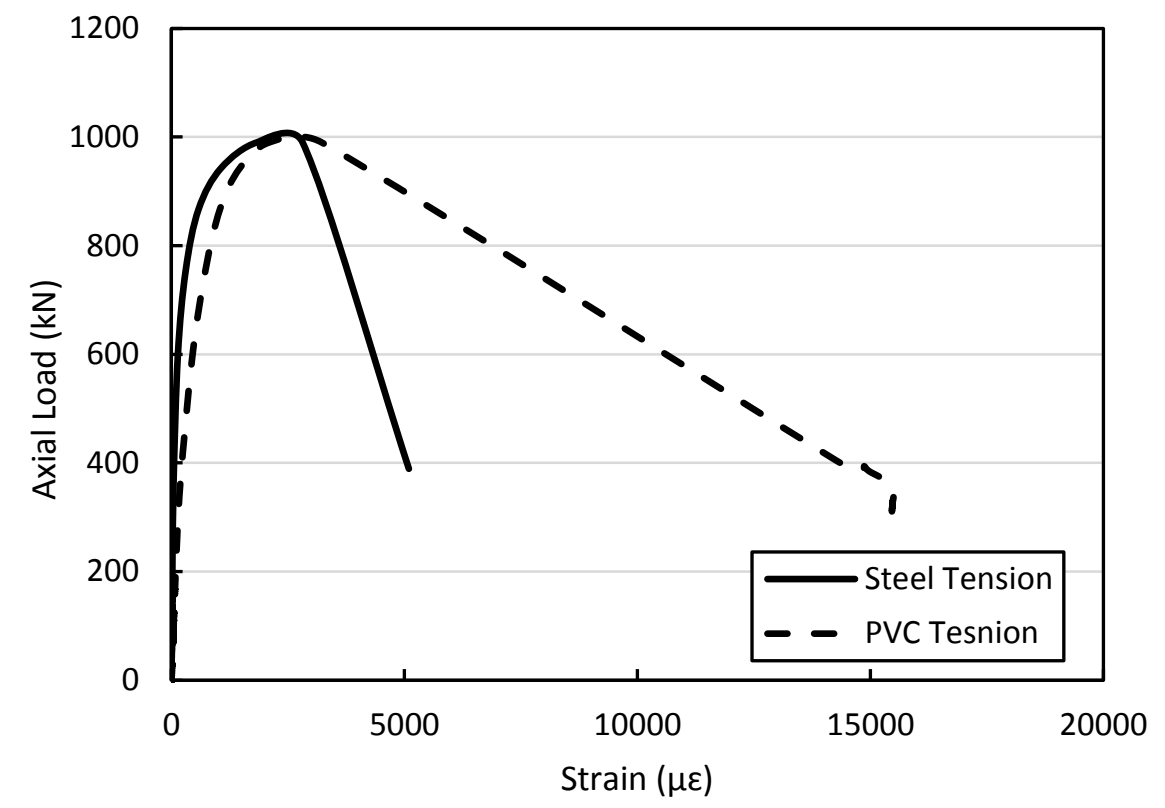

Figure 3.17 - Load versus tension strain readings for the PVC encased wall specimen (Oe3-10) 


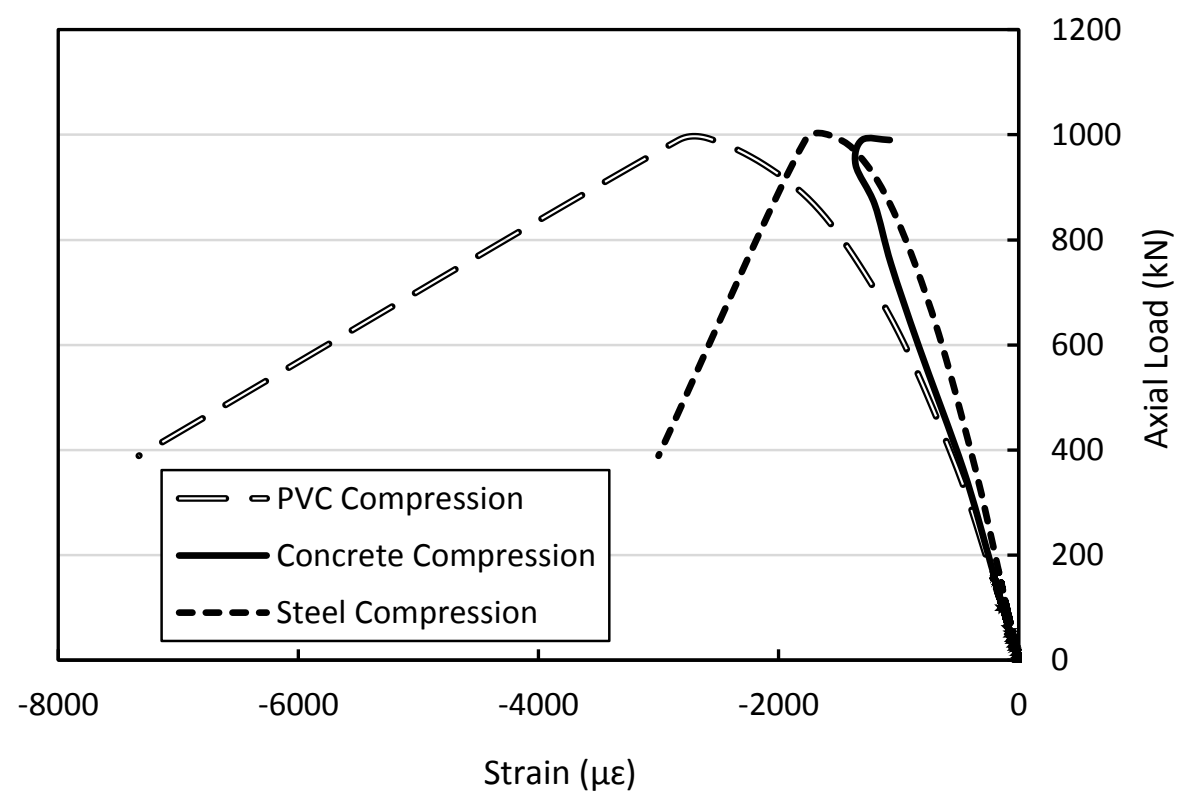

Figure 3.18 - Load versus compression strain readings for the PVC encased wall specimen $(\mathrm{O}-\mathrm{e} 3-10)$

At the highest eccentricity (101.6 mm), all specimens (control and PVC encased walls) tested showed a similar load versus strain behaviour in steel, concrete and polymer. The readings of the strain gauges were reflecting the mode of failure. This group of walls failed by steel yielding followed by concrete crushing then buckling of the PVC panels for the encased walls. Figures 3.19 and 3.20 show the load versus strain gauge readings for the PVC encased wall (O-e2-10).

Similar to the walls tested at the intermediate eccentricity $(67.73 \mathrm{~mm})$, the strain gauge readings for both the tension steel reinforcement and the PVC were compatible until reaching the peak load, however, the steel strain was less than that in the PVC panels. The steel reinforcement yielded at about $427 \mathrm{kN}$ (97\% of the peak load). Past the peak load, the strains in both the PVC panel and the tension steel increased. Similar to the walls 
tested at the intermediate eccentricity $(67.73 \mathrm{~mm})$, the PVC panels showed a more ductile behaviour compared to the steel reinforcement (Figure 3.19).

For the compression face, the PVC panels and the concrete had almost the same strain readings. However, the strain readings for the compression steel were remarkably less than the strain readings for the concrete and the PVC panels (Figure 3.20). At failure, the compression steel reinforcement showed about $700 \mu \varepsilon$ strain failure, which is considerably less than the expected strains in the compression steel for the walls tested at the low and intermediate eccentricity.

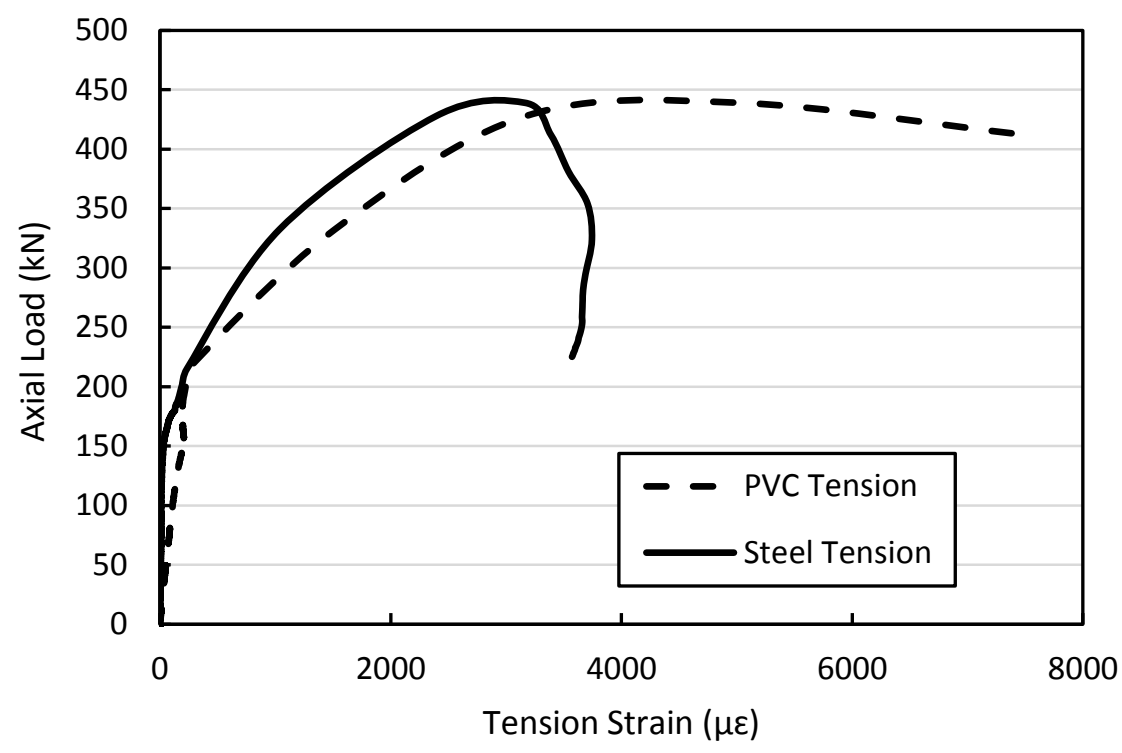

Figure 3.19 - Load versus tension strain readings for the PVC encased wall specimen (Oe2-10) 


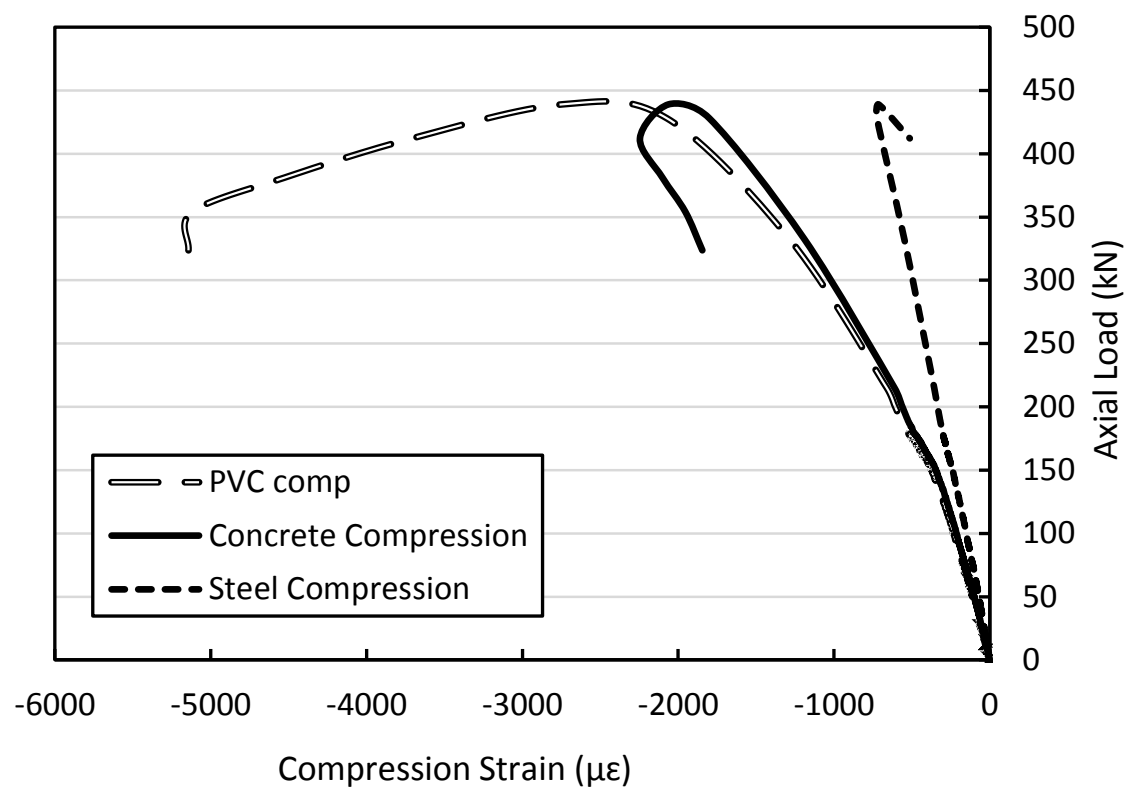

Figure 3.20 - Load versus compression strain readings for the PVC encased wall specimen $(\mathrm{O}-\mathrm{e} 2-10)$

Figures 3.21 and 3.22 compare the typical tension and compression strain gauge readings for the PVC panels at different eccentricities. It is clear that the tensile strain gauge readings on the PVC panels increased as the eccentricity increased (Figure 3.21). Thus, the PVC panels on the tension side showed higher contribution at larger eccentricities where the mode of failure shifted from a compression failure to a tension failure. For the wall specimens tested at an eccentricity of $101.6 \mathrm{~mm}$, both the tension and the compression strain gauge readings for the PVC panels showed a more ductile post peak response compared to those tested at eccentricities of $33.87 \mathrm{~mm}$ and $67.73 \mathrm{~mm}$ where a sharp drop was observed (Figures 3.21 and 3.22 ) .

For a given eccentricity, the strain gauge readings on the PVC panels at any intermittent load increased as the amount of reinforcement decreased (from $4-15 \mathrm{M}$ to $4-10 \mathrm{M}$ ) as shown in Figure 3.22. Therefore, the contribution of the PVC increased as the 
reinforcement ratio decreased. The distribution of the forces between the steel rebar and the PVC panel is based on the ratios of their cross sectional areas and Young's modulus. Therefore, as the steel rebar diameter increases, the steel cross sectional area increases and its contribution to resisting the tensile forces increases.

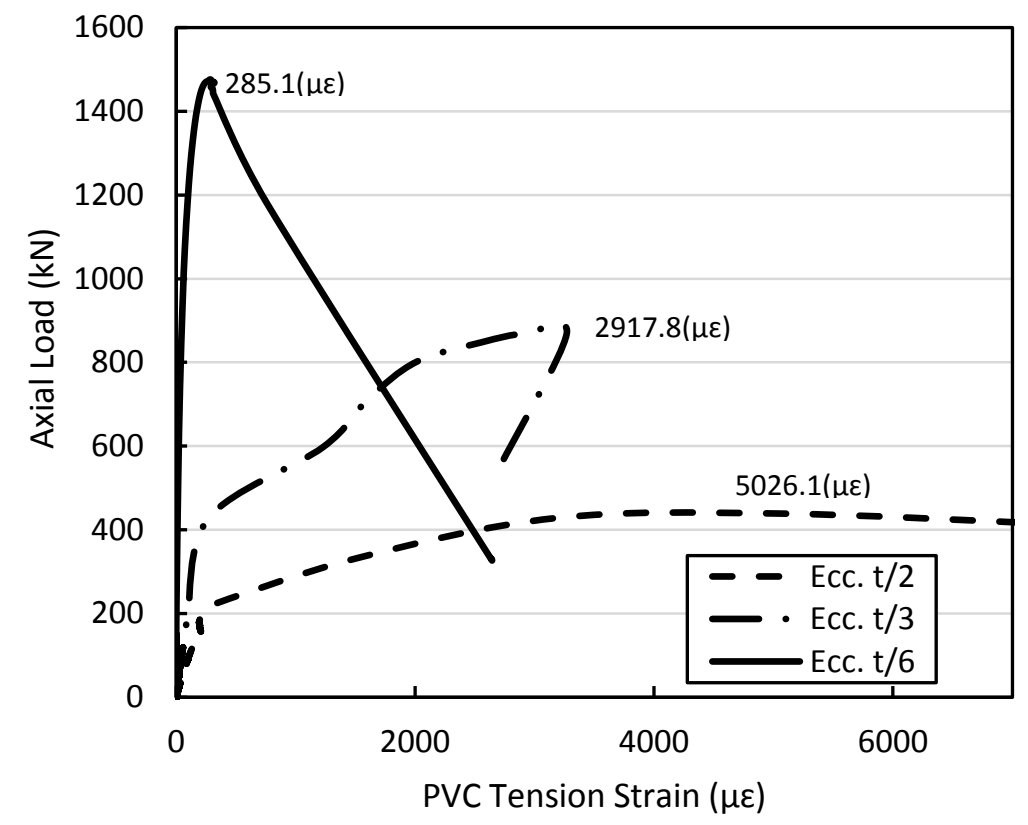

a- Tension strain

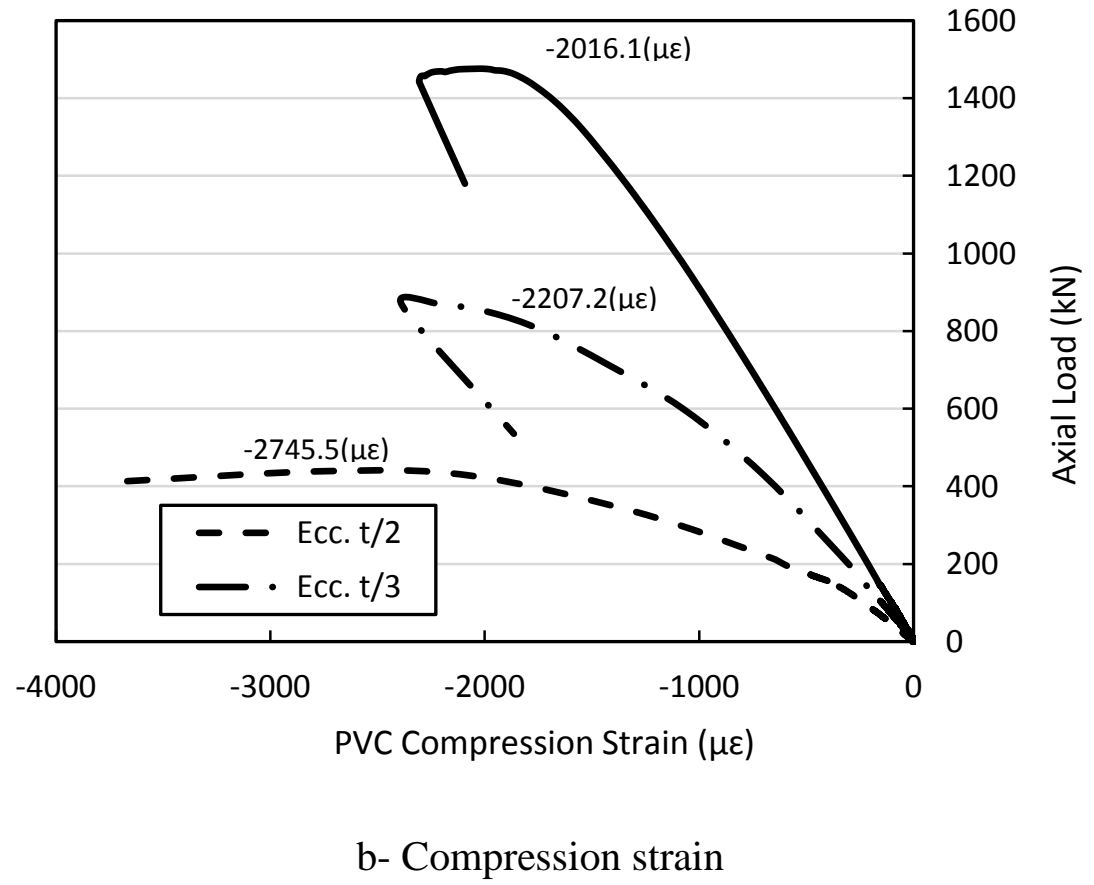

Figure 3.21 - Load versus PVC strain gauge readings at different eccentricities for the walls reinforced with $4-10 \mathrm{M}$ 


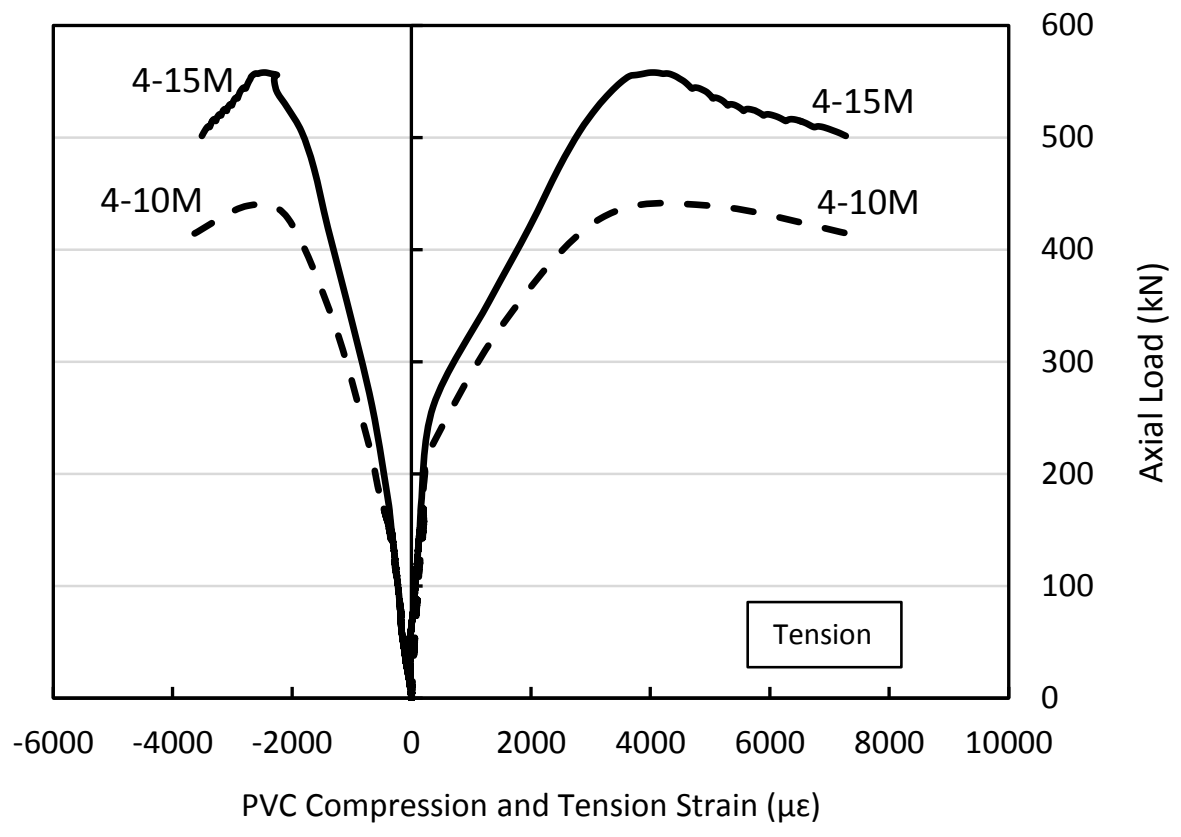

Figure 3.22 - Load versus PVC strain gauge readings at a given eccentricity for different reinforcement ratios (O-e2-10 and O-e2-15)

\subsubsection{Energy absorption capacity}

The energy absorption capacity at any given load level is proportional to the area under the load-deformation curve. This measure becomes vital when designing members that may be accidently overloaded.

The energy absorption capacity for a given wall was calculated as the area underneath the load vertical displacement curve until the peak load was attained. Table 3.3 shows the energy absorption capacity for all of the specimens and the percentage of increase in the absorption capacity for the PVC encased walls compared to the control walls. There is a significant enhancement in the energy absorption capacity of the PVC encased concrete walls compared to their equivalent control walls. 
The control walls reinforced with $4-10 \mathrm{M}$ and tested at different eccentricities of 33.87 $\mathrm{mm}, 67.73 \mathrm{~mm}$ and $101.6 \mathrm{~mm}$ showed an energy absorption capacity of $3857.3 \mathrm{kN} . \mathrm{mm}$, 2070.4 kN.mm and 1270.881 kN.mm, respectively. On the other hand, their equivalent PVC encased walls showed an energy absorption capacity of 4575.2 kN.mm, 2752.5 kN.mm and $1842.8 \mathrm{kN} . \mathrm{mm}$ at an applied eccentricity of $33.87 \mathrm{~mm}, 67.73 \mathrm{~mm}$ and 101.6 $\mathrm{mm}$, respectively. Hence, the PVC encased walls showed an increase in the energy absorption capacity of $18.6 \%, 32.9 \%$ and $45 \%$ at $33.87 \mathrm{~mm}, 67.73 \mathrm{~mm}$ and $101.6 \mathrm{~mm}$ eccentricity, respectively.

For the higher reinforcement ratio (4-15M), the control walls tested at an eccentricity of $33.87 \mathrm{~mm}, 67.73 \mathrm{~mm}$ and $101.6 \mathrm{~mm}$ showed an energy absorption capacity of 3648.9 kN.mm, 2804.3 kN.mm and 2214 kN.mm, respectively. The equivalent PVC encased walls showed an energy absorption capacity of $4183.8 \mathrm{kN} . \mathrm{mm}, 3311.2 \mathrm{kN} . \mathrm{mm}$ and $2332.2 \mathrm{kN} . \mathrm{mm}$ at an applied eccentricity of $33.87 \mathrm{~mm}, 67.73 \mathrm{~mm}$ and $101.6 \mathrm{~mm}$, respectively. The PVC encased walls showed an increase in the energy absorption capacity of $14.7 \%, 18.1 \%$ and $5.3 \%$ at $33.87 \mathrm{~mm}, 67.73 \mathrm{~mm}$ and $101.6 \mathrm{~mm}$ eccentricity, respectively.

For a given eccentricity, the effect of the PVC on increasing the energy absorption capacity was more significant for the walls reinforced with 4-10M than the walls reinforced with $4-15 \mathrm{M}$ as shown in Table 3.3. In addition, it is clear that the contribution of the PVC system is more noticeable at higher eccentricities where the increase in the energy absorption capacity was greater for the specimens tested at high eccentricities (67.73 $\mathrm{mm}$ and $101.6 \mathrm{~mm}$ ) compared to those tested at low eccentricities $(33.87 \mathrm{~mm})$. 
Table 3.3 - Energy absorption capacity

\begin{tabular}{|c|c|c|}
\hline Specimen & $\begin{array}{c}\text { Energy absorption capacity } \\
(\mathrm{kN} . \mathrm{mm})\end{array}$ & \multirow{2}{*}{ Percentage of increase } \\
\hline O-e6-10 & 4575.2 & $18.6 \%$ \\
\hline C-e6-10 & 3857.3 & \multirow{2}{*}{$32.9 \%$} \\
\hline O-e3-10 & 2752.5 & \multirow{2}{*}{$45 \%$} \\
\hline C-e3-10 & 2070.4 & \multirow{2}{*}{$15 \%$} \\
\hline O-e2-10 & 1842.8 & \multirow{2}{*}{$14.7 \%$} \\
\hline C-e2-10 & 1270.6 & $18.1 \%$ \\
\hline O-e6-15 & 4183.8 & \\
\hline C-e6-15 & 3648.9 & \multirow{2}{*}{$5.3 \%$} \\
\hline O-e3-15 & 3311.2 & \\
\hline C-e3-15 & 2804.3 & \\
\hline O-e2-15 & 2332.2 & \\
\hline C-e2-15 & 2214 & \\
\hline
\end{tabular}

\subsection{Sources of errors}

Based on the casting and testing phase in this study, the author identified some parameters that are crucial for this type of testing and that may affect the test results. In this section, the possible sources of errors that affect the accuracy of the results are presented and discussed.

- There is a difference in the compressive strength between the PVC encased specimens and the control specimens. The PVC components present in this configuration (panels with middle connectors) may not result in a full consolidation of the concrete compared to the control specimens. However, in this study, the PVC encasement was removed at multiple sections and the specimens were fully consolidated.

- The axial tests are known to be affected greatly by the concrete strength. In this study, the same mix was used for two different batches but the results were not identical. This was noticed when the same specimens were tested twice from two 
different batches. There was a difference in the peak loads by 80 to $121 \mathrm{kN}$ (about $10 \%$ to $15 \%$ of the capacity of the specimen).

- The ends of the walls were cast against smooth levelled surfaces to ensure full contact between the ends of the walls and the steel plates during testing. However, the differences in heights between the components of the PVC system (panels and connectors), even if minimal, could cause an uneven applied load during testing causing an un-equal stress distribution and leading to premature failure of the specimen. Hence, capping and levelling the ends using a filler material is crucial (hydrostone was used here).

- The initial out-of-straightness of the wall may cause an additional eccentricity (uni-axial or bi-axial loading). The out-of-straightness in this study was associated with the end plates holes clearance tolerance that could vary from one specimen to another.

- The inclination of the wires of the string pots during testing may lead to an inaccurate reading of the mid span and vertical displacements. 


\section{Chapter 4: Analysis}

\subsection{Introduction}

This chapter presents a model to predict the behaviour of the reinforced concrete specimens with and without the PVC encasement. The model is based on the equilibrium of forces to predict the peak load. It can also be used to calculate the strains in the concrete and the steel at failure using different eccentricities.

\subsection{Assumptions of the model}

The following assumptions were employed in the analysis of the reinforced concrete sections subjected to combined axial compression and flexural load.

- Plane sections remained plane before and after bending.

- Tensile strength of the concrete was neglected.

- Concrete was assumed to fail in compression when the strain reached the crushing strain $\left(\varepsilon_{\mathrm{c}}=0.0035\right)$.

- Maximum tensile stress in the steel reinforcement was taken equal to the yield stress of the steel.

- Perfect bond existed between the concrete, steel and the PVC panels until failure.

- Contribution of the PVC panels in resisting the compression forces was neglected however its contribution is considered in tension.

\subsection{Behaviour of the materials}

\subsubsection{Concrete}

The relationship between the stress in the concrete and its corresponding strain can be expressed according to Equation 4.1 (Collins and Mitchell 1987). 


$$
f_{c}=f^{\prime}{ }_{c}\left[\frac{2 \varepsilon}{\varepsilon_{0}}-\left[\frac{\varepsilon}{\varepsilon_{0}}\right]^{2}\right]
$$

Eq.4.1

$$
\begin{gathered}
\varepsilon_{0}=\frac{2 f^{\prime}{ }_{c}}{E_{c}} \\
E_{c}=4500 \sqrt{f^{\prime}{ }_{c}}
\end{gathered}
$$

Where;

$f_{c}$ : the concrete stress corresponding to a given concrete strain $(\varepsilon)$

$f_{c}^{\prime}:$ the concrete compressive strength (MPa)

$\varepsilon:$ the concrete strain corresponding to a given concrete stress $\left(f_{c}\right)$

$\varepsilon_{o}:$ the concrete strain corresponding to the concrete compressive strength

$E_{c}$ : the Young's modulus of concrete

The actual concrete compressive stress in the compression zone can be simplified by replacing it with an equivalent rectangular block (Figure 4.1). This block can be obtained by using the stress-block factors $\left(\alpha_{1}\right.$ aand $\left.\beta_{1}\right)$ given by Equations 4.2 (Collins and Mitchell 1987)

Eq.4.2

$$
\alpha_{1} * \beta_{1}=\frac{2 \varepsilon}{\varepsilon_{0}}-\frac{1}{3}\left[\frac{\varepsilon}{\varepsilon_{0}}\right]^{2}
$$

$$
\beta_{1}=\frac{4-\frac{\varepsilon}{\varepsilon_{0}}}{6-\frac{2 * \varepsilon}{\varepsilon_{0}}}
$$

Where;

$\alpha_{1}$ : ratio of the average stress in the compression stress block to the concrete strength

$\beta_{1}$ : ratio of the depth of the compression stress block to the depth of the neutral axis 


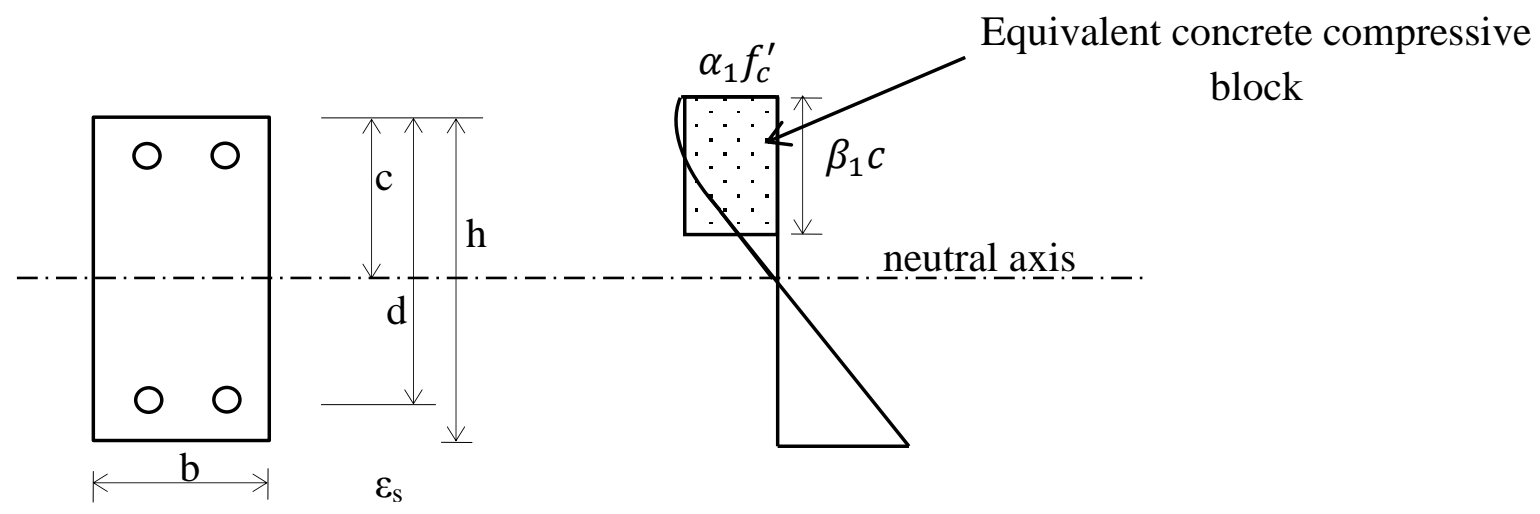

Figure 4.1 - Equivalent compressive stress in concrete

Based on CSA A23.3-04, at ultimate state, the compression stress block factors can be taken according to Equation 4.3.

$$
\alpha_{1}=0.85-0.0015 f^{\prime}{ }_{c} \geq 0.67
$$

Eq.4.3

$$
\beta_{1}=0.97-0.0025 f^{\prime}{ }_{c} \geq 0.67
$$

\subsubsection{Steel}

The tension and compression reinforcement are assumed to be elastic-perfectly plastic.

Equation 4.4 defines the relationship between the steel versus the corresponding strain.

Eq.4.4

$$
f_{s}= \begin{cases}\varepsilon_{s} E_{s} & \varepsilon_{s} \leq \varepsilon_{y} \\ f_{y} & \varepsilon_{s} \geq \varepsilon_{y}\end{cases}
$$

Where;

$f_{s}$ : steel stress corresponding to a given steel strain $\left(\varepsilon_{s}\right)$

$f_{y}$ : steel yield stress corresponding to the yield strain $\left(\varepsilon_{y}\right)$

$\varepsilon_{s}:$ steel strain corresponding to a given steel stress $\left(\mathrm{f}_{\mathrm{s}}\right)$

$\varepsilon_{y}$ : steel yield strain corresponding to the yield stress $\left(f_{y}\right)$

$E_{s}$ : Young's modulus for the steel before yielding (pre-yielding stage), taken equal to $200 \mathrm{GPa}$ 


\subsubsection{PVC}

Figure 4.2 shows the relationship between the strain and the stress of the PVC material.

The relationship between the strain and the stress in the PVC is expressed according to Equation 4.5(Wahab and Soudki 2013).

Eq.4.5

$$
f_{P V C}=-71518 \varepsilon_{P V C}^{2}+3412.1 \varepsilon_{P V C}
$$

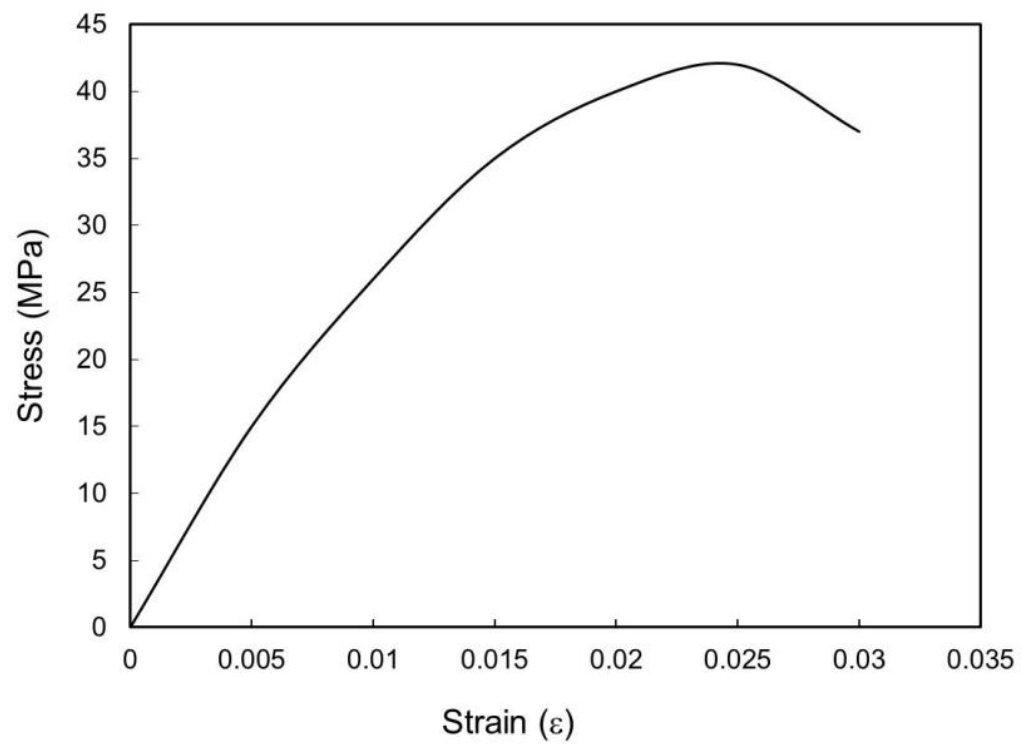

Figure 4.2 - Stress-strain relation for the PVC (Wahab and Soudki 2013)

\subsection{Sectional analysis neglecting the confinement effect of the PVC encasement}

The strain and the stress distribution at the peak load depended on the mode of failure.

Three modes of failure were identified as follows;

\section{Tension failure}

The steel reinforcement yielded then the concrete reached the crushing strain $\left(\varepsilon_{c}=\right.$ 0.0035). For the PVC encased walls, buckling of the PVC panels occurred after crushing 
of the concrete. This mode of failure was observed for specimens tested at the highest eccentricities in addition to some walls with an intermediate eccentricity.

$\Rightarrow$ At failure: $\varepsilon_{s}>\varepsilon_{y}, \varepsilon_{c}=0.0035$

\section{Compression failure}

Concrete crushed $\left(\varepsilon_{c}=0.0035\right)$ before steel yielded. For the PVC encased walls, buckling of the PVC panels occurred after crushing of the concrete. This mode of failure was observed for sections tested at the lowest eccentricities in addition to some walls with intermediate eccentricities.

$\rightarrow$ At failure: $\varepsilon_{s}<\varepsilon_{y}, \varepsilon_{c}=0.0035$

\section{Balanced failure}

It is the mode of failure that separates the tension failure from the compression failure. The strain in the steel reached the yield strain $\left(\varepsilon_{y}\right)$ and the strain in the concrete reached the crushing strain at the same time. For the PVC encased walls, buckling of the PVC occurred after crushing of the concrete. This mode of failure was observed for one PVC encased wall reinforced with $4-10 \mathrm{M}$ and tested at the intermediate eccentricity.

$\rightarrow$ At failure: $\varepsilon_{s}=\varepsilon_{y}, \varepsilon_{c}=0.0035$

Therefore, the failure occurred for the control and the PVC encased wall specimens when the concrete reached the crushing strain in compression $\left(\varepsilon_{c}=0.0035\right)$.

Cracked sectional analysis was carried out based on the strain and the stress compatibility to define the strength of the section. The strain in each material (steel, concrete and PVC) 
at any location was determined by assuming a linear strain distribution and a failure mode as shown in Figure 4.3 and Equation 4.6.

Eq.4.6

$$
\frac{\varepsilon_{c}}{c}=\frac{\varepsilon_{s}^{\prime}}{c-d^{\prime}}=\frac{\varepsilon_{S}}{d-c}=\frac{\varepsilon_{P V C}}{h-c}
$$

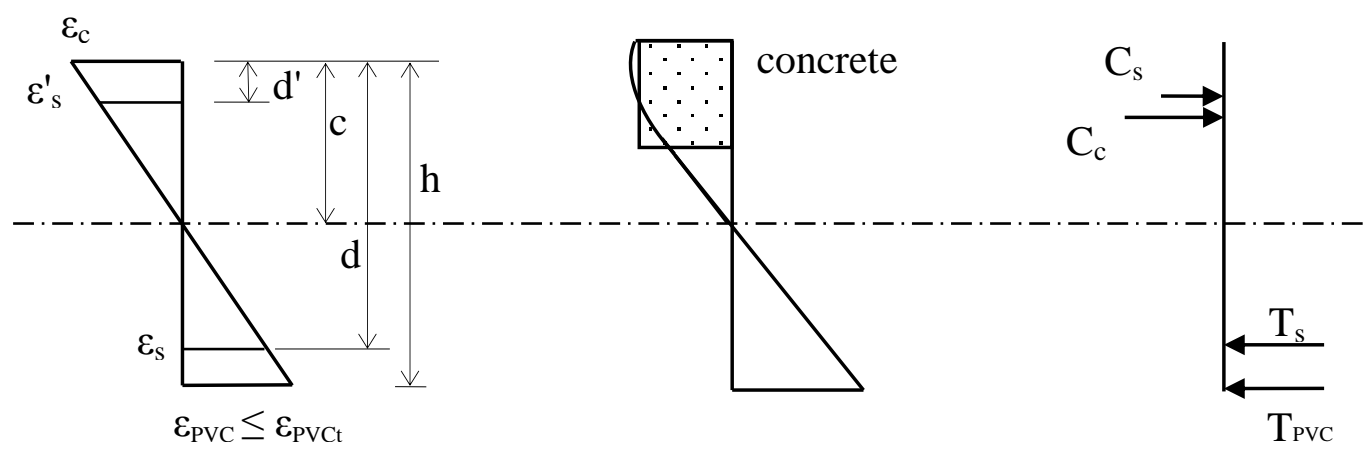

Figure 4.3 - Strain, stress and internal force distribution for specimens subjected to combined flexure and axial loads

The forces and stresses in the steel reinforcement and the PVC panels were calculated using Equation 4.7. Then, the position of the neutral axis (c) was determined using the equilibrium of the internal forces and external forces as shown in Equation 4.8.

Eq.4.7

$$
C_{c}=\alpha_{1} f^{\prime} b \beta_{1} c
$$

$$
\begin{array}{ll}
C_{s}=\varepsilon_{s}^{\prime} E_{s} A^{\prime}{ }_{s} & \varepsilon_{s}^{\prime} \leq \varepsilon_{y} \\
C_{s}=f_{y} A^{\prime}{ }_{s} & \varepsilon_{s}^{\prime} \geq \varepsilon_{y}
\end{array}
$$

$$
\begin{array}{ll}
T_{s}=\varepsilon_{s} E_{s} A_{s} & \varepsilon_{s} \leq \varepsilon_{y} \\
T_{s}=f_{y} A_{s} & \varepsilon_{s} \geq \varepsilon_{y}
\end{array}
$$

$$
T_{P V C}=A_{P V C} f_{P V C}
$$

Eq.4.8

$$
P=C_{C}+C_{s}-T_{s}-T_{P V C}
$$

$$
M=C_{c}\left(\frac{h}{2}-\beta_{1} \frac{c}{2}\right)+C_{s}\left(\frac{h}{2}-d^{\prime}\right)+T_{s}\left(\frac{h}{2}-d\right)+T_{P V C}\left(\frac{h}{2}\right)
$$


Where;

$C_{c}$ : concrete compression force $(\mathrm{N})$

$C_{S}$ : steel compression force $(\mathrm{N})$

$\varepsilon_{s}^{\prime}$ : strain in the compression steel

$\varepsilon_{s}:$ strain in the tension steel

$T_{s}$ : steel tension force $(\mathrm{N})$

$A_{P V C}$ : area of the PVC $\left(\mathrm{mm}^{2}\right)$

$A_{s}$ : area of the tension steel $\left(\mathrm{mm}^{2}\right)$
$A^{\prime}{ }_{s}$ : area of compression steel $\left(\mathrm{mm}^{2}\right)$

$h$ : depth of the section (mm)

$c$ : position of the neutral axis (mm)

$T_{P V C}:$ PVC tension force $(\mathrm{N})$

$d^{\prime}$ : depth of the compression steel (mm)

$P:$ resistance force of the section $(\mathrm{N})$

$M$ : moment resistance of the section (N.mm)

The specimen tested here represented a strip from a reinforced concrete wall. The reinforcement provided in this study reflected that representation as well. However, since the dimensions of the specimen were $203.2 \mathrm{~mm}$ thick by $304.8 \mathrm{~mm}$ wide by $1829 \mathrm{~mm}$ long, the specimens were considered as slender columns to account for the P- $\Delta$ effect.

Slender columns have a small relative cross section relative to the height. In these columns, secondary stresses associated with the column deformations become significant. Slender columns are subjected to an increase in the bending moment compared to those calculated by the first order structural analysis. Different codes provide different equations relating the column's length and stiffness to the applied load to account for the slenderness effects. Based on CSA A23.3-04, the slenderness effects can be ignored for columns if Equation 4.7 is satisfied. However, based on Equation 4.9, the specimens in this study are considered as slender columns.

Eq.4.9

$$
\frac{k l_{u}}{r} \leq \frac{25-10(M 1 / M 2)}{\sqrt{P / f_{c}^{\prime} A_{g}}}
$$


Where;

$k$ : effective length factor for columns

$l_{u}$ : un-supported length of the column (mm)

$r$ : radius of gyration $(\mathrm{mm})$
$P$ : resistance force of the section $(\mathrm{N})$

$f^{\prime}{ }_{c}$ : concrete compressive strength $(\mathrm{MPa})$

$A_{g}:$ area of the gross section $\left(\mathrm{mm}^{2}\right)$

$M 1 / M 2$ : ratio of smaller to larger end moments

A slender column under the influence of eccentric axial load will have a deformation at mid-span, in addition to the end moment, which will be affected by the length and stiffness of the column. The moment magnification method was used to magnify the end moments to account for the secondary stresses and include the P- $\Delta$ effect as shown in Equation 4.10 (Chahrour and Soudki 2006).

Eq.4.10

$$
M_{c}=\text { magnification factor } \times M
$$

$$
M_{c}=\frac{1}{1-\frac{P}{P_{c}}} M
$$

Where:

$M$ : maximum moment due to applied loads but not including $\mathrm{P}-\Delta$ effect (N.mm)

$M_{c}:$ applied moment (N.mm)

$P_{c}$ : Euler buckling load (N)

$P$ : axial load applied at the ends of the walls (N)

The Euler buckling load is a function of the unsupported length of the specimen $\left(l_{u}\right)$, Young's modulus $(E)$ and the moment of inertia of the cross section $(I)$ as given by 
Equation 4.11. The inertia of the cross section of the concrete column is calculated using Equation 4.12 (CSA A23.3-04).

Eq.4.11

$$
P_{c}=\frac{\pi^{2} E I}{\left(K l_{u}\right)^{2}}
$$

Eq.4.12

$$
E I=\frac{0.2 E_{c} I_{g}+E_{s} I_{s t}}{1+\beta_{d}}
$$

Where;

$E_{c}$ : concrete modulus of elasticity $\left(\mathrm{N} / \mathrm{mm}^{2}\right)$

$E_{S}:$ steel modulus of elasticity $\left(\mathrm{N} / \mathrm{mm}^{2}\right)$

$I_{g}:$ moment of inertia of the gross section $\left(\mathrm{mm}^{4}\right)$

$I_{s t}:$ moment of inertia if reinforcement about the cross-sectional centroid $\left(\mathrm{mm}^{4}\right)$

$\beta_{d}$ : ratio of the maximum factored axial dead load to the total factored axial load $k$ : effective length factor for columns

The magnification factor is the ratio between the total moment at mid-span to the end applied moment. Based on the experimental mid span deflection and knowing the applied eccentricity and peak loads, the total moment at the mid height of all of the specimens can be computed. Also, the maximum moment due to applied loads not including $\mathrm{P}-\Delta$ effect is known and equal to the applied load multiplied by the eccentricity. Therefore, the experimental magnification factor can be computed for the control and the PVC encased walls. The results are provided in Table 4.1. It is clear that for a given reinforcement ratio and eccentricity, the magnification factor for the control and the PVC encased walls is 
almost the same. Therefore, for any PVC encased wall, the magnification factor is taken equal to its peer control wall.

Table 4.1 - Magnification factor for both the control and the PVC encased walls

\begin{tabular}{|c|c|c|c|c|c|c|c|}
\hline & Specimen & $\begin{array}{c}\text { Eccentricity } \\
(\mathrm{mm})\end{array}$ & $\begin{array}{l}\text { Mid-span } \\
\text { deflection } \\
\quad(\mathrm{mm})\end{array}$ & $\begin{array}{c}\text { Experimental } \\
\text { peak Load } \\
(\mathrm{kN})\end{array}$ & $\begin{array}{l}\text { Moment at } \\
\text { mid-span } \\
\text { (kN.mm) }\end{array}$ & $\begin{array}{l}\text { Moment } \\
\text { at the } \\
\text { ends } \\
\text { (kN.mm) }\end{array}$ & $\begin{array}{l}\text { Mag.* } \\
\text { factor }\end{array}$ \\
\hline \multirow{7}{*}{ 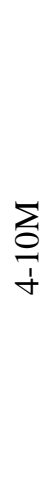 } & C-e6-10 & \multirow{2}{*}{33.87} & 9 & 1445.1 & 61951.4 & 48945.5 & 1.265 \\
\hline & O-e6-10 & & 7.3 & 1475.9 & 60762.8 & 49988.73 & 1.215 \\
\hline & C-e3-10 & \multirow{3}{*}{67.73} & 16.4 & 677.9 & 57031.7 & 45914.2 & 1.242 \\
\hline & O-e3-10 & & 11.8 & 990.3 & 78758.6 & 67073 & 1.174 \\
\hline & O-e3-10 & & 13.4 & 869.3 & 70526.3 & 58877.7 & 1.197 \\
\hline & C-e2-10 & \multirow{2}{*}{101.6} & 20.9 & 374.8 & 45913 & 38079.7 & 1.205 \\
\hline & O-e2-10 & & 22.7 & 438.9 & 54555.3 & 44592.3 & 1.223 \\
\hline \multirow{7}{*}{$\frac{\sum}{\frac{i}{7}}$} & C-e6-15 & \multirow{2}{*}{33.87} & 8.3 & 1266.7 & 53416.74 & 42903.1 & 1.245 \\
\hline & O-e6-15 & & 7.5 & 1393.5 & 57649.1 & 47197.8 & 1.221 \\
\hline & C-e3-15 & \multirow{3}{*}{67.73} & 15.4 & 856 & 57992.3 & 54976.9 & 1.227 \\
\hline & O-e3-15 & & 7.2 & 624.6 & 46801.3 & 42304.2 & 1.106 \\
\hline & O-e3-15 & & 14.3 & 905 & 74237.2 & 61295.7 & 1.211 \\
\hline & C-e2-15 & \multirow{2}{*}{101.6} & 23.2 & 504.1 & 62911.7 & 51216.6 & 1.228 \\
\hline & O-e2-15 & & 20.3 & 557.9 & 68008 & 56682.6 & 1.199 \\
\hline
\end{tabular}

*: stands for magnification factor

\section{Calculation steps:}

1- Knowing the material properties, calculate the compression block factors

$$
\begin{aligned}
& \alpha_{1}=0.85-0.0015 f^{\prime}{ }_{c} \geq 0.67 \\
& \beta_{1}=0.97-0.0025 f^{\prime}{ }_{c} \geq 0.67
\end{aligned}
$$

2- Knowing the dimensions of the section, calculate Euler buckling load

$$
P_{c}=\frac{\pi^{2} E I}{\left(K l_{u}\right)^{2}}
$$


3- Assume the concrete strain equal to the crushing strain (0.0035)

4- Assume $c=5 \mathrm{~mm}$

5- Using strain compatibility, find the strains in the PVC and steel

$$
\frac{\varepsilon_{c}}{c}=\frac{\varepsilon_{S}^{\prime}}{c-d^{\prime}}=\frac{\varepsilon_{S}}{d-c}=\frac{\varepsilon_{P V C}}{h-c}
$$

6- Calculate the forces in the concrete, steel and the PVC

7- Using the force equilibrium equation, find the external applied load $(\mathrm{P})$ and the moment (M)

$$
\begin{gathered}
P=C_{c}+C_{s}-T_{s}-T_{P V C} \\
M=C_{c}\left(\frac{h}{2}-\beta_{1} \frac{c}{2}\right)+C_{s}\left(\frac{h}{2}-d^{\prime}\right)+T_{s}\left(\frac{h}{2}-d\right)+T_{P V C}\left(\frac{h}{2}\right)
\end{gathered}
$$

8- Calculate the magnification factor and the applied moment including P- $\Delta$ effect $\left(M_{c}\right)$

$$
M_{c}=\frac{1}{1-\frac{P}{P_{c}}} * P * e
$$

9- If; $M_{c} \neq M$, then increase c by $1 \mathrm{~mm}$ and repeat steps 2 to 8 .

- If; $M_{c}=M$, then the solution is correct.

The above procedure is summarized in a flowchart as shown in Figure 4.4 


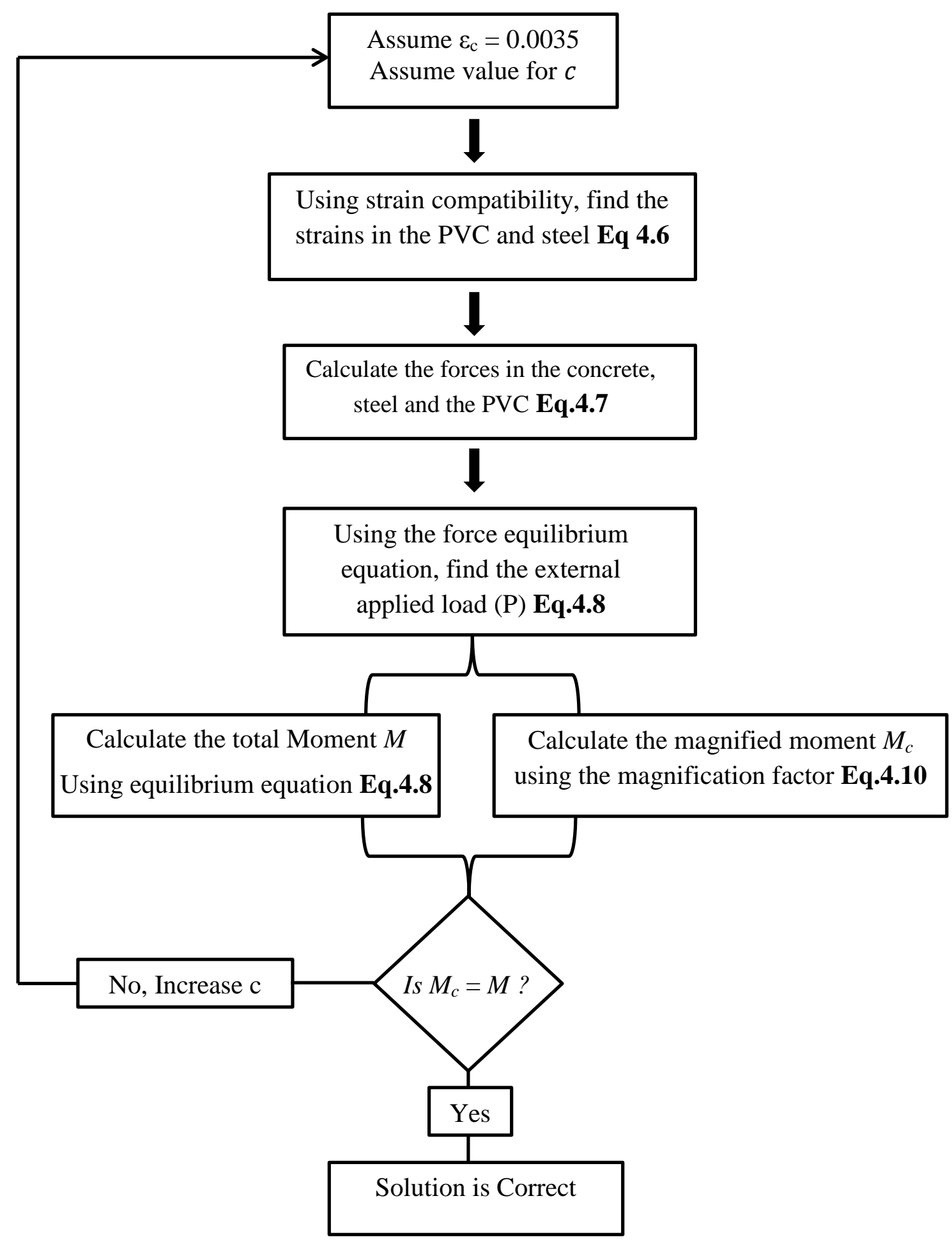

Figure 4.4 - Calculation steps for unconfined wall specimens 


\subsection{Comparison between the experimental and calculated results}

Initially, the peak load was calculated for all of the control and the PVC encased specimens by ignoring the confinement effect of the PVC encasement. The results are presented in Table 4.2. The calculated peak load showed a good correlation with the experimental peak load for the control walls (Figure 4.5). The calculated peak loads were conservative by an average error of $7.7 \%$. For the PVC encased walls, the calculated peak loads were too conservative. They were less than the experimental test results by $16 \%$ on average (a maximum of $28 \%$ ).

Table 4.2 - Experimental and calculated peak loads

\begin{tabular}{|c|c|c|c|c|c|c|}
\hline & Specimen & Batch & Collar & $\begin{array}{c}\text { Experimental } \\
\text { Peak Load } \\
(\mathrm{kN})\end{array}$ & $\begin{array}{c}\text { Calculated } \\
\text { Peak Load } \\
(\mathrm{kN})\end{array}$ & $\begin{array}{c}\text { Percentage } \\
\text { Difference } \\
(\%)\end{array}$ \\
\hline \multirow{8}{*}{$\frac{\sum_{0}}{\dot{f}}$} & C-e6-10 & Batch1 & Present & 1445.1 & 1145.23 & 20.8 \\
\hline & O-e6-10 & Batch1 & Absent & 1339.7 & -- & -- \\
\hline & O-e6-10 & Batch 2 & Present & 1475.9 & 1148.5 & 22.1 \\
\hline & C-e3-10 & Batch1 & Present & 677.9 & 654.26 & 3.5 \\
\hline & O-e3-10 & Batch1 & Present & 990.3 & \multirow{2}{*}{669} & \multirow{2}{*}{28} \\
\hline & O-e3-10 & Batch 2 & Present & 869.3 & & \\
\hline & C-e2-10 & Batch1 & Present & 374.8 & 356.58 & 4.9 \\
\hline & O-e2-10 & Batch 2 & Present & 438.9 & 381.6 & 13 \\
\hline \multirow{8}{*}{$\frac{\sum}{\frac{i}{7}}$} & C-e6-15 & Batch1 & Absent & 1266.7 & 1271.9 & 0.41 \\
\hline & O-e6-15 & Batch1 & Absent & 1393.5 & 1274.3 & 8.6 \\
\hline & C-e3-15 & Batch1 & Present & 856 & 789.69 & 7.74 \\
\hline & O-e3-15 & Batch1 & Absent & 624.6 & -- & -- \\
\hline & O-e3-15* & Batch1 & Present & 984 & \multirow{2}{*}{794.5} & \multirow{2}{*}{15.9} \\
\hline & O-e3-15 & Batch 2 & Present & 905 & & \\
\hline & C-e2-15 & Batch1 & Present & 504.1 & 497.41 & 1.32 \\
\hline & O-e2-15 & Batch 2 & Present & 557.9 & 510.9 & 8.4 \\
\hline
\end{tabular}

*: An average value of the peak load was used for duplicate specimens 


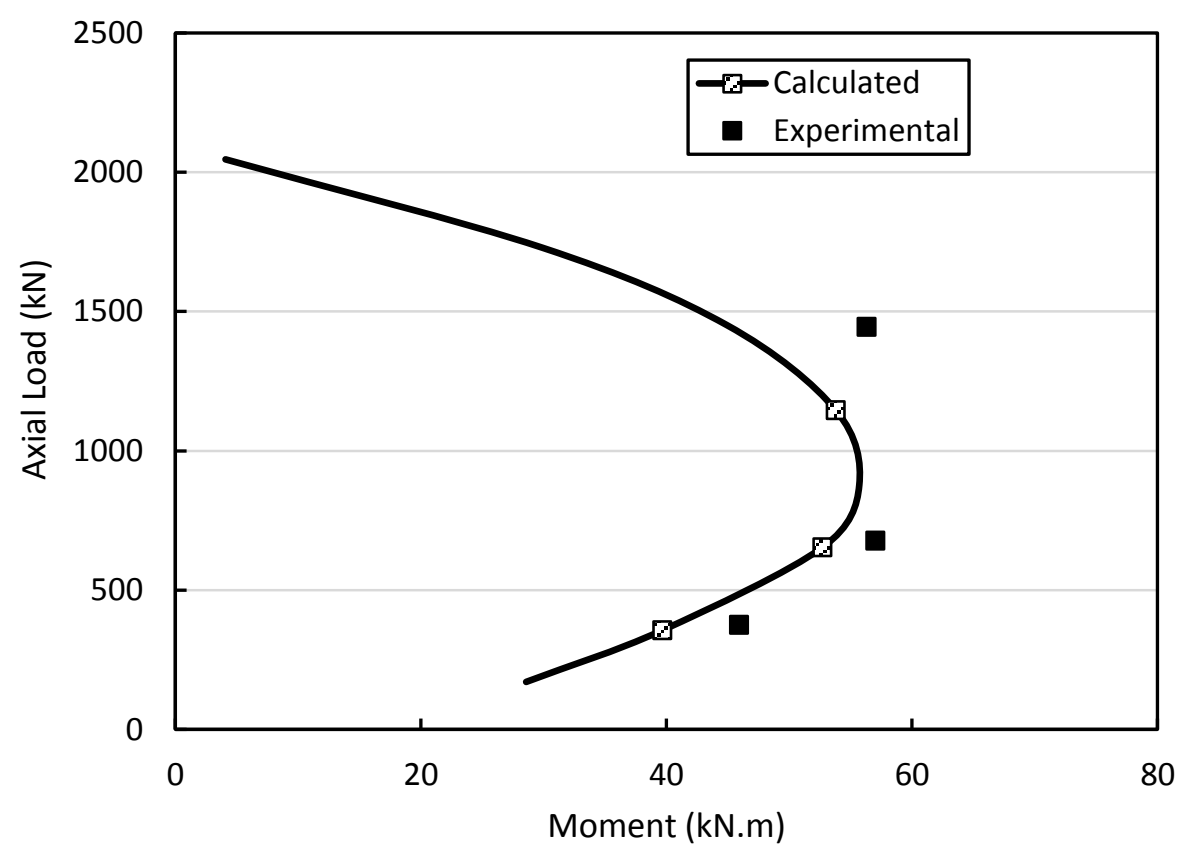

a- Walls reinforced with 4-10M

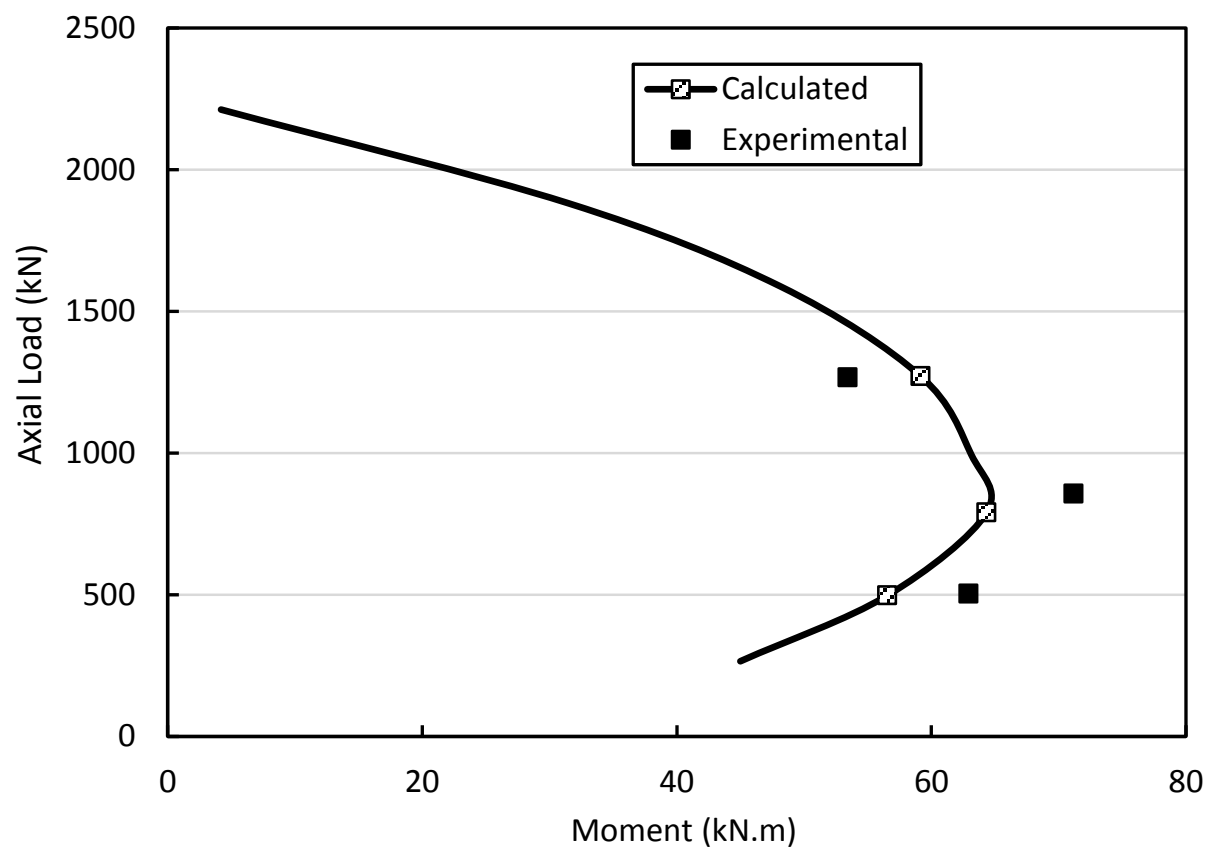

b- Walls reinforced with $4-15 \mathrm{M}$

Figure 4.5 - Interaction diagram for control walls 


\subsection{Sectional analysis including the PVC confinement effect}

Kuder et al. (2006 and 2009) and Gupta et al. (2009) investigated the confinement effect for the same configuration of the PVC panels and connectors used in this study (See Chapter 2). They reported that this particular configuration increased the axial load capacity (confinement effect of the PVC system) by $23 \%$ to $25 \%$ over the control specimens. On the other hand, for eccentrically loaded columns, Pham et al. (2013) reported that the confinement effect decreased as the eccentricity increased for reinforced concrete columns wrapped with fiber reinforced polymer (FRP) sheets. The FRP wraps increased the axial capacity for the concentrically loaded columns by 200 to $400 \%$ depending on the column's configuration. However, the increase was only 132 to $274 \%$ when the same columns were loaded under eccentric loading. It is clear that as the applied eccentricity increases, the confinement effect decreases.

In this study, when the confinement effect was initially taken equal to zero, the calculated results were too conservative (See Table 4.4). Based on the literature, the confinement effect under concentric axial load for the same PVC encasement used here was about $20 \%$. In the current study, the load was applied at different eccentricities. It is expected that the confinement effect decreases as the eccentricity increases (Pham et al. 2013). This was confirmed by conducting the sectional analysis and assuming the PVC confinement effect to be equal to $20 \%$. The calculated peak loads were close to the experimental peak loads but on the un-conservative side (calculated load higher than experimental load). Pham et al. (2013) reported a reduction in the confinement effect by $40 \%$ when the eccentricity was increased from zero to $25 \mathrm{~mm}(t / 6$ of the specimen's thickness). Due to the lack of data of PVC encased walls, the confinement effect of the PVC was approximately estimated to increase the axial load capacity by $10 \%$ at all 
eccentricities. Using a $10 \%$ confinement effect, the calculated loads were in good agreement with the experimental results as explained in the next section.

The analysis was repeated for all of the PVC encased walls to account for the confinement effect of the PVC system. Section analysis was carried out based on the stress and the strain compatibility to define the strength of the section. To account for the confining effect of the PVC, the strength of the confined concrete $\left(f^{\prime}{ }_{c c}\right)$ was taken equal to $1.1 f^{\prime}{ }_{c}$. The stress, strain and force distribution related to the analysis of the PVC encased specimens are illustrated in Figure 4.6, where the PVC contributes to the tension forces and provides confinement.

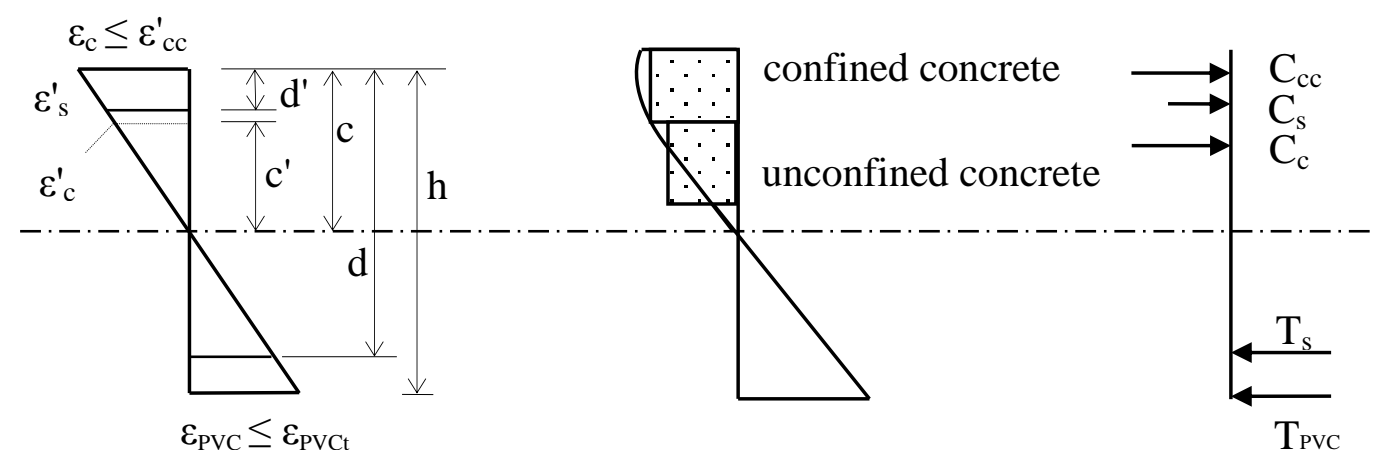

Figure 4.6 - Strain, stress and internal force distribution for PVC encased specimens subjected to combined flexure and axial load

Three modes of failure were defined, as follows;

\section{Tension failure}

Steel reinforcement yielded followed by the concrete reaching the maximum confined strain $\varepsilon^{\prime}{ }_{c c}$, then buckling of the PVC

$\Rightarrow$ At failure: $\varepsilon_{s}<\varepsilon_{y}, \varepsilon_{c}=\varepsilon^{\prime}{ }_{c c}$ 


\section{Compression failure}

Concrete crushed $\left(\varepsilon_{c}=\varepsilon^{\prime}{ }_{c c}\right)$ followed by buckling of the PVC, before yielding of the steel

$\Rightarrow$ At failure: $\varepsilon_{s}<\varepsilon_{y}, \varepsilon_{c}=\varepsilon_{c c}^{\prime}$

\section{Balanced failure}

Steel yielded and the concrete crushed, followed by bucking of the PVC

$\rightarrow$ At failure: $\varepsilon_{s}=\varepsilon_{y}, \varepsilon_{c}=\varepsilon^{\prime}{ }_{c c}$

The failure occurred for the PVC encased wall specimens when the concrete reached the maximum confined strain $\left(\varepsilon^{\prime}{ }_{c c}\right)$ in compression. The maximum confined strain was estimated by De Lorenzis and Tepfers (2003) (Equation 4.13).

Eq.4.13

$$
\frac{\varepsilon^{\prime}{ }_{c c}}{\varepsilon^{\prime}{ }_{c}}=5\left[\frac{f^{\prime}{ }_{c c}}{f^{\prime}{ }_{c}}-1\right]+1
$$

The strain in each material (steel, concrete and steel) at any location was determined by assuming a linear strain relation (Equation 4.14).

Eq.4.14

$$
\frac{\varepsilon_{c}}{c}=\frac{\varepsilon^{\prime}{ }_{c}}{c^{\prime}}=\frac{\varepsilon^{\prime}{ }_{s}}{c-d^{\prime}}=\frac{\varepsilon_{s}}{d-c}=\frac{\varepsilon_{P V C}}{h-c}
$$

The forces in the PVC and steel were estimated using Equation 4.7. However, the force in the concrete was divided into the force in the confined concrete $\left(C_{c c}\right)$ and Unconfined concrete $\left(C_{c}\right)$ using Equation 4.15 (ISIS Canada 2009).

Eq.4.15

$$
\begin{gathered}
C_{c c}=\phi_{c} \frac{f^{\prime}{ }_{c}+f^{\prime}{ }_{c c}}{2} b\left[C-\frac{c}{\varepsilon^{\prime}{ }_{c c}} \varepsilon^{\prime}{ }_{c}\right] \\
C_{c}=\phi_{c} \alpha_{1} f^{\prime}{ }_{c} b \beta_{1}\left[\frac{c}{\varepsilon^{\prime}{ }_{c c}} \varepsilon^{\prime}{ }_{c}\right]
\end{gathered}
$$


The position of the neutral axis $(c)$ and the applied load $(P)$ can be determined using the equilibrium of the internal forces and external forces using Equation 4.16 (ISIS Canada 2009).

$$
P=C_{c C}+C_{c}+C_{s}-T_{s}-T_{P V C}
$$

Eq. 4. 16

$$
\begin{aligned}
& M=C_{c c}\left(\frac{h}{2}-\left[c-\frac{C}{\varepsilon^{\prime}{ }_{c c}} \varepsilon^{\prime}{ }_{c}\right] \frac{2 f^{\prime}{ }_{c}+f^{\prime}{ }_{c c}}{3 f^{\prime}{ }_{c}+3 f^{\prime}{ }_{c c}}\right)+C_{c}\left(\left[\frac{h}{2}-C\right]\right. \\
& \left.+\left[1-\frac{\beta_{1}}{2}\right]\left[\frac{C}{\varepsilon^{\prime} \varepsilon_{c c}^{\prime}}{ }_{c}\right]\right) \\
& +C_{s}\left(\frac{h}{2}-d^{\prime}\right)+T_{s}\left(\frac{h}{2}-d\right)+T_{P V C}\left(\frac{h}{2}\right)
\end{aligned}
$$

\section{Calculation steps for the PVC encased walls accounting for the confinement effect:}

1- Knowing the material properties, calculate the compression block factors

$$
\begin{aligned}
& \alpha_{1}=0.85-0.0015 f^{\prime}{ }_{c} \geq 0.67 \\
& \beta_{1}=0.97-0.0025 f^{\prime}{ }_{c} \geq 0.67
\end{aligned}
$$

2- Calculate Euler buckling load for the peer control wall tested at the same eccentricity

$$
P_{c}=\frac{\pi^{2} E I}{\left(K l_{u}\right)^{2}}
$$

3- Calculate the concrete crushing strain $\left(\varepsilon^{\prime}{ }_{c c}\right)$

$$
\frac{\varepsilon^{\prime}{ }_{c c}}{\varepsilon^{\prime}{ }_{c}}=5\left[\frac{f^{\prime}{ }_{c c}}{f^{\prime}{ }_{c}}-1\right]+1
$$

Where;

$f^{\prime}{ }_{c c}=1.1 f^{\prime}{ }_{c}$

$\varepsilon^{\prime}{ }_{c}=0.0035$

4- Assume the concrete strain equals to the confined concrete crushing strain $\left(\varepsilon^{\prime}{ }_{c c}\right)$

5- Assume $\mathrm{c}=5 \mathrm{~mm}$

6- Using strain compatibility, find the strains in the PVC and steel 


$$
\frac{\varepsilon_{c}}{c}=\frac{\varepsilon^{\prime}{ }_{c}}{c^{\prime}}=\frac{\varepsilon^{\prime}{ }_{s}}{c-d^{\prime}}=\frac{\varepsilon_{s}}{d-c}=\frac{\varepsilon_{P V C}}{h-c}
$$

7- Calculate the forces in the concrete, steel and the PVC

8- Using the force equilibrium equations, find the external applied load (P) and the moment (M)

$$
\begin{gathered}
P=C_{c c}+C_{c}+C_{s}-T_{s}-T_{P V C} \\
M=C_{c c}\left(\frac{h}{2}-\left[c-\frac{C}{\varepsilon^{\prime}{ }_{c c}} \varepsilon^{\prime}{ }_{c}\right] \frac{2 f^{\prime}{ }_{c}+f^{\prime}{ }_{c c}}{3 f^{\prime}{ }_{c}+3 f^{\prime}{ }_{c c}}\right)+C_{c}\left(\left[\frac{h}{2}-C\right]+\left[1-\frac{\beta_{1}}{2}\right]\left[\frac{C}{\varepsilon_{c c}^{\prime}} \varepsilon_{c}^{\prime}\right]\right) \\
+C_{s}\left(\frac{h}{2}-d^{\prime}\right)+T_{s}\left(\frac{h}{2}-d\right)+T_{P V C}\left(\frac{h}{2}\right)
\end{gathered}
$$

9- Calculate the magnification factor and the applied moment including P- $\Delta$ effect

$$
M_{c}=\frac{1}{1-\frac{P}{P_{c}}} * P * e
$$

10 - If; $M_{c} \neq M$, then increase c by $1 \mathrm{~mm}$ and repeat steps 5 to 9 .

- If; $M_{c}=M$, then the solution is correct.

The above procedure is summarized in a flowchart as shown in Figure 4.7 


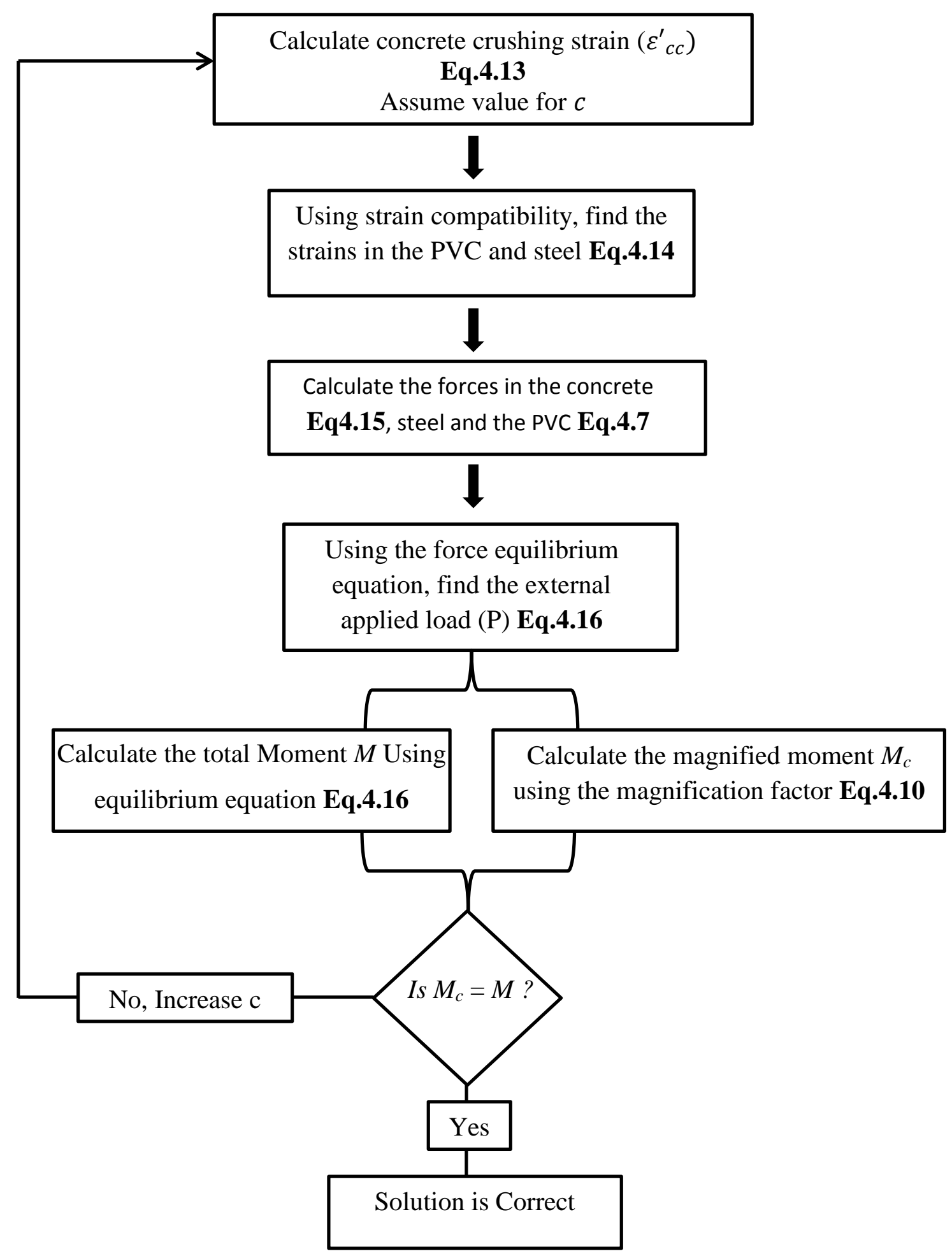

Figure 4.7 - Calculation steps for the PVC encased walls accounting for the confinement effect 


\subsection{Calculated and experimental results for the PVC encased specimens}

The peak load was calculated for all of the PVC encased specimens. The results are presented in Table 4.3 Figure 4.8 shows the calculated and the experimental interaction diagrams for all of the PVC encased specimens. Figure 4.9 shows the calculated interaction diagram for all of the specimens (control and PVC confined specimens). The calculated peak loads showed better correlation with the experimental peak loads than the case with zero confinement (Section 4.5). The difference between the experimental and the calculated load was $5.9 \%$ on average (15.5\% maximum) as opposed to an average error of $16 \%$ ( $28 \%$ maximum) for the calculated loads without confinement (Section 4.5).

Table 4.3 - Calculated peak loads with confinement effect

\begin{tabular}{|c|c|c|c|c|c|c|}
\hline & Specimen & Batch & Collar & $\begin{array}{c}\text { Experimental } \\
\text { Peak Load } \\
(\mathrm{kN})\end{array}$ & $\begin{array}{c}\text { Theoretical } \\
\text { Peak Load } \\
(\mathrm{kN})\end{array}$ & $\begin{array}{c}\text { Percentage } \\
\text { Difference } \\
(\%)\end{array}$ \\
\hline \multirow{8}{*}{ 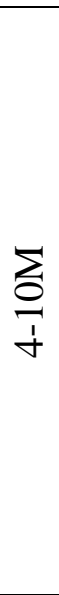 } & C-e6-10 & Batch1 & Present & 1445.1 & 1145.23 & 20.8 \\
\hline & O-e6-10 & Batch1 & Absent & 1339.7 & -- & -- \\
\hline & O-e6-10 & Batch 2 & Present & 1475.9 & 1367 & 7.3 \\
\hline & C-e3-10 & Batch1 & Present & 677.9 & 654.26 & 3.5 \\
\hline & O-e3-10 & Batch1 & Present & 990.3 & \multirow{2}{*}{786} & \multirow{2}{*}{15.5} \\
\hline & O-e3-10 & Batch 2 & Present & 869.3 & & \\
\hline & C-e2-10 & Batch1 & Present & 374.8 & 356.58 & 4.9 \\
\hline & O-e2-10 & Batch 2 & Present & 438.9 & 427.5 & 2.6 \\
\hline \multirow{8}{*}{$\frac{\sum}{\frac{i}{7}}$} & C-e6-15 & Batch1 & Absent & 1266.7 & 1271.9 & 0.41 \\
\hline & O-e6-15 & Batch1 & Absent & 1393.5 & 1494.8 & 7.8 \\
\hline & C-e3-15 & Batch1 & Present & 856 & 789.69 & 7.74 \\
\hline & O-e3-15 & Batch1 & Absent & 624.6 & -- & -- \\
\hline & O-e3-15* & Batch1 & Present & 984 & \multirow{2}{*}{950.3} & \multirow{2}{*}{0.61} \\
\hline & O-e3-15 & Batch 2 & Present & 905 & & \\
\hline & C-e2-15 & Batch1 & Present & 504.1 & 497.41 & 1.32 \\
\hline & O-e2-15 & Batch 2 & Present & 557.9 & 569.7 & 2.1 \\
\hline
\end{tabular}

* An average value of the peak load was used for duplicate specimens. 


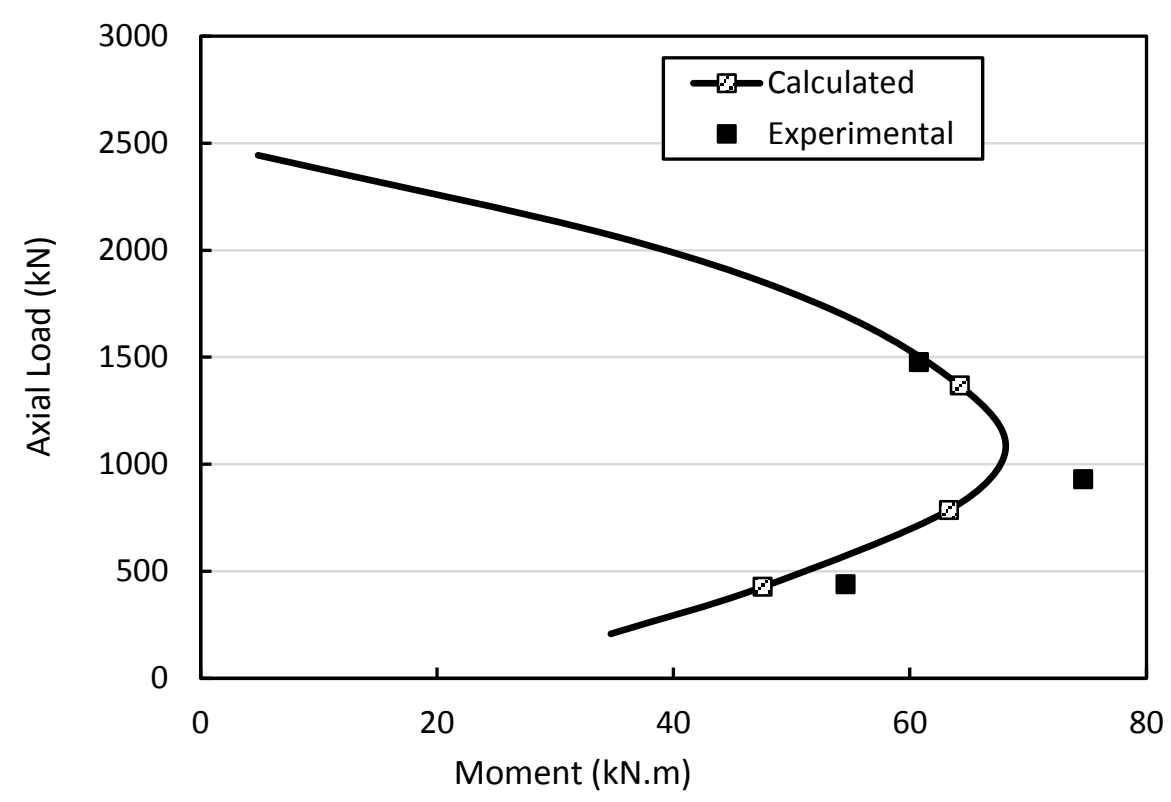

a- Walls reinforced with $4-10 \mathrm{M}$

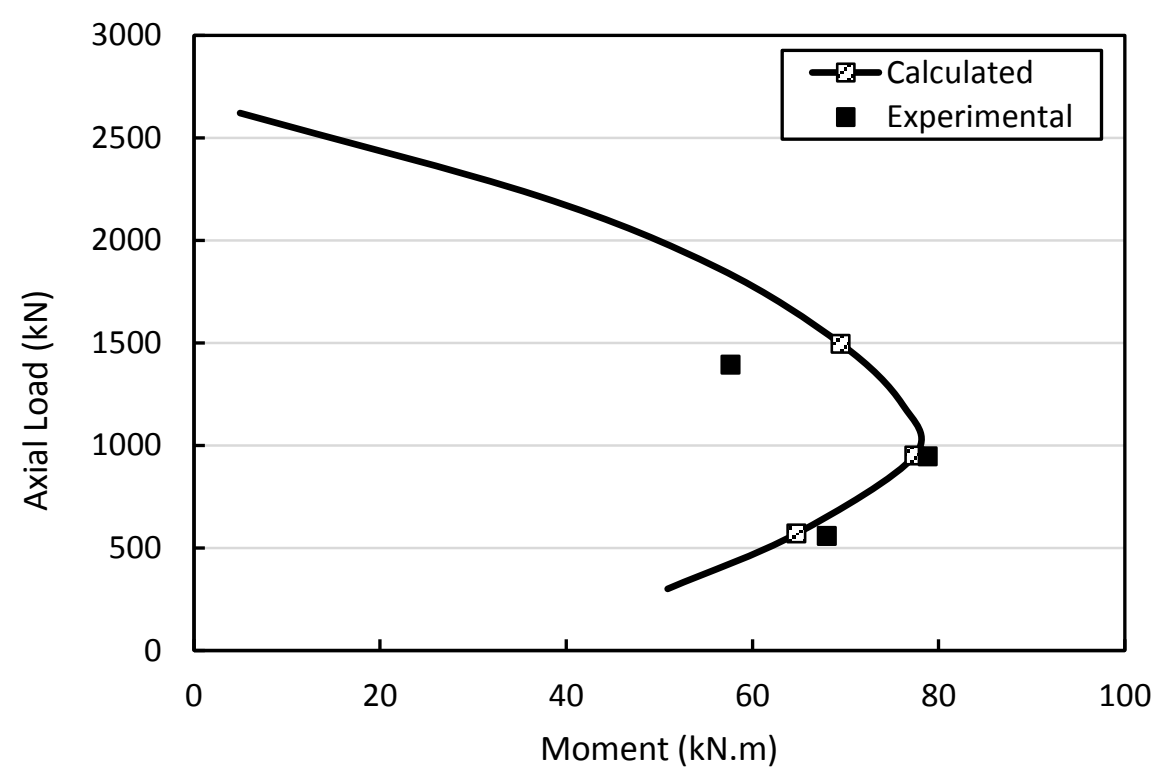

b- Walls reinforced with $4-15 \mathrm{M}$

Figure 4.8 - Interaction diagram for PVC encased walls 


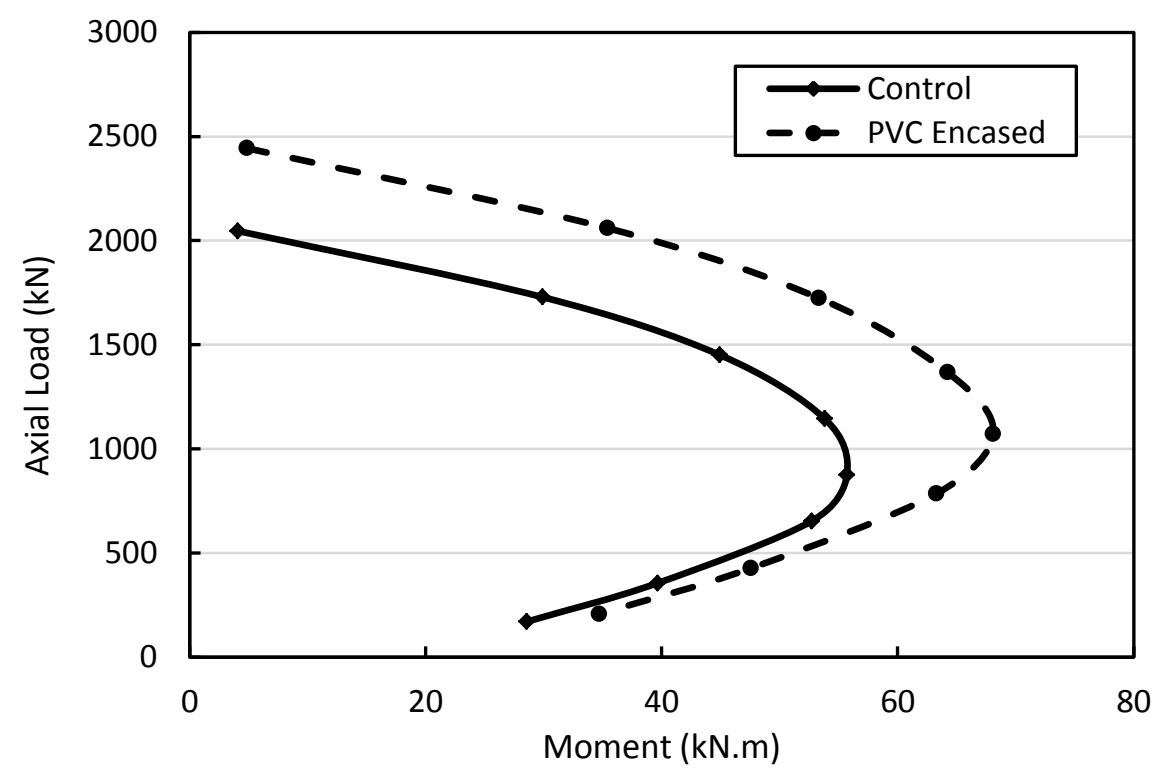

a- Walls reinforced with 4-10M

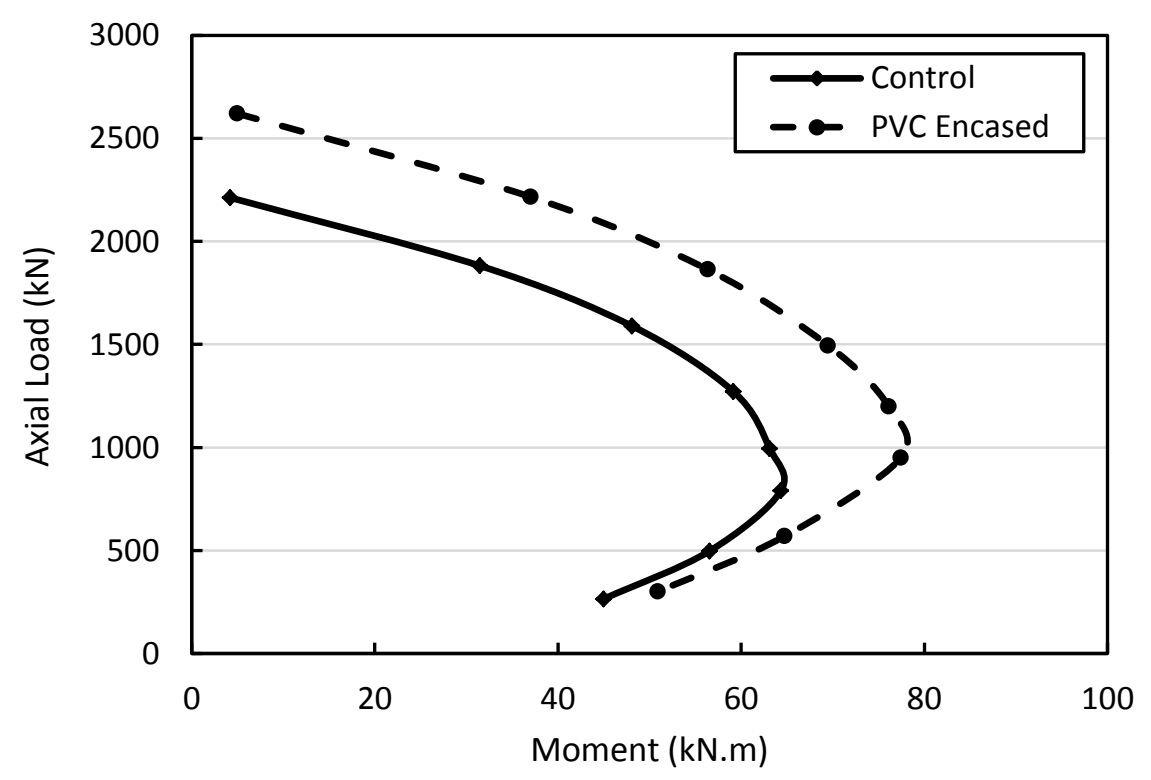

b- Walls reinforced with $4-15 \mathrm{M}$

Figure 4.9 - Calculated interaction diagrams for both control and PVC encased walls 


\section{Chapter 5: Conclusion and Recommendation}

\subsection{Conclusion}

A total of eighteen reinforced concrete specimens were cast and tested up to failure under eccentric axial loading to evaluate the performance of the PVC encasement system. The behaviour of the PVC encased specimens was compared to the control specimens. In addition, the experimental results were analyzed to determine the effect of the reinforcement ratio and applied eccentricity on the behaviour of the PVC encased specimens. A summary of the conclusions that can be drawn from the experimental and analytical program is given below:

- Both the control and PVC encased specimens showed the same load versus deflection behaviour. The load increased with deflection until failure where the load dropped abruptly and the deflection increased. The PVC encased specimens were stiffer than the control specimens, where the slope of the load versus deflection increased compared to the control specimens.

- For both the control and the PVC encased specimens, the behaviour of the load versus strain of steel, concrete and PVC was characterized by an ascending curve until failure where the load dropped with an increase in strain reading, resulting in the descending part of the curve.

- The control walls (without PVC encasement) failed by yielding of the steel followed by crushing of the concrete, or by crushing of the concrete without yielding of the steel. For the PVC encased walls, buckling of the PVC occurred after the concrete crushed.

- The control walls and their peer PVC encased walls showed the same mode of failure except for the control and the PVC encased walls reinforced with 4-10M and tested at $67.73 \mathrm{~mm}$ eccentricity. The control wall failed by steel yielding 
followed by concrete crushing, but the PVC encased wall failed by concrete crushing and steel yielding together followed by buckling of the PVC.

- The PVC encased specimens showed a higher peak load than their peer control walls.

- The effect of the PVC encasement on increasing the ultimate capacity at a given eccentricity was more significant for the walls reinforced with 4-10M than the walls reinforced with $4-15 \mathrm{M}$. The PVC encased specimens reinforced with $4-10 \mathrm{M}$ showed an increase in the peak load by $37.2 \%$ and $17.1 \%$ at an eccentricity of $67.73 \mathrm{~mm}$ and $101.6 \mathrm{~mm}$, respectively. However, when the reinforcement was increased to 4-15 M, the increase in the peak load dropped at all eccentricities to $10 \%$.

- For all of the specimens, it was observed that as the eccentricity increased the peak load decreased due to the increase in the curvature and the additional moment caused by the eccentric loading.

- For the vertical and the mid-span deflection, the PVC encased specimens and the control specimens showed the same values.

- Test results showed an increase in the energy absorption capacity for the PVC encased specimens compared to the controls specimens. The increase at a given eccentricity was more evident for the walls reinforced with 4-10M compared to the walls reinforced with $4-15 \mathrm{M}$

- At the same eccentricity, the effect of the reinforcement ratio was more evident for the control specimens than the PVC encased specimens.

- The control and the PVC encased specimens reinforced with 4-15M and tested at an eccentricity of $67.73 \mathrm{~mm}$ showed an increase in the peak load of $26.3 \%$ and $1.6 \%$, respectively, over their peers reinforced with 4-10M. 
- At the highest eccentricity $(101.6 \mathrm{~mm})$, the control and the PVC encased specimens reinforced with $4-15 \mathrm{M}$ showed an increase in the peak load of 34.5. \% and $27.1 \%$, respectively, over those reinforced with $4-10 \mathrm{M}$.

- Sectional analysis based on the moment magnification factor was carried out to calculate the capacity of the walls.

- The calculated peak loads for control specimens were conservative by an average error of $7.7 \%$.

- Initially, the confinement effect of the PVC encasement was neglected. The calculated capacities of the PVC encased specimens underestimated the actual capacity of the PVC encased walls by an average error of $16 \%$ (a maximum of $28 \%$ ).

- When the confining effect of the PVC was taken into consideration (10\%), the calculated capacities showed better correlation with the experimental peak loads than the case with zero confinement. The difference between the experimental and the calculated load was $5.9 \%$ on average $(15.5 \%$ maximum).

\subsection{Recommendation for Future Work}

Based on the work conducted here, it is recommended that the following should be considered for future work;

- The relation between the increase in applied eccentricity and the reduction in the confinement effect for the PVC encasement system needs more investigation to determine the optimum system. It is worth mentioning that as the eccentricity increases, the confinement effect decreases but the contribution of the PVC in tension increases. 
- An experimental investigation on the effect of the concrete compressive strength on the behaviour of PVC encasement at different eccentricities is required. This investigation will enhance the use of the PVC system to fully utilize the load carrying capacity of the PVC encasement system. 


\section{References}

ACI Committee 440. 2007. Report on Fiber-Reinforced Polymer (FRP) Reinforcement for Concrete Structures. American Concrete Institute, Detroit, Michigan.

Chahrour, A., Soudki, K., and Straube, J. 2005. RBS Polymer encased concrete wall. Part I:experimental study and theoretical provisions for flexure and shear. Construction and Building Material. Vol. 19, No. 7: PP. 550-63.

Chahrour, A., and Soudki, K. 2006. RBS Polymer Encased Concrete Wall part II: Experimental Study and Theoretical Provisions for Combined Axial Compression and Flexure. Construction and Building Materials. Vol. 20, No. 10: pp. 1016-1027.

Collins, M.P. and Mitchell, D. 1987. Prestressed Concrete Basics. Canadian Prestressed Concrete Institute (CPCI). Ottawa, Canada.

De Lorenzis, L. and Tepfers, R. 2003. Comparative Study of Models on Confinement of Concrete Cylinders with Fiber-Reinforced Polymer Composites. Journal of Composites for Construction. Vol. 7, No. 3: pp. 219-237.

Fam, A., Flisak, B., and Rizkalla, S. 2003. Experimental and Analytical Modeling of Concrete-filled Fiber reinforced Polymer Tubes Subjected to Combined Bending and Axial Loads. ACI Structural Journal. Vol. 100, No. 4: pp. 499-509.

Gupta, R., 2009. Evaluation of the Compressive Strength Behaviour of the Octaform Concrete Forming System (PhaseII). Octaform System Inc., Vancouver, BC.

ISIS Canada. 2009. Design Manual No. 4 - FRP Rehabilitation of Reinforced Concrete Structures, Winnipeg, Manitoba, Canada.

Kuder, K. 2006. Effect of PVC Stay-in-place Formwork on the Mechanical Performance of Concrete. Octaform System Inc., Vancouver, BC 
Kuder, K., Rishi, G., Harris-Jones, C., Hawksworth, R., Henderson, S., and Whitney J. 2009. Effect of PVC Stay-In-Place Formwork on Mechanical Performance of Concrete. Journal of Materials in Civil Engineering. Vol. 21, No. 7: pp. 309-315.

Li, G., Torres, S., Alaywan, W., and Abadie, C. 2005. Experimental study of FRP TubeEncased Concrete Columns. Journal of Composite Materials. Vol. 39, No. 13: pp. 11311145 .

Mirmiran, A., Shahawy, M., and Samaan, M. 1999. Strength and Ductility of Hybrid FRP-Concrete Beam-Columns. Journal of Structural Engineering. Vol. 125, No. 10: pp. 1085-1093.

Mirmiran, A. 2003. Stay-In-Place FRP for concrete Columns. Advances in Structural Engineering. Vol. 6, No. 3: pp. 231-241.

Nawy, E. G. 2006. Prestressed Concrete A Fundamental Approach. Prentice Hall. United States of America.

Octaform, 2010. Construction Guide: version 2 updated 2010. Octaform System Inc., Vancouver, BC.

Ozbakkaloglu, T., and Saatcioglu, M. 2006. Seismic Behavior of High-Strength Concrete Columns Confined by Fiber-Reinforced Polymer Tubes. Journal of Composites for Construction. Vol. 10, No. 6: pp. 538-549.

Petersons, N. 1964. Strength of Concrete in Finished Structures. Elanders Boktryckeri Aktiebolag. Stockholm. Sweden.

Pham, T.M, Lei, X. and Hadi, M N.S. 2013. Effect of eccentric load on retrofitted reinforced concrete columns confined with FRP. $22^{\text {nd }}$ Australasian Conference on the Mechanics of Structures and Materials (ACMSM22). London: Taylor \& Francis Group. pp. 139-144. 
Richart FE, Brandtzaeg A, Prown RL. 1928. A Study of the Failure of Concrete under Combined Compressive Stress. Bulletin No. 190 Urbana: Engineering Experiment Station, University of Illinois, 103 p.

Rteil, A., Soudki K., and Richardson, D. 2008. Flexural Behavior of Octaform $^{\mathrm{TM}}$ Forming System. ACI SP. ACI SP, St. Louis, CD format

Van Den Einde, L., Zhao, L., and Seible, F. 2003. Use of FRP composites in civil structural applications. Construction and Building Materials. Vol. 17, pp. 389-403.

Wahab, N. and Soudki, K. 2013. Flexural behaviour of PVC stay-in-place formed RC walls. Construction and Building Materials. Vol. 48, PP. 830-839. 


\section{Appendix-A}

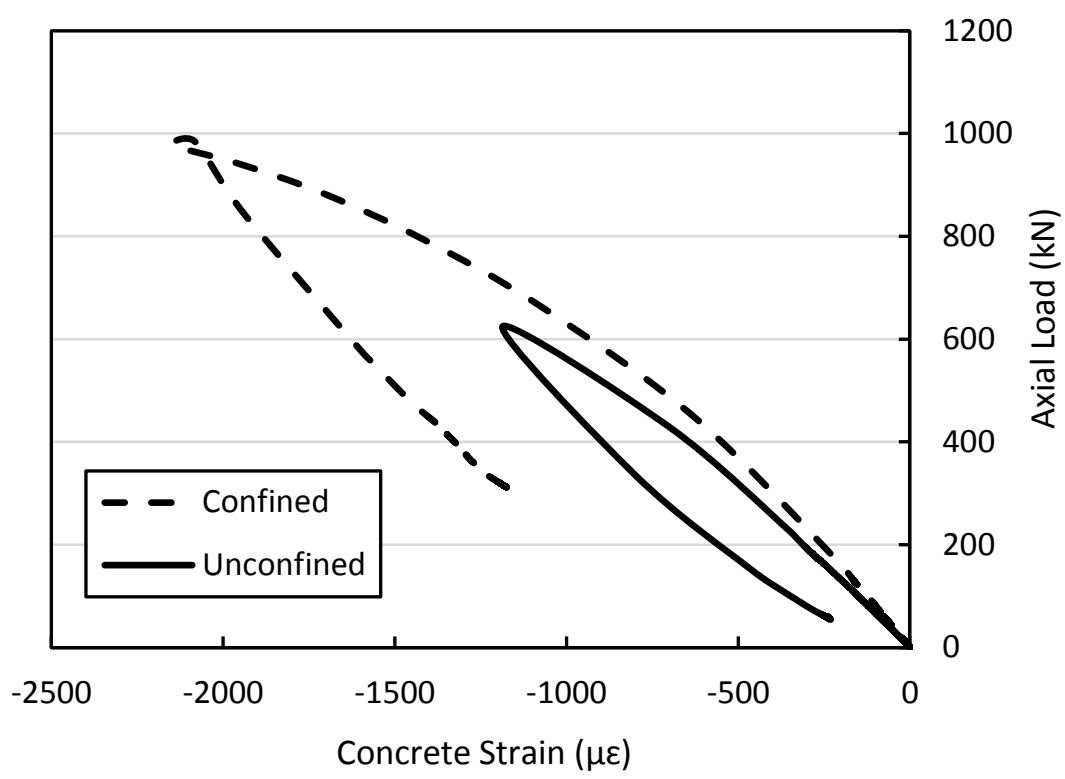

Figure A.1 - Load versus concrete strain response for collar confined and unconfined Oe3-15 wall specimens

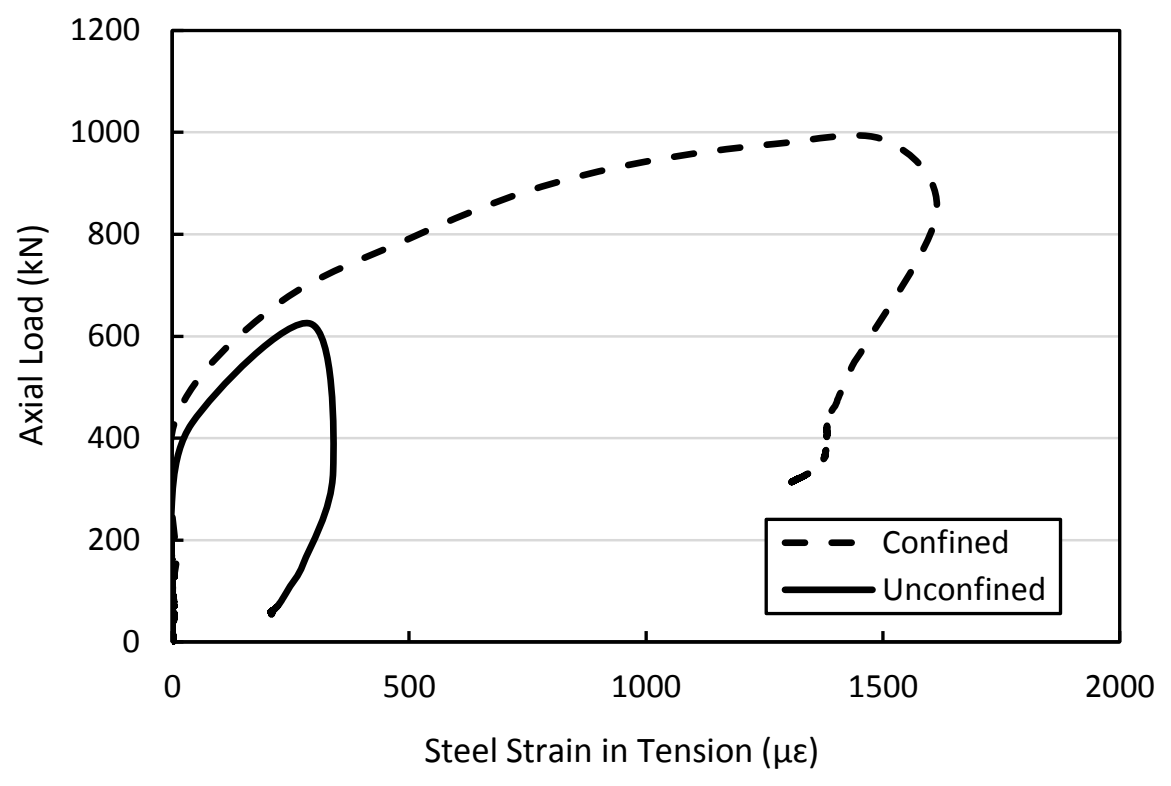

Figure A.2 - Load versus steel strain in tension for collar confined and unconfined O-e315 wall specimens 


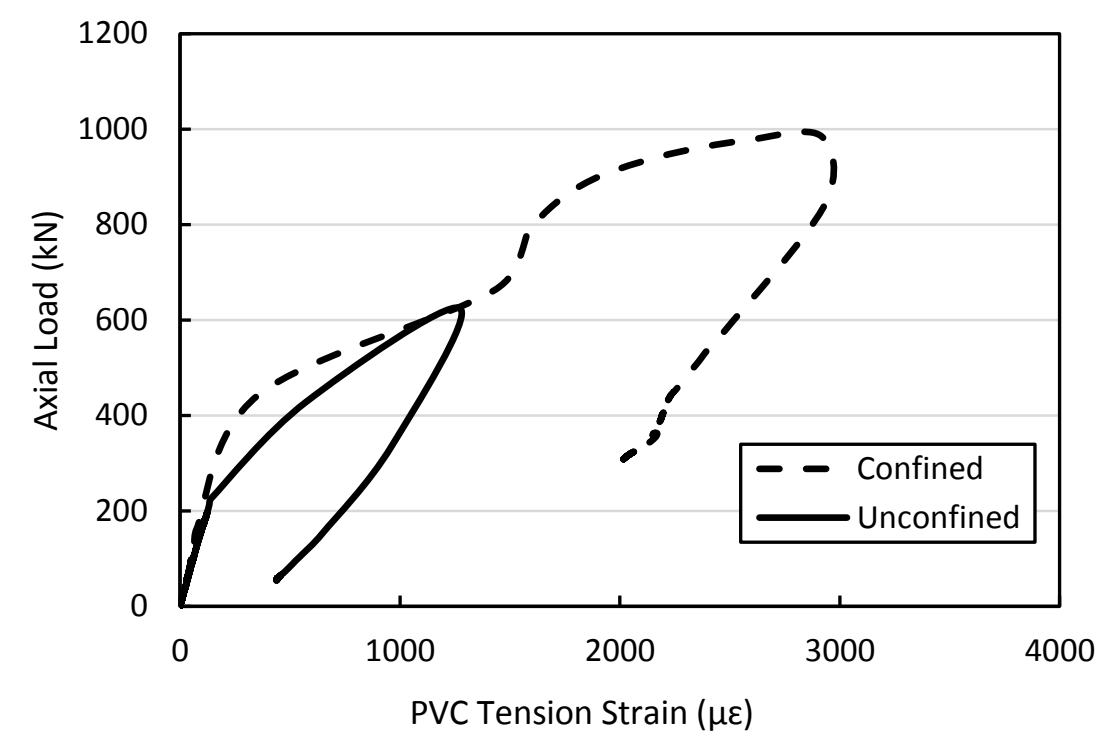

Figure A.3 - Load versus PVC strain in tension for collar confined and unconfined O-e315 wall specimens

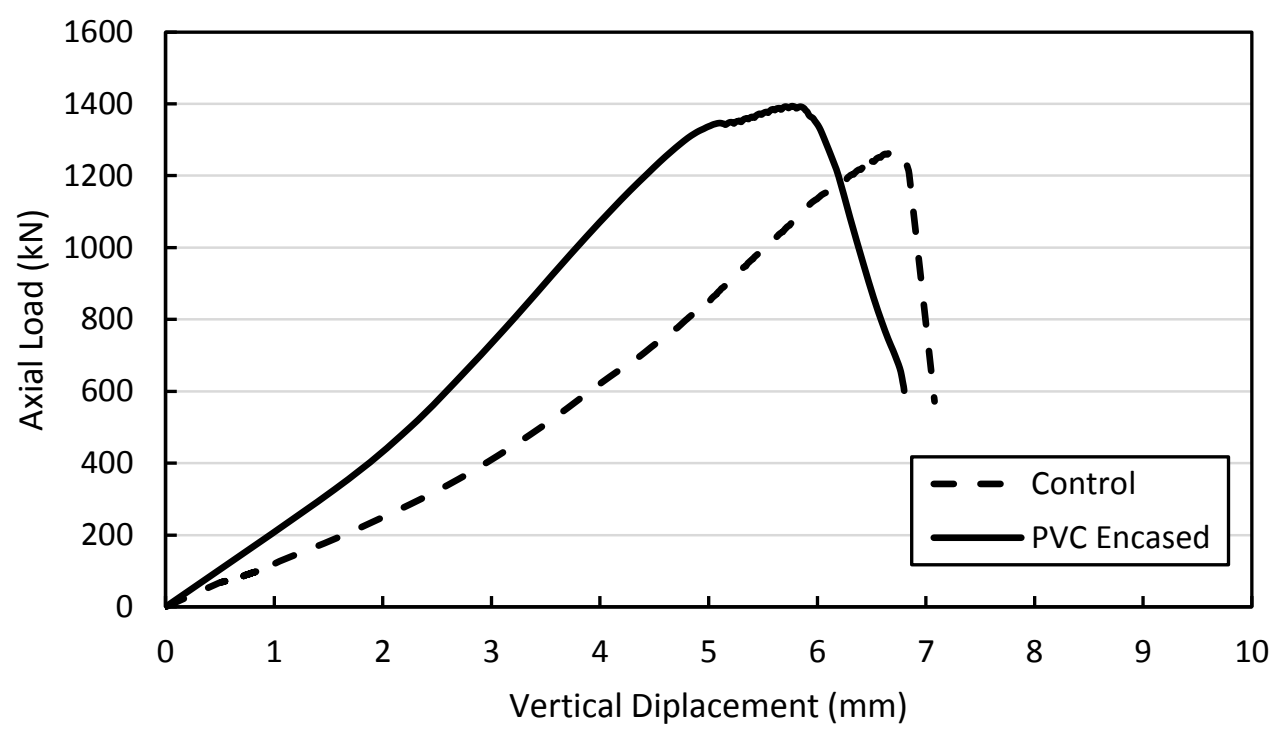

Figure A.4 - Load versus vertical displacement for C-e6-15 and O-e6-15 wall specimens 


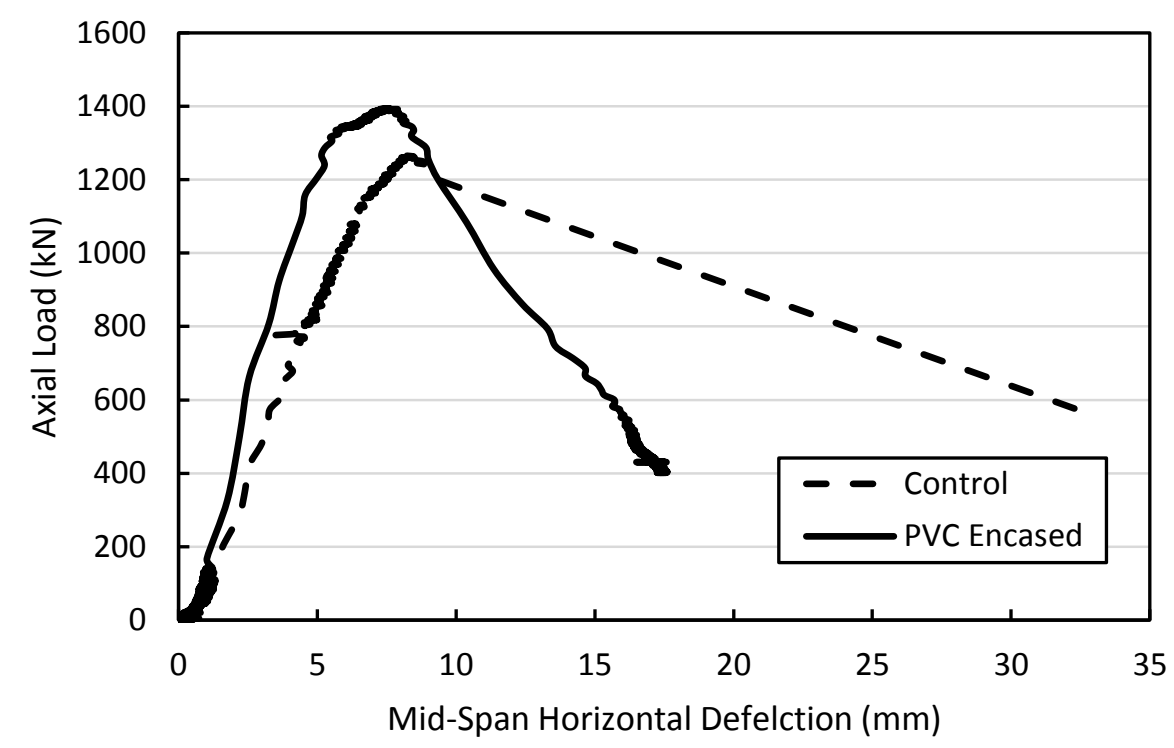

Figure A.5 - Load versus mid-span horizontal deflection for C-e6-15 and O-e6-15 wall specimens

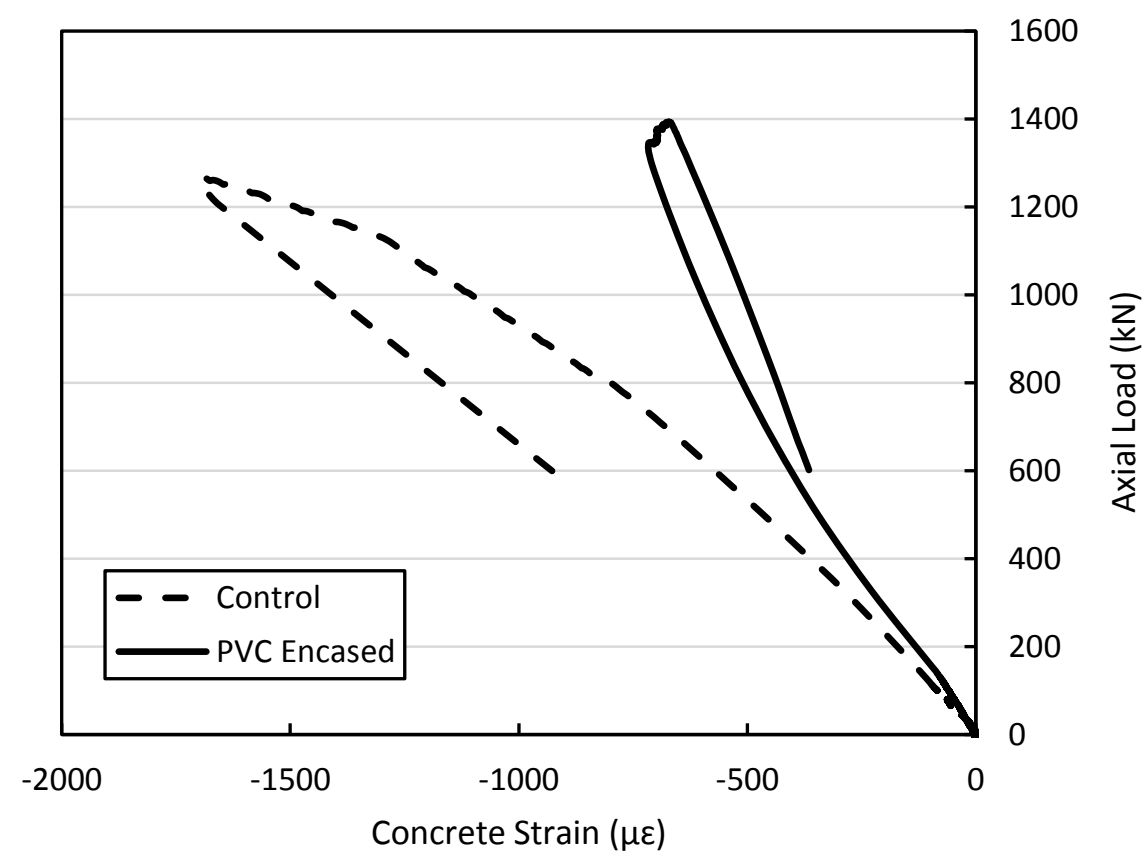

Figure A.6 - Load versus concrete strain for C-e6-15 and O-e6-15 wall specimens 


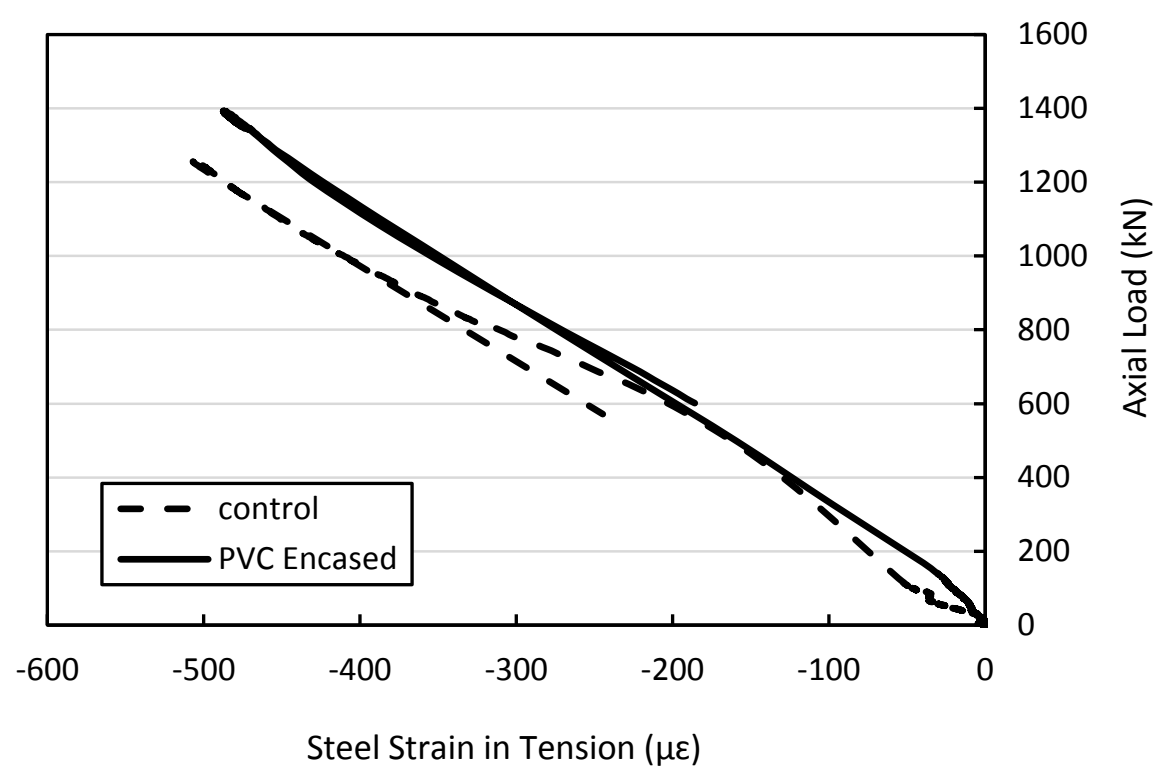

Figure A.7 - Load versus tension steel strain for C-e6-15 and O-e6-15 wall specimens

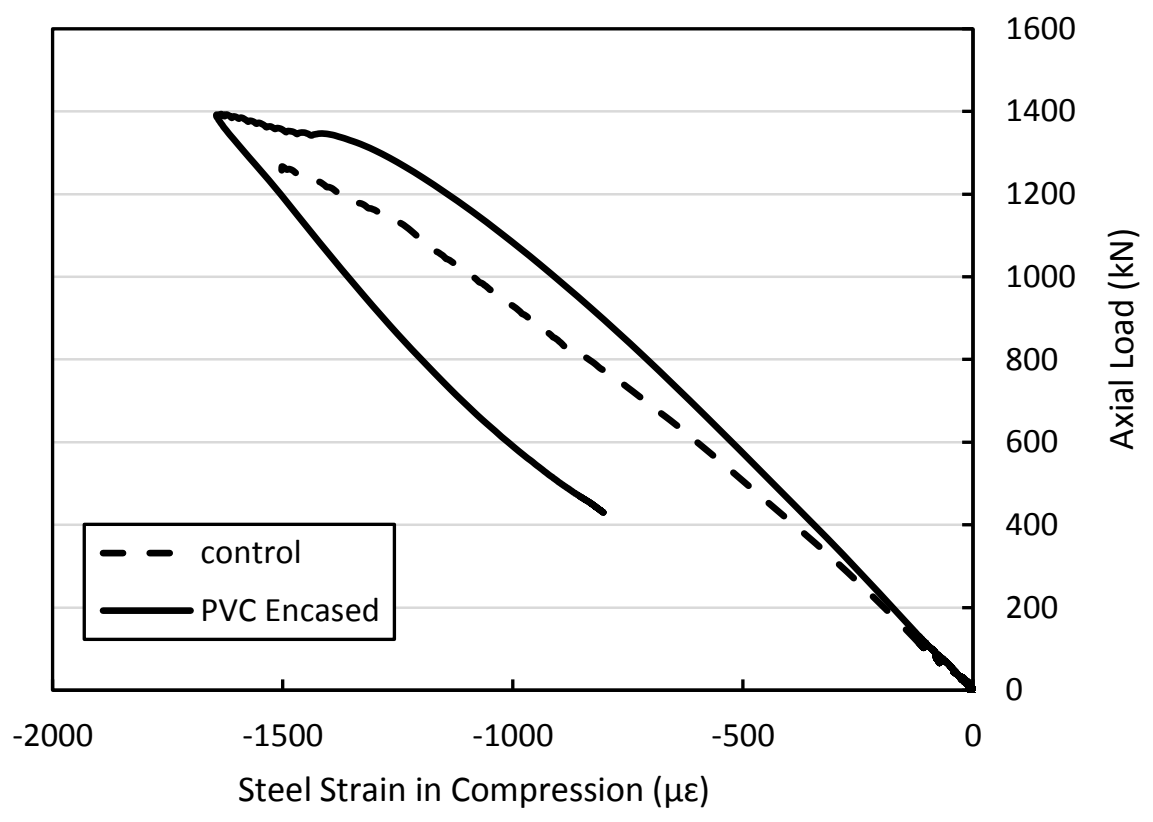

Figure A.8 - Load versus compression steel strain for C-e6-15 and O-e6-15 wall specimens 


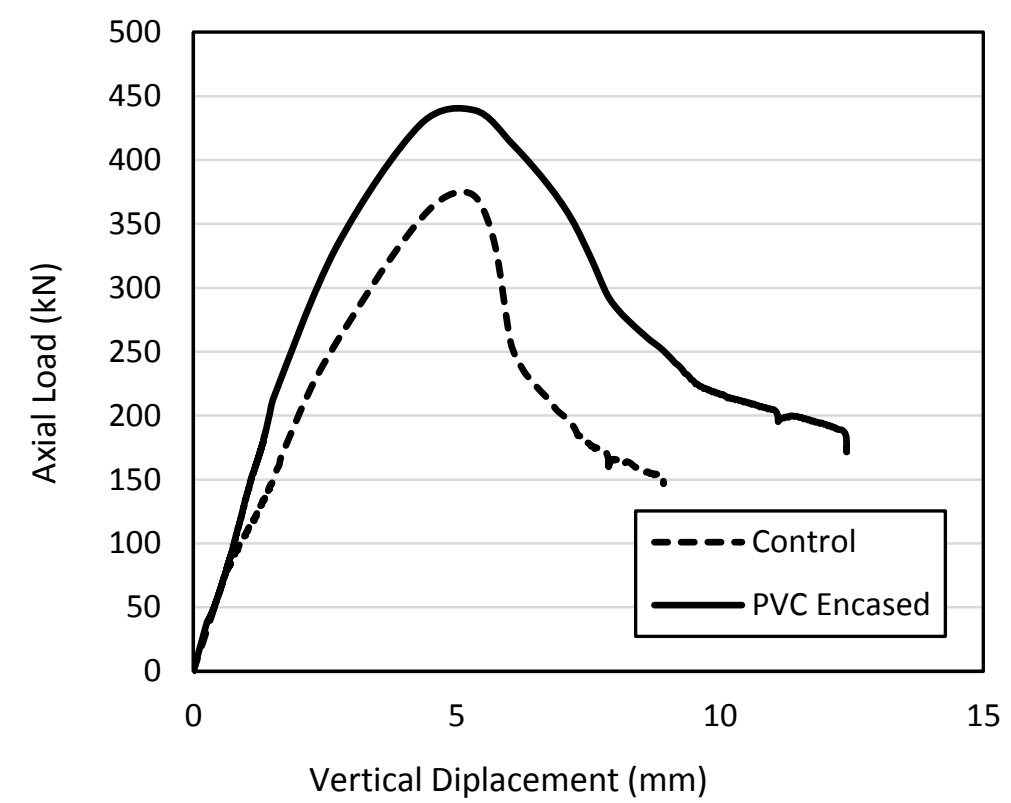

Figure A.9 - Load versus vertical displacement for O-e2-10 and C-e2-10 wall specimens

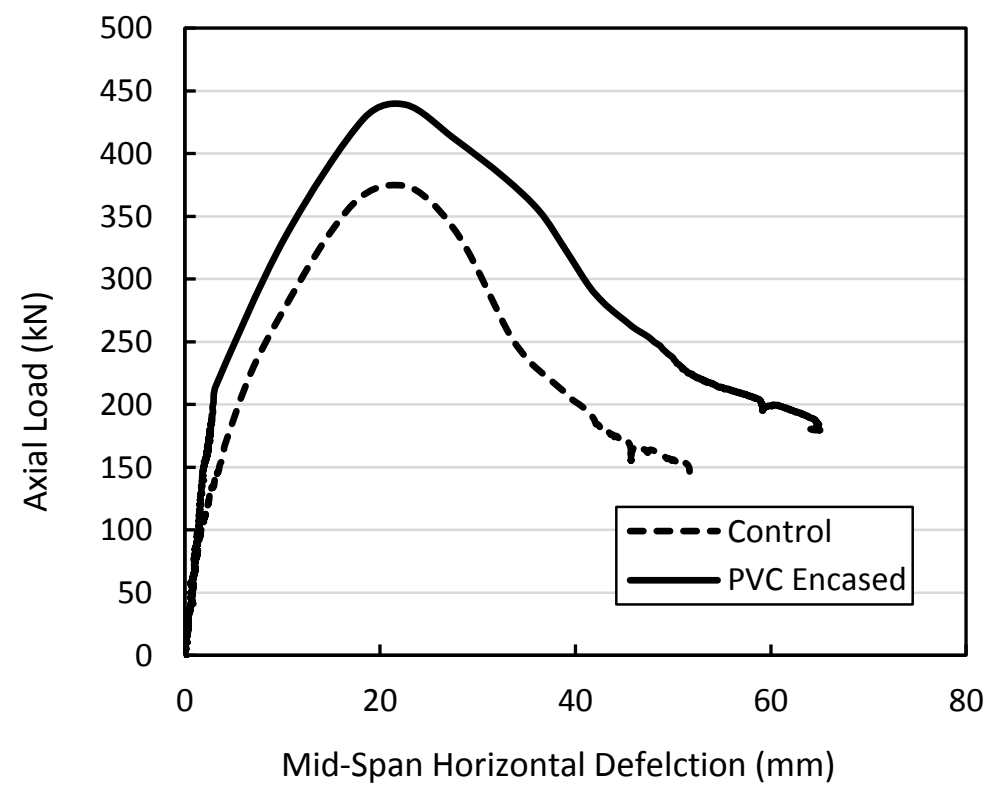

Figure A.10 - Load versus mid-span horizontal deflection for O-e2-10 and C-e2-10 wall specimens 


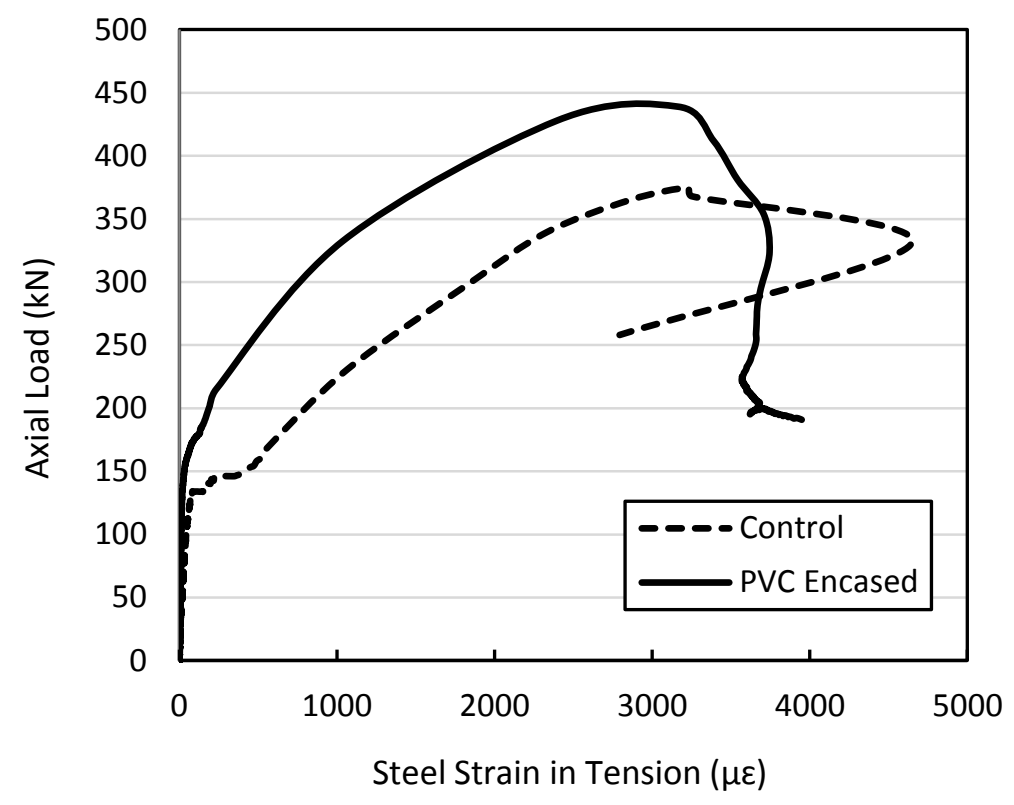

Figure A.11 - Load versus tension steel strain for O-e2-10 and C-e2-10 wall specimens

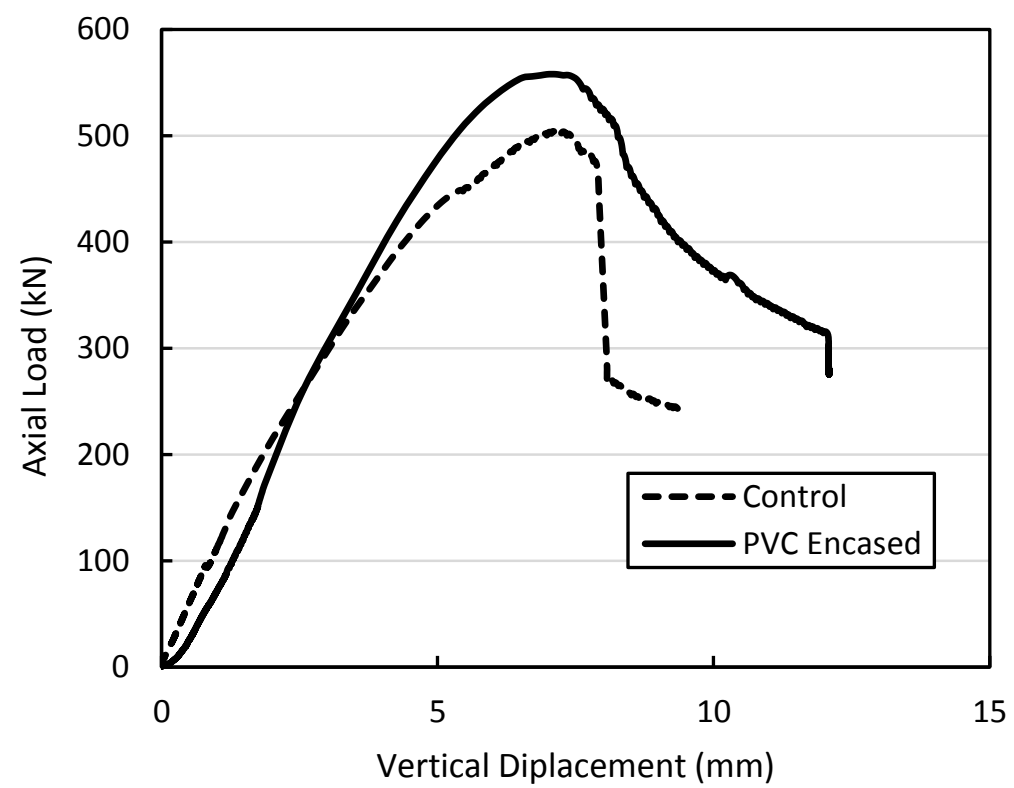

Figure A.12 - Load versus vertical displacement for O-e2-15 and C-e2-15 wall specimens 


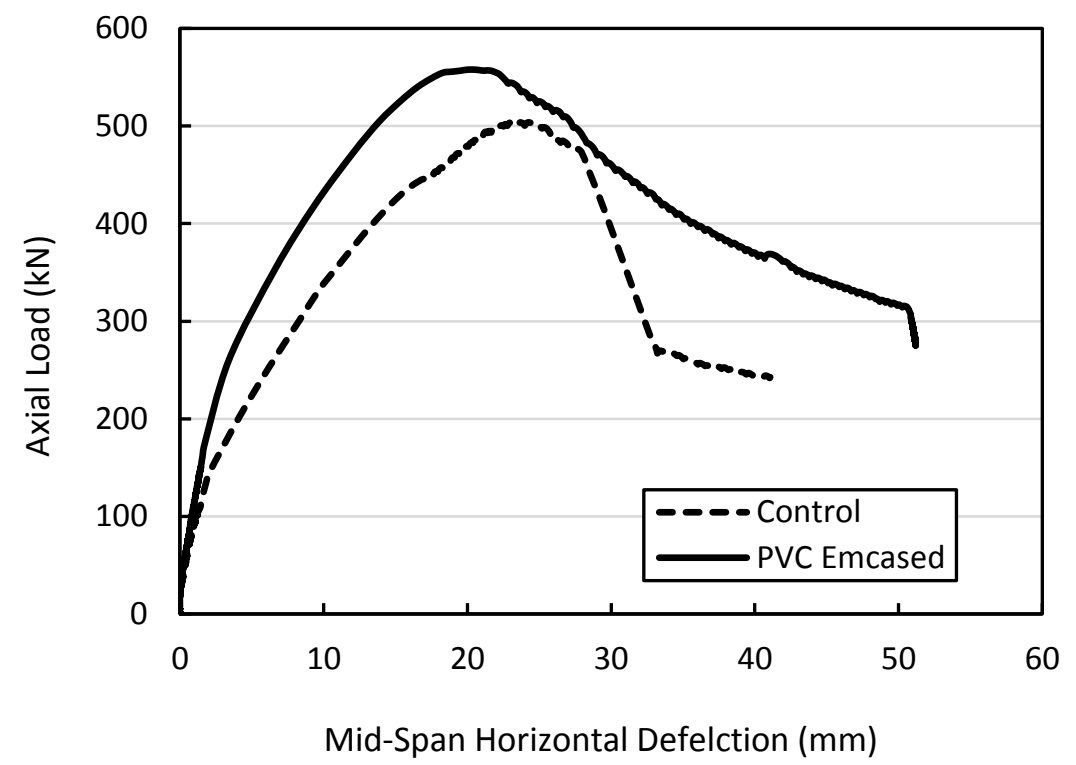

Figure A.13 - Load versus mid-span horizontal deflection for O-e2-15 and C-e2-15 wall specimens

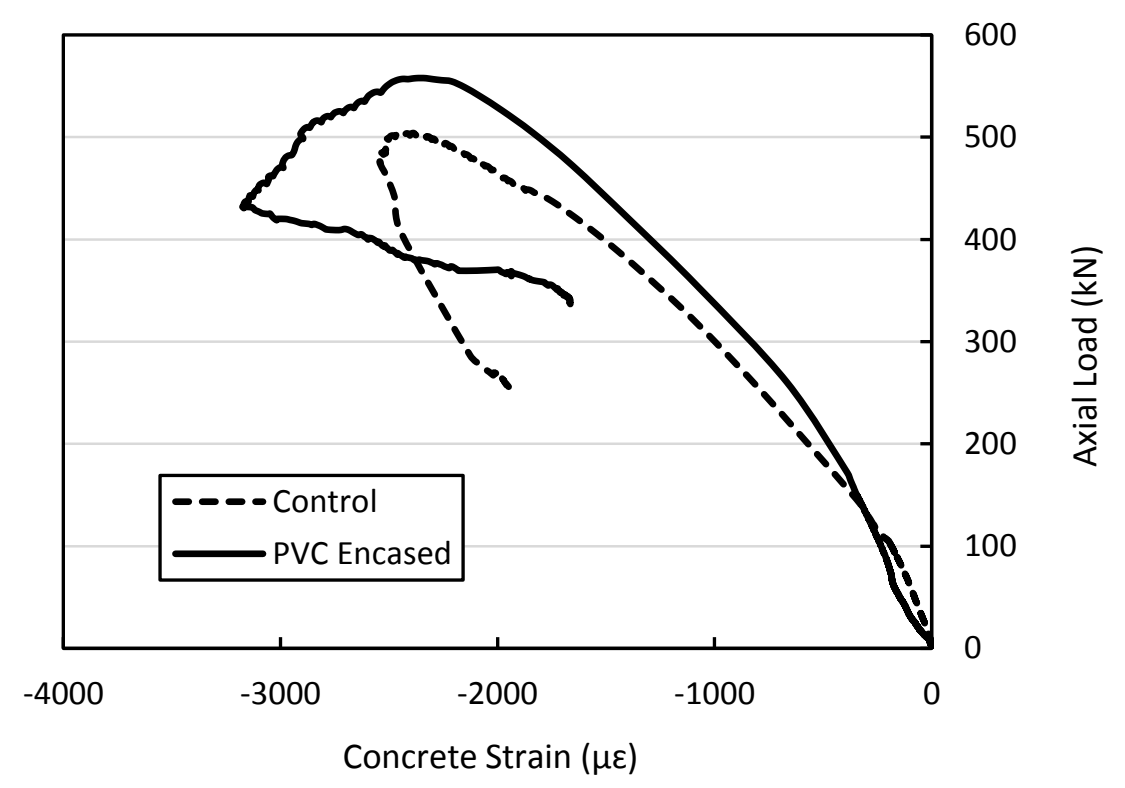

Figure A.14 - Load versus concrete strain for O-e2-15 and C-e2-15 wall specimens 


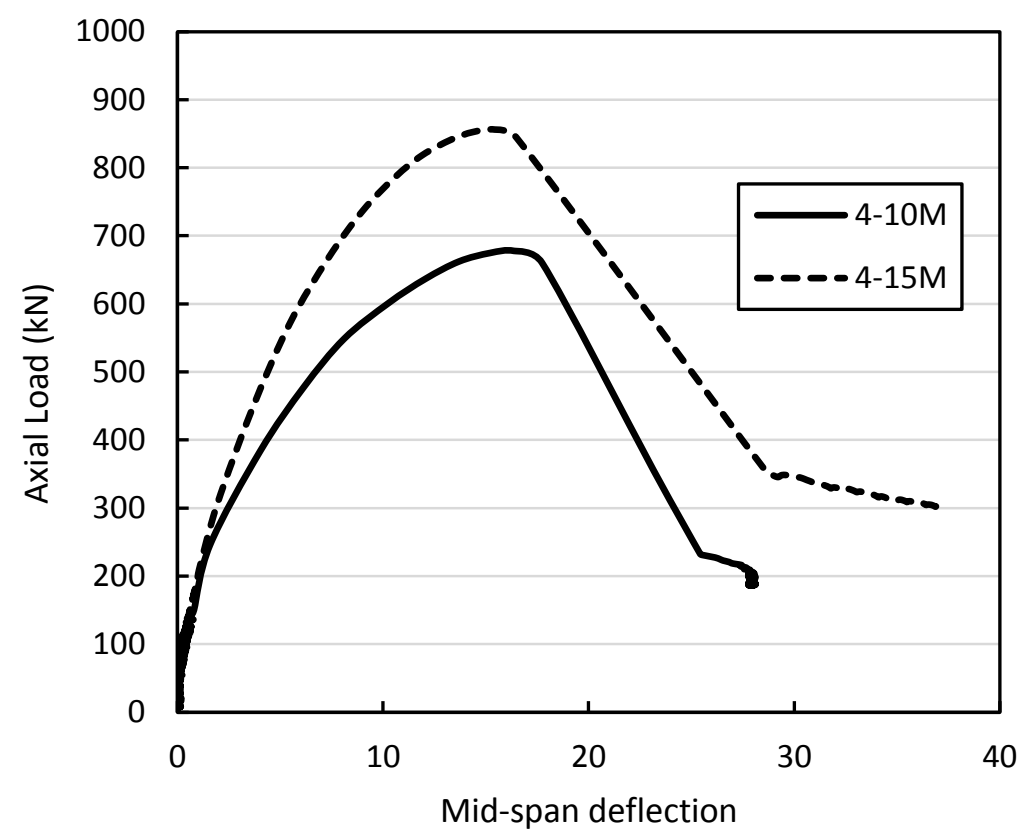

Figure A.15 - Load versus mid-span deflection for control wall specimens with different reinforcement ratios (C-e3-10 and C-e3-15)

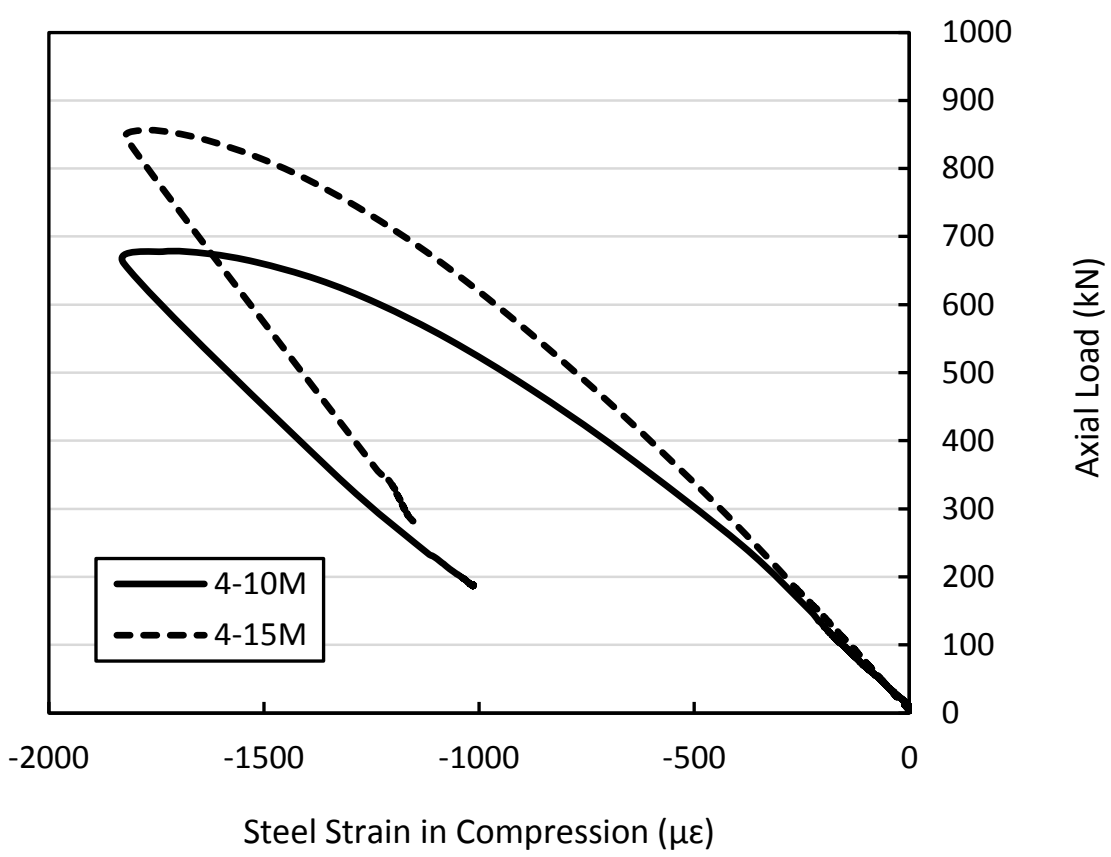

Figure A.16 - Load versus compression steel strain for control wall specimens with different reinforcement ratios (C-e3-10 and C-e3-15) 


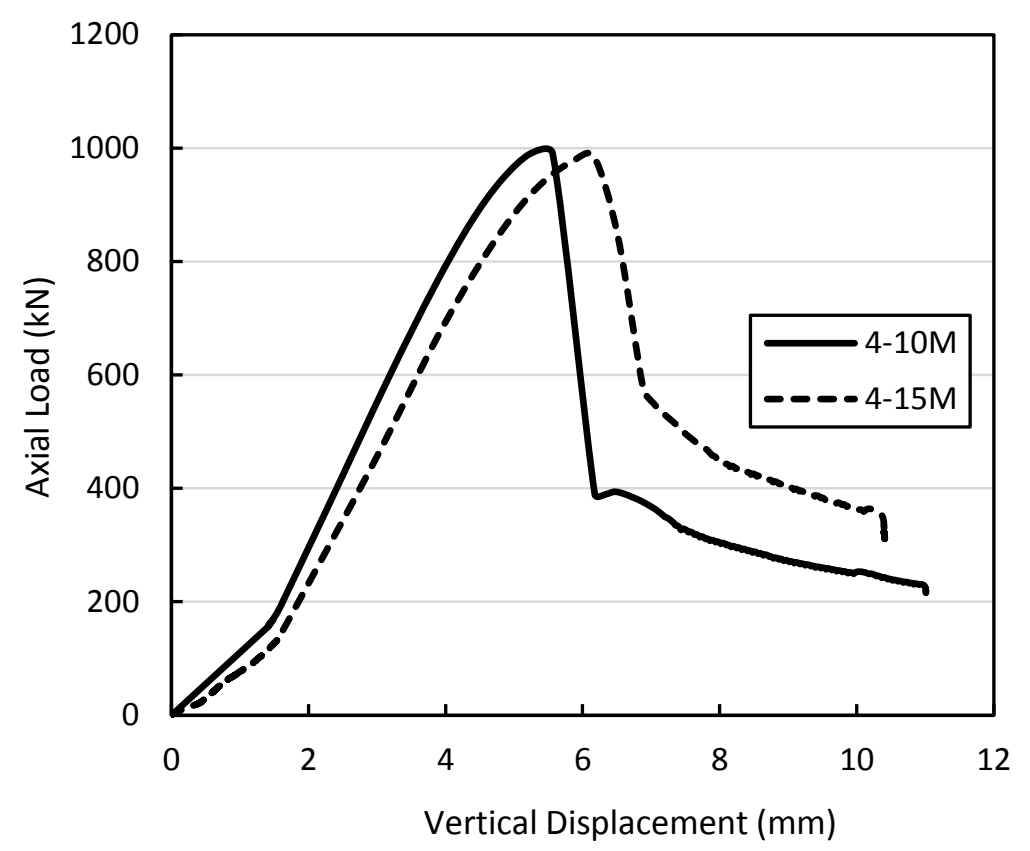

Figure A.17 - Load versus vertical displacement for PVC encased wall specimens with different reinforcement ratios (O-e3-10 and O-e3-15)

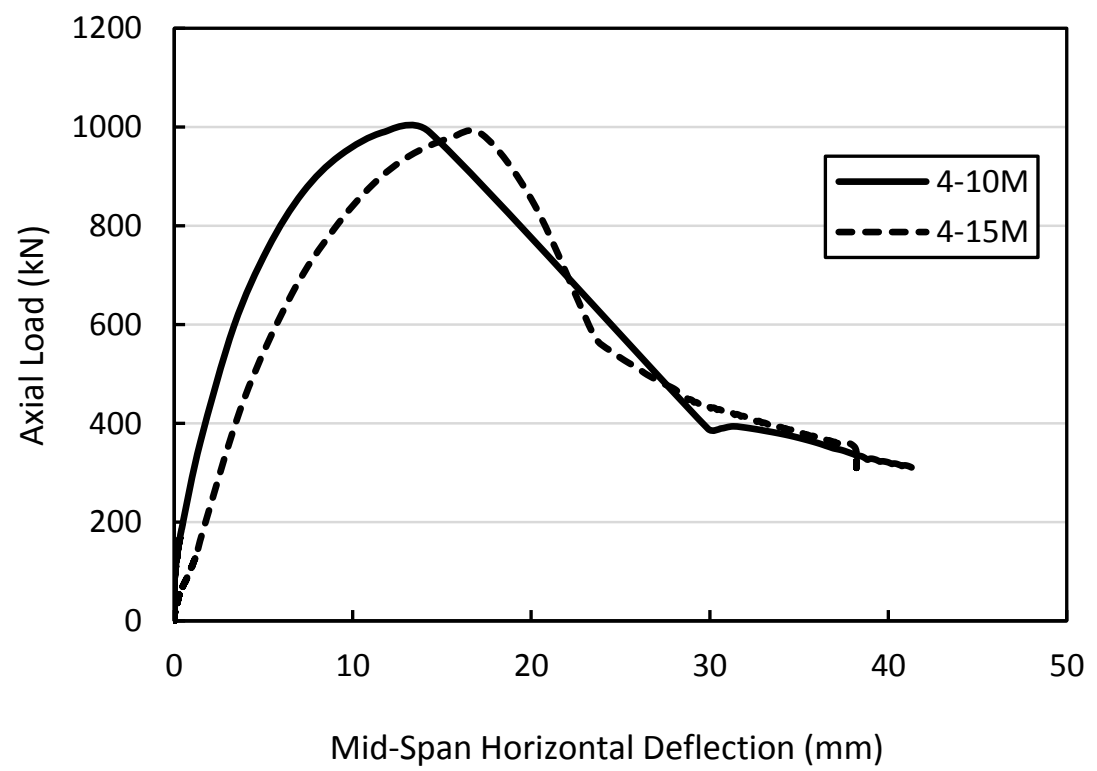

Figure A.18 - Load versus mid-span horizontal deflection for PVC encased wall specimens with different reinforcement ratios (O-e3-10 and O-e3-15) 


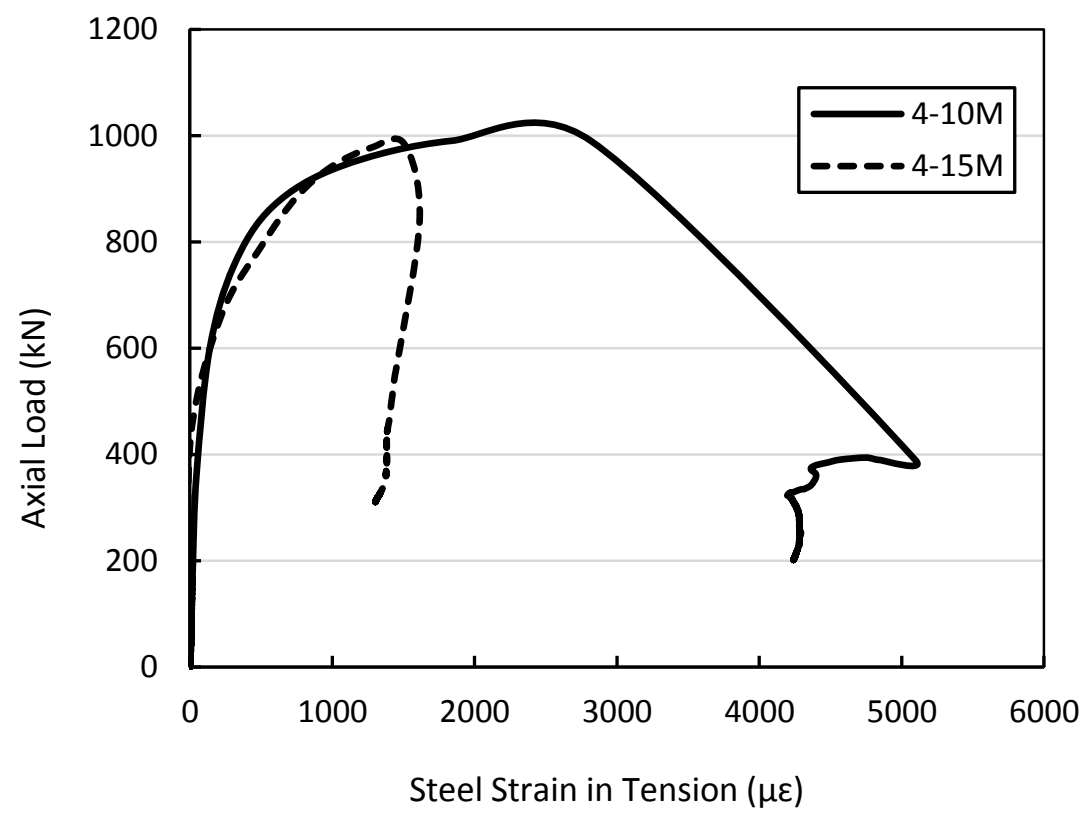

Figure A.19 - Load versus steel strain in tension for PVC encased wall specimens with different reinforcement ratios (O-e3-10 and O-e3-15)

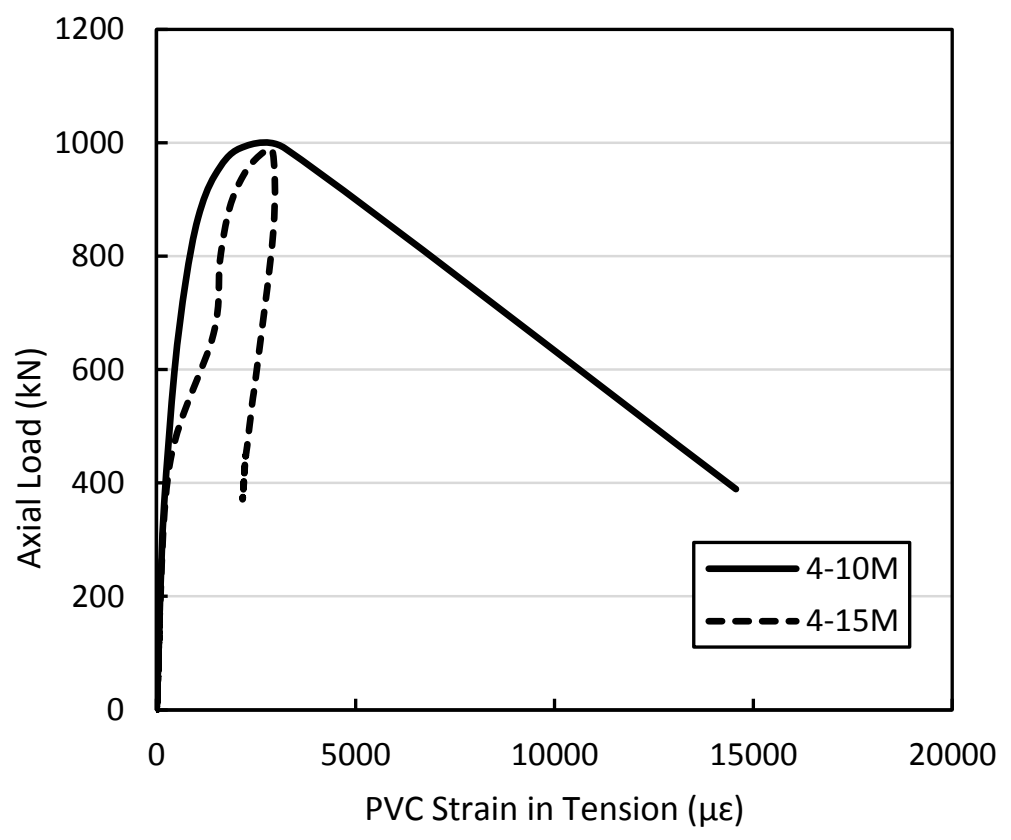

Figure A.20 - Load versus PVC strain in tension for PVC encased wall specimens with different reinforcement ratios (O-e3-10 and O-e3-15) 